Florida International University

FIU Digital Commons

$3-20-2020$

\title{
A Qualitative Study Examining Camaraderie and Conflict Between Female Academic Advisors in One Higher Education Institution
}

Alexandra C. Lejarza

aleja001@fiu.edu

Follow this and additional works at: https://digitalcommons.fiu.edu/etd

Part of the Higher Education Commons

\section{Recommended Citation}

Lejarza, Alexandra C., "A Qualitative Study Examining Camaraderie and Conflict Between Female Academic Advisors in One Higher Education Institution" (2020). FIU Electronic Theses and Dissertations. 4433.

https://digitalcommons.fiu.edu/etd/4433

This work is brought to you for free and open access by the University Graduate School at FIU Digital Commons. It has been accepted for inclusion in FIU Electronic Theses and Dissertations by an authorized administrator of FIU Digital Commons. For more information, please contact dcc@fiu.edu. 


\section{FLORIDA INTERNATIONAL UNIVERSITY}

Miami, Florida

\section{A QUALITATIVE STUDY EXAMINING CAMARADERIE AND CONFLICT BETWEEN FEMALE ACADEMIC ADVISORS IN ONE HIGHER EDUCATION INSTITUTION}

A dissertation submitted in partial fulfillment of

the requirements for the degree of

DOCTOR OF PHILOSOPHY

in

HIGHER EDUCATION

by

Alexandra C. Lejarza 
To: Dean Michael R. Heithaus

College of Arts, Sciences and Education

This dissertation, written by Alexandra C. Lejarza, and entitled A Qualitative Study Examining Camaraderie and Conflict Between Female Academic Advisors in One Higher Education Institution, having been approved in respect to style and intellectual content, is referred to you for judgment.

We have read this dissertation and recommend that it be approved.

Daniel Saunders

Rebekah Schulze

Thomas Reio

Sarah Mathews

Douglas Robertson, Major Professor

Date of Defense: March 20, 2020

The dissertation of Alexandra C. Lejarza is approved.

Dean Michael R. Heithaus College of Arts, Sciences and Education

Andrés G. Gil

Vice President for Research and Economic Development and Dean of the University Graduate School

Florida International University, 2020 
(C) Copyright 2020 by Alexandra C. Lejarza

All rights reserved. 


\section{DEDICATION}

I dedicate this dissertation to my husband, Eduardo Salcedo, who inspires me with his optimism, encouragement, and genuine willingness to help. You are my life force.

I also dedicate this to my parents, Raul and Elga Lejarza, who fully support my deep commitment to education and instilled in me the value of hard work and determination. I carry this spirit in all of my endeavors. 


\section{ACKNOWLEDGMENTS}

I would like to acknowledge the eight women who graciously offered to share their stories, not just for research purposes, but to help a student in need (as they do on a daily basis). I also want to thank all of the mentors I have met along the way who helped me keep the momentum I needed to finish this life goal. To my colleagues (who I absolutely consider close friends): Thank you for patiently listening to my incoherent brainstorming sessions, as well as sitting through my practice PowerPoint presentations. You showed me what true support can look like in the workplace setting. Finally, I want to express my appreciation to all of my committee members who helped me focus my thoughts to create a body of work I am greatly proud of. A special thanks goes to Dr. Douglas Robertson who knew how to best provide the gentle guidance I needed to get to the finish line. We did it! 


\title{
ABSTRACT OF THE DISSERTATION \\ A QUALITATIVE STUDY EXAMINING CAMARADERIE AND CONFLICT BETWEEN FEMALE ACADEMIC ADVISORS IN ONE HIGHER EDUCATION INSTITUTION
}

by

\author{
Alexandra C. Lejarza \\ Florida International University, 2020 \\ Miami, Florida \\ Professor Douglas Robertson, Major Professor
}

Women in higher education face several challenges including visibility, chilly work climates, and barriers to leadership positions. Research on women in academia has focused on faculty and leadership and less on the female staff working service jobs, such as the role of the academic advisor. The present interpretive qualitative study uses oneon-one interviews with eight full-time, female academic advisors working in a single, public, 4-year university.

The interviews revealed the experiences of women working in this role, explored their intradepartmental climates, their career aspirations, and the interactions they have with their female coworkers. The objective of the study was to take a closer look at their day-to-day working conditions, and the connections that are inevitably built in the office. Carol Gilligan's theory on the ethic of care was used to frame the interpersonal relationships among women, specifically to determine if the relationships were supportive or competitive in nature. 
The results revealed that frequent face-to-face interactions among advisors, having a say in hiring decisions, and a shared space for advisors to work together contributed to a positive departmental climate. Factors closely associated with conflict include an unclear pathway for promotion, limited opportunities to demonstrate leadership abilities, and having access to view and compare coworkers' salaries. Factors associated with support included physical proximity, small-sized teams, and nurturing relationships between the advisors.

Keywords: higher education, female staff, academic advisors, department climate, ethic of care, support, conflict 


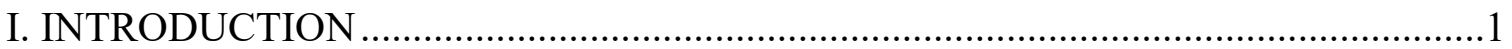

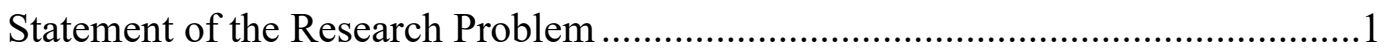

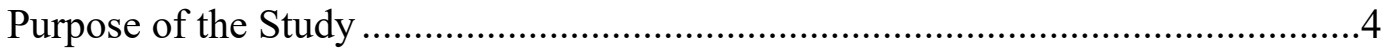

Research Questions ....................................................................................

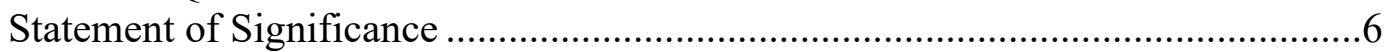

Delimitations and Assumptions of the Study......................................................

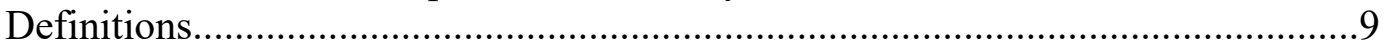

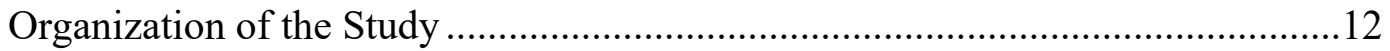

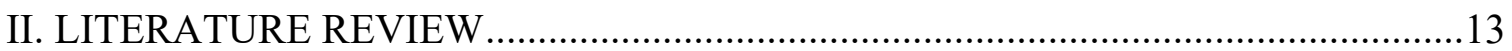

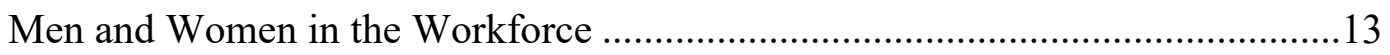

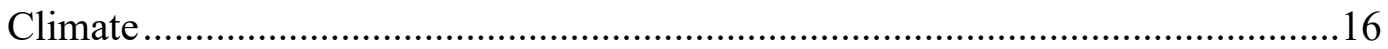

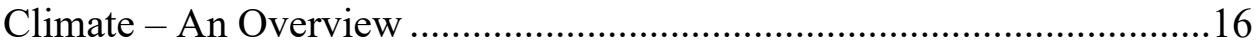

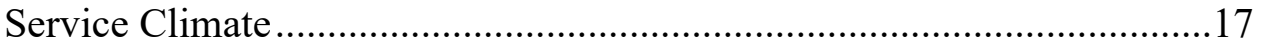

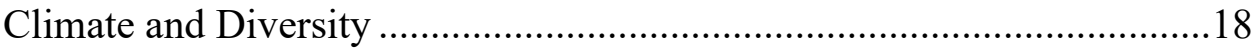

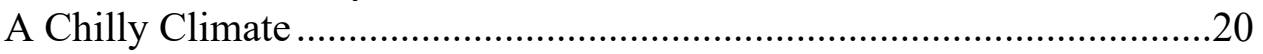

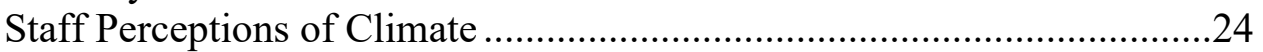

Ostroff's Framework on Climate .............................................................24

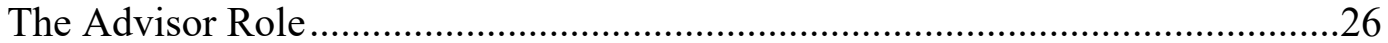

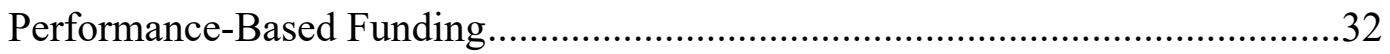

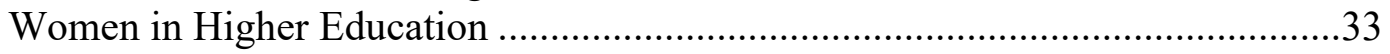

Women in Support Staff Roles ............................................................39

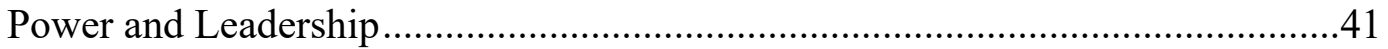

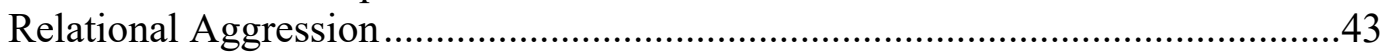

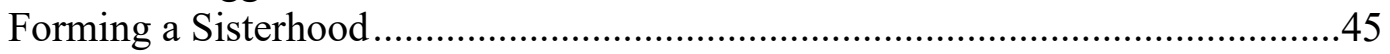

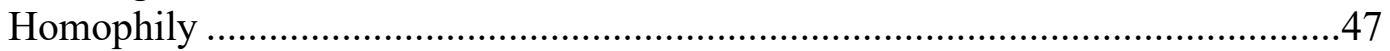

Theoretical Framework - An Ethic of Care ......................................................47

Justifying the Research Problem...................................................................50

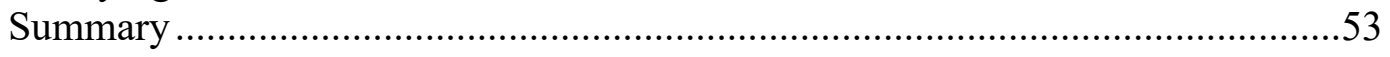

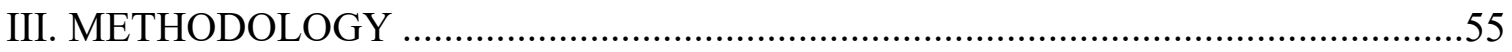

Research Design and Methodology .............................................................55

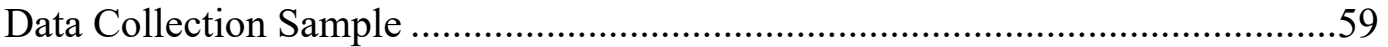

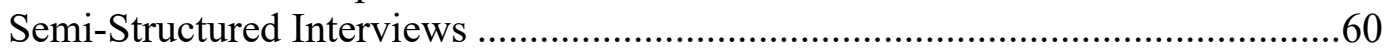

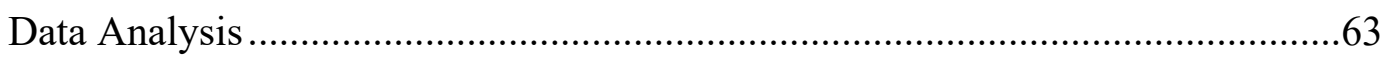

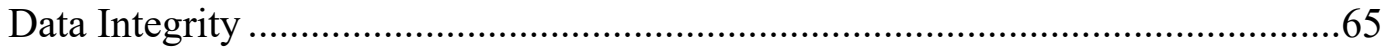

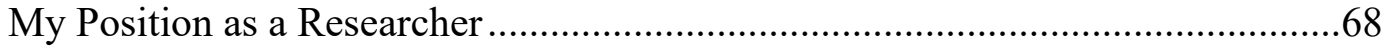

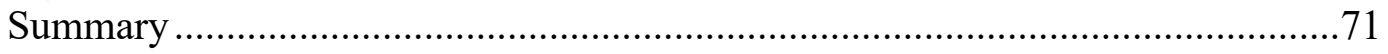

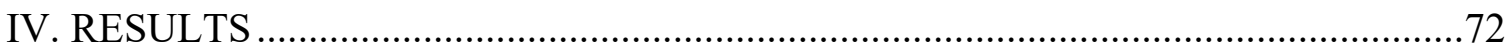

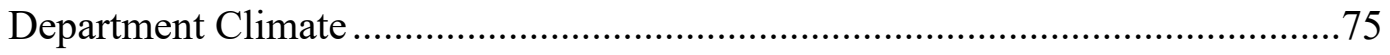

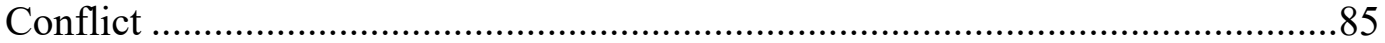




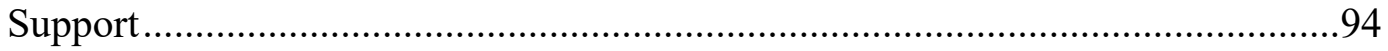

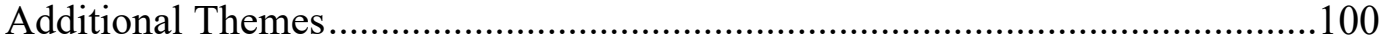

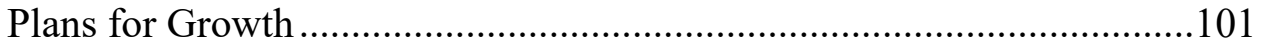

Relationship with Supervisor.............................................................107

Conflict with Supervisor ......................................................................109

Skill-Building ................................................................................110

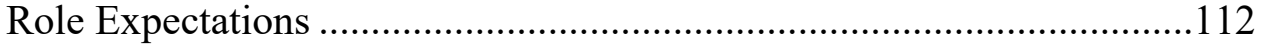

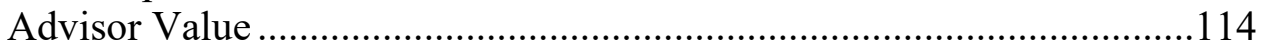

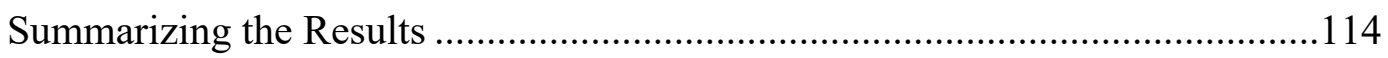

V. DISCUSSION

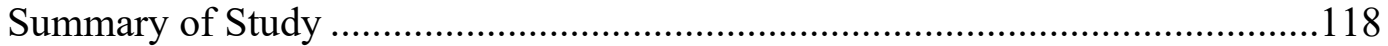

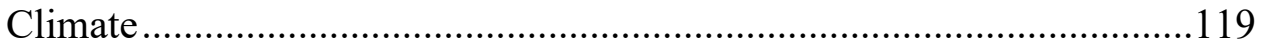

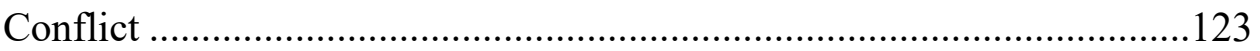

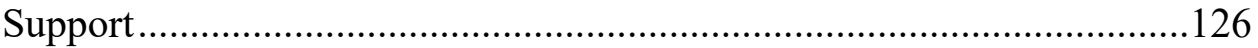

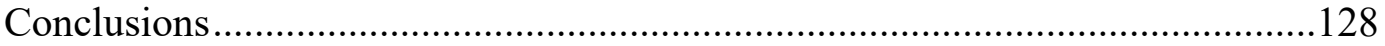

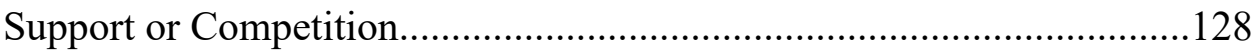

The Role of The Supervisor............................................................130

Becoming Visible..............................................................................132

The Supervisor - Employee Relationship...............................................134

Evidence of a Gender Inclusive Environment ………….........................135

Faculty and Advisor Collaboration......................................................136

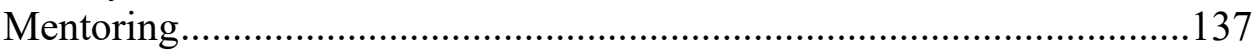

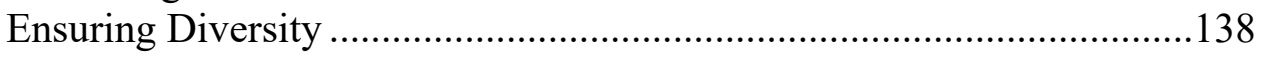

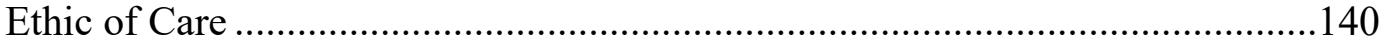

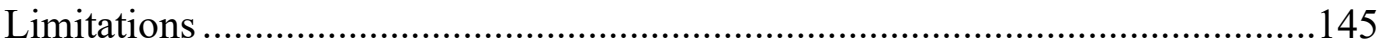

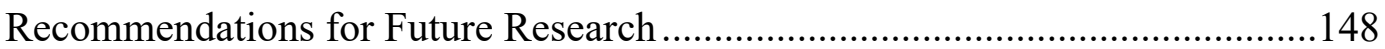

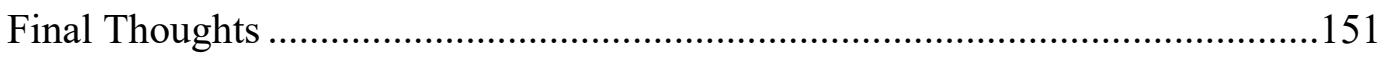

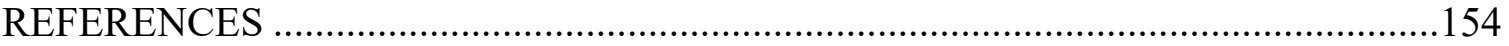

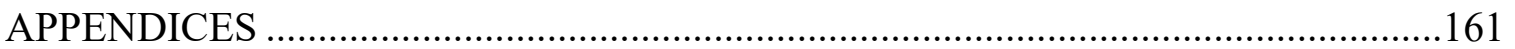

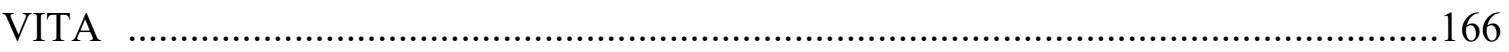




\section{CHAPTER I}

\section{INTRODUCTION}

This interpretive qualitative study explored the relationships that emerge between female academic advisors working in departments that are majority-women.

Consequently, the research provides descriptions of their intradepartmental climates, as told by eight different women who participated in one-on-one interviews. The first chapter covers a brief background on the problem statement, followed by the purpose of the study and the research questions guiding the research. The statement of significance is addressed, as well as the delimitations of the study. The chapter concludes with the definitions of key terms.

\section{Statement of the Research Problem}

Vaccaro (2011) calls attention to gender inequity issues that plague higher education. She writes that, "women at all levels of a university hierarchy can experience institutional and interpersonal sexism" (p. 27). For example, the existence of the "glass ceiling" in higher education can impact women's career growth. The "glass ceiling" refers to the barriers that block women and minorities from growing into top management positions within an organization (Pai \& Vaidya, 2009, p. 106). Costello (2012) asserts that in addition to gender and organizational issues, institutional climate can also create a barrier for women in higher education (p. 99). She explains that women, particularly female staff, are sometimes left out of work meetings and professional development opportunities. As a result, being excluded from meetings leaves women at a disadvantage when it comes to networking and job promotions (Costello, 2012, p. 99). Vaccaro explains that issues such as the glass ceiling and exclusion (often contributing to an 
overall chilly climate) can be counteracted if women come together and develop supportive relationships on campus; Vaccaro refers to this as a "sisterhood" (2011, p. 2728). However, Allen and Flood (2018) claim that "women in higher education, although increasing in numbers, experience difficulty in building and maintaining positive relationships with female colleagues" (p. 14). After interviewing and surveying a group of 34 faculty and administrative women, Allen and Flood describe incidents of relational aggression (a form of bullying typically associated with women) in one university environment. The study provided emerging themes such as, exclusion/ignoring, gossiping/spreading rumors, professional sabotage, and taking credit for others' work" (Allen \& Flood, 2018, p. 17). The authors also propose that because relatively fewer women than men hold high-level leadership positions in higher education, women may view each other as competition (Allen \& Flood, 2018, p. 20).

As women's roles in the academy have evolved, research has focused on female leaders and female faculty. Less attention has been given to the staff members working in higher education (Costello, 2012, p. 99). Costello explains that women in higher education can find themselves caught in "sticky floor jobs" which are low-level and largely invisible. Although "sticky floor jobs" can affect men as well, these jobs are believed to be more common for women than men. Examples of "sticky floor jobs" include staff jobs such as clerical workers, paraprofessionals, and administrative support employees; these jobs tend to be held by women (Costello, 2012, p. 100). Additionally, Walsh and Morley make a comparison between higher education and the workforce and explain that, "as with other large employment organizations, women are found in a narrow range of low-paid 'feminine,' caring and personal service areas while men are in a 
wider range of posts" $(2005$, p. 14). Kanter (2008) corroborates, stating that "even in areas decreed by tradition to encompass 'female concerns,' such as the service fields, and in areas where the workers are largely women, managers are still overwhelmingly likely to be men" (p. 17). Although the advisor role is not typically perceived to be secretarial in nature, it is an office job that may be viewed as routine or clerical in its duties.

According to Walsh and Morley (2005), both in the general workforce and in higher education institutions, organizations are "strongly gender-segmented" (p. 14). For example, men are more likely to hold positions in the physical sciences, while more women work in the social sciences (horizontal gender segmentation). They refer to this gendered phenomenon as a "stone floor" (similar to the concept of the "sticky floor") (Walsh \& Morley, 2005, p. 16).

Academic advisors represent a portion of the staff population in colleges and universities. This role is neither administrative nor faculty-related in nature as they typically do not supervise other employees and they primarily provide support outside of the classroom. Allan claims those who fall in the category (working in professional, clerical, or technical roles) are typically "overlooked in examinations of workforce issues in higher education" (2011, p. 55). The role of academic advisor may be considered a service job, as it involves providing direct services to college students in the form of academic or emotional support. According to the National Academic Advising Association, more women than men work in the advising profession (NACADA, 2000).

To address a gap in the literature surrounding female staff members, my study focused on the lived experiences of full-time, female academic advisors in higher education. I intentionally targeted departments where there are more female than male 
advisors to take a closer look at environments where women are the majority group. The present study provides background information on staff, whom Costello refers to as "found at the bottom of the college hierarchy" (2012, p. 100). Academic advisors are integral to the overall functioning of the institution, as they are responsible for the bulk of face-to-face interactions with the student population. The connection between academic advisor and student is important, as it could mean the difference between student retention and student attrition.

The study addresses issues about gender and organizational hierarchy, but primarily focuses on departmental climate as perceived and described by the women involved. The climate was explored largely through thick descriptions of the interpersonal relationships among women. Reports of conflict and hostility or sisterhood and support, and the areas in between revealed the dynamics that were taking place inside these departments.

\section{Purpose of the Study}

The qualitative study made female staff members in higher education the central focus--specifically female academic advisors in largely female-representative departments. Female staff members are a group that is underrepresented in research, despite the fact that they "often are the frontline to students and the public" (Costello, 2012, p. 113). Staff members and their titles can vary from institution to institution, so I targeted one specific subgroup of staff. To narrow down the population, I only interviewed full-time, female academic advisors working at a single institution.

Advisors provide services for college students by giving academic and career guidance, explaining the steps to graduation, and looking out for the student's emotional 
well-being (Lee \& Metcalfe, 2017, p. 946). By definition, the advisor role is expected to provide students with holistic support, both on an academic level and on a personal level. Students may be dealing with a wide range of external factors (such as work duties, family responsibilities, or health-related concerns) that impact their success in school. Consequently, the advisor may be asked to handle unique issues such as helping firstgeneration students navigate their college experience, finding resources for low-income students, and tackling mental health concerns. Although the academic advisor title implies that the role is to provide assistance by guiding the student through his or her coursework sequence, students may view the advisor role as a "one-stop-shop" to answer many of their questions.

My research focused on the interpersonal relationships and interactions between female academic advisors. I focused exclusively on women, in part because the profession itself is reported to be comprised of more women than men. Through interviews, the study investigated departmental climates in one institution (as perceived by the female employees). Their responses helped determine whether their department climates leaned more toward competition and conflict (including examples of relational aggression) or solidarity and support that is promoted in sisterhood.

\section{Research Questions}

1) How do female academic advisors in majority-female departments describe their intradepartmental climate?

2) What factors are associated with competitive workplace climates among female academic advisors in departments that are primarily female? 
3) What factors are associated with supportive workplace climates among female academic advisors in departments that are primarily female?

\section{Statement of Significance}

Allen and Flood (2018) make claims that women remain underrepresented not

just in leadership positions but underrepresented in higher education institutions overall (p. 20). Additionally, research on women in higher education focuses on leadership and faculty roles which excludes female staff. Allen and Flood contend that the topic of interpersonal relationships among women working in higher education should be dealt with great care. They explain that "the [societal] perception that women have difficulties working with one another, regardless of whether based on fact or fiction, could have negative work-related consequences for women" (2018, p. 22). I contributed to the existing literature on female staff in higher education by exploring the experiences of academic advisors using their first-hand accounts through one-on-one interviews.

The stories regarding their day-to-day interactions among female colleagues will help us learn more about their departmental climates. I predicted that if the findings of the study demonstrated that the climates leaned toward solidarity between the participating female colleagues, it could help challenge the idea that women have difficult relationships with each other at work. If the women expressed a sense of support, then the study may lend itself to reveal possible factors that contribute to a productive working environment. Alternatively, a chilly climate ripe with conflict and bullying behaviors would call attention to an ignored group and further help explain what workplace bullying looks like in the higher education realm, specifically in largely female spaces. 
The study is useful for managers who lead a team; it may be especially beneficial for managers leading a team made up of several women. Research on the experiences of female staff may pique the interest of supervisors who wish to create or a maintain positive climate for their organization. These leaders can learn to spot toxic behaviors in the office before they escalate into considerable problems. The study may be advantageous for women working in academia, as well, for they may identify and label harmful interactions with other coworkers. Some women may be experiencing bullying (like relational aggression) but may not view it as such because of a lack of familiarity with the concept.

Ultimately, it is necessary for us to learn about factors and conditions that contribute to a positive working environment (or alternatively, the factors that contribute to a negative working environment) if management wants to retain employees. Academic advisors experiencing job dissatisfaction may leave their role or leave higher education entirely. High levels of employee turnover are taxing on both the department and institution overall. When an advisor leaves the department, student caseloads are shifted onto the remaining employees. Additionally, the department must then assemble a hiring committee to find a candidate to fill the advisor role. Once the new advisor is hired, the department must use its resources (time, personnel) to train the new employee.

Properly trained advisors are the liaison between students and the school, provide accurate information on policies and resources, and serve as a counselor when guiding students through difficult situations. If the university hopes to increase its enrollment, then it needs to be adequately staffed with knowledgeable academic advisors. Thus, 
advisors are important both on a microlevel within departments, but on a macrolevel as well as they help meet institutional goals.

Although the context of the study revolves around higher education, the study can make contributions to the body of literature in the areas of business, industrial/organizational psychology, women and gender studies, and human resources.

\section{Delimitations and Assumptions of the Study}

All participants of the study were women employed as full-time academic advisors at the time data collection was completed. They worked in different departments (with the exception of two women who worked in the same department) and advised their respective caseloads of undergraduate students. All participants were employees of a public metropolitan research university in Miami, Florida, with 56,718 students and Carnegie highest research activity (R1) designation (Fall 2017 enrollment: 47,629 undergraduates, 9,089 graduate students). In the Fall semester of 2017, $64 \%$ of all students enrolled identified as Hispanic (making this a Hispanic Serving Institution) with Black or African American and White following with $13 \%$ and 10\%, respectively (National Center for Education Statistics). Recently, the university implemented the Graduation Success Initiative (GSI) from 2011 to 2015 in an attempt to increase on-time graduation rates and align with the metrics of performance-based funding. Through strategic interventions, advisors guide students as they determine their proper pathway and meet graduate requirements within a desired time frame. University personnel worked together to increase the number of students obtaining their college degree (Robertson \& Pelaez, 2018, p. 3). 


\section{Definitions}

\section{Academic Advisors}

In the present study, academic advisors are "non-faculty staff members whose main responsibility is providing holistic academic-oriented support services to college and university students" (Lee \& Metcalfe, 2017, p. 946). The job duties include discussing personal goals and career goals, as well as selecting a major, course selection, and building schedules (O'Banion, 1994, p. 10). Academic advisors in the current study do not hold managerial positions and do not formally supervise other employees.

\section{Climate}

Although the definition may vary, climate can refer to "a property of the university context or a subjective perception of the university by its participants" (Rania, Siri, Bagnasco, Aleo, \& Sasso, 2012, p. 2). It is also seen as a collection of "norms, goals, values, interpersonal relationships, teaching and learning practices, and organizational structures" of an institution. A positive climate is achieved when individuals come together and share a vision, are engaged, and feel respected (Cohen, Mccabe, Michelli, \& Pickeral, 2009, p. 182). For the purposes of the present study, participants (female academic advisors working in a single higher education institution) described their intradepartmental climate rather than the university climate as a whole.

The advisors' descriptions of the office climate included the relationships they have with their immediate supervisor, how new hires are generally received by coworkers, the advisor's interactions with others, and how they expressed the overall environment of the department, whether in positive or negative terms. 


\section{Relational Aggression}

The words relational aggression, social aggression, and indirect aggression are sometimes perceived as similar in meaning, especially because at the root, manipulative tactics are involved in each aggressive display. To distinguish, relational aggression "is defined in terms of its endpoint, which is to manipulate or disrupt relationships and friendships" (Archer \& Coyne, 2005, p. 212). Although the literature makes a distinction between the different types of aggression, "all forms of aggression can be viewed as social strategies, in that they have evolved and are currently used to pursue certain competitive goals" (Archer \& Coyne, 2005, p. 213).

Relational aggression is believed to be a subtle form of bullying, alongside physical bullying and verbal bullying; however, relational aggression is primarily seen displayed by women (Crothers, Lipinski, \& Minutolo, 2009). My study was conducted in a workplace context, specifically in a higher education environment. Relational aggression in a workplace environment can be displayed through the following actions:

(a) someone sabotaging the target or the target's project; (b) the target being left out from meetings or gatherings; (c) rumors or gossip being spread about the target; and (d) things being said behind the target's back (Allen \& Flood, 2018, p. 17). Archer and Coyne (2005) include the "silent treatment" as an act of relational aggression, in which the aggressor excludes the targeted individual from a group unless the target behaves in a way the aggressor wants them to (p. 217). In a work environment, Archer and Coyne list other examples including dismissing coworkers' opinions, reducing or increasing a coworkers' tasks, and reducing a coworker's ability to state their own opinions $(2005, \mathrm{p}$. 216). 


\section{Sisterhood}

The term "sisterhood" is used "interchangeably with many concepts such as support, friendship, and mentoring” among women (Vaccaro, 2011, p. 28). Lugones (1995) describes the term as an "egalitarian" relationship or kinship between women marked by respect and appreciation (p. 136). In the current study, the presence or absence of sisterhood within departments comprised mostly of female advisors was explored and the term itself is synonymous with support experienced between colleagues.

\section{Gender}

As the current study is gendered in nature, specifically in exploring the behavior taking place between groups of women, it is important to mention the concept of gender. The term sex typically is in reference to the "biologically based categories of male and female" while gender is thought of as the "psychological features frequently associated with these biological states, assigned either by an observer or by the individual subject" (Deaux, 1985, p. 51). In other words, sex refers to the physical and biological characteristics of humans, while gender is a social construction specifying what is considered masculine or feminine. According to Thomas (1990), research on gender "requires an examination of the cultural creation of male dominance as well as the creation of female subordinance" (p. 11).

For my research, I targeted advisors (through referrals) who self-identified as women (cisgender women). The term cisgender refers to people who have male or female reproductive organs that match their gender identity (Aultman, 2014, p. 61). Though different interpretations may exist, one's gender identity may be their "psychological sense of self" or their public identity that they present to others (Cava, 2016, p. 3). 


\section{Organization of the Study}

The first chapter of this dissertation describes current issues women face working in higher education such as sexism, obstacles impeding professional growth, invisibility, and low salaries. In an attempt to narrow my research interest on women in academia, I selected female academic advisors. Advisors are a group that may be at a disadvantage in terms of pay and visibility, yet they are key players in student retention and typically the first stop students make when they have a question. Chapter II provides a review on the literature surrounding women's descriptions of their work climate, advisor role expectations, and the relationships (both positive and negative) that emerge between groups of women. Chapter III will provide justification for the methods used in this study, as well as a description of the sampling, data collection, and data analysis protocols based on the recommendations of seminal authors in the field of qualitative research. Chapter IV presents relevant findings in the form of direct quotations from eight women working as academic advisors in one institution. The fifth and final chapter connects the results to the theories and ideas from the literature review and suggests future research. 


\section{CHAPTER II}

\section{LITERATURE REVIEW}

The study focused on eight female academic advisors and opened up a dialogue on their intradepartmental climates, and consequently, the relationships they have with their coworkers. The dissertation intentionally explored individuals in workspaces where the majority of the advisors are women. Through one-on-one interviews, the study aimed to gather information on the individual experiences of these eight women —including the good, the bad, and the in-between that occurs in their day-to-day routine amongst their female coworkers. The literature review will begin with a discussion about differences found between men and women at work. There is a section on women in higher education, including their presence in various roles (leadership, faculty, and staff). In addition, there is literature on climate descriptions, as reported by female staff working in the academy. Next, this chapter provides a definition for the academic advisor role, including the job duties and expectations. The literature review includes information on academic advising in the United States, but also how the role looks in international institutions. Because the research looked at the interpersonal relationships between the female coworkers, the literature discusses instances of tension in the office (in the form of relational aggression) and alternatively, the strong "sisterhood" bonds that can emerge in healthy work environments. The chapter concludes with a summary of Carol Gilligan's ethic of care, which is the theoretical framework that guided this study.

\section{Men and Women in the Workforce}

In an article from 2003, Jacobs discusses the gender segregation that is still found within occupations. The author uses a sociological approach to explain that individuals, 
through gender roles, learn that there are "men's jobs" and "women's jobs" (p. 33). In addition to society's expectations of appropriate gendered behavior, the structure of work itself may be a deterrent for some women. Both the length of the work week and the increasing workload in the labor force may have a negative impact on individuals with caregiving responsibilities (Jacobs, 2003, p. 35).

Jacobs (2003) predicts that very little will change by the year 2020, stating that total gender integration would require the input of "political, cultural, social and economic reforms" such as: mandating anti-discrimination policies, creating training programs for gender-typed occupations, as well as looking into the value of women's work (which may include caregiving) (p. 40). Walsh and Morley (2005) support the belief that women may have challenges in achieving promotions in part because of their familial responsibilities (p. 16).

Kanter (1987) has been cited for her work on men and women in the workforce, postulating that when men and women are given equal opportunities, they will behave similarly. In other words, differences between men and women's career success should not be attributed to gender but rather the organizational structure in which they work ( $\mathrm{p}$. 14). In addition to career success, the organization can impact women's levels of productivity and motivation. Kanter describes that employees in low-level positions may feel as if they cannot grow and this could lead to "lower aspirations for performance and less commitment" (1987, p. 14). In large, hierarchical organizations, Kanter explains that individuals tend to remain employed longer in "routine, lower-status jobs with little opportunities" while those in high-status positions "flow-through" and continue climbing upward (2008, p. 163). 
The social interactions we have with one another can influence different aspects of our lives "including the formation of our opinions, decisions of which products to buy, investment in education, access to jobs, and social mobility" (Currarini, Jackson, \& Pin, 2007, p. 2). Forret and Dougherty (2004) claim that networking is linked to positive career outcomes because networking helps boost one's social capital (p. 421). Using a survey, they targeted 1,180 business school graduates from a large state university and examined the ties between networking and career success. In their study, networking behaviors are defined as 'individuals' attempts to develop and maintain relationships with others who have the potential to assist them in their work or career" (Forret \& Dougherty, 2004, p. 420). Specifically, they looked at five kinds of networking behaviors: "maintaining external contacts, socializing, engaging in professional activities, participating in community activities, and increasing internal visibility” (p. 430 - 431). Through quantitative analyses, they were able to show that both increasing visibility and being involved in professional activities were linked to career success. Visibility in the workplace was linked to promotions and compensation (such as salary and bonuses) because employees who take on visible work tasks are able to demonstrate their competence and, consequently, are rewarded for doing so. Similarly, Forret and Dougherty explain that engaging in professional activities leads employees to meet influential people (sometimes including people from other organizations) that can offer lucrative job opportunities (2004, p. 431).

Using gender as a variable in their study, Forret and Dougherty's research supported the claim that networking was "more beneficial for the career progress of males than of females" (2004, p. 432). The data were able to support the notion that 
"visibility was significantly related to number of promotions and total compensation for men but not for women" (2004, p. 432).

A qualitative study conducted in Germany used interviews to explore the nature of women's networks and their effect on professional growth. A group of thirty-seven women (a combination of members of executive boards, successful entrepreneurs, and women in top leadership positions in large corporations) were asked to compare and contrast male and female networks and asked to describe how the women built their professional networks. Greguletz, Diehl, and Kreutzer (2019) summarize existing literature on women's networks, stating that men in the workforce tend to benefit more from social networks than women. They corroborate claims that women are often left out of "powerful social circles," and their study addresses obstacles that may get in the way for women when it comes to building networks (Greguletz et al., 2019, p. 1240). Walsh and Morley also address this claim, by adding that men tend to be asked to apply to positions, or asked to edit journals and books, while women have to actively look for these kinds of opportunities (2005, p. 20).

\section{Climate}

\section{Climate - An Overview}

The term climate can have several interpretations and definitions, but generally, it is used to describe the perception of the environment as interpreted by individuals in the environment; climate can include the rules, procedures, and the goals of an organization (Carr, Schmidt, Ford, and DeShon, 2003, p. 605). In addition, an organization can be comprised of multiple climates (Schneider, White, \& Paul, 1998, p. 151). Climate should be distinguished from culture, as it is considered "malleable...patterns of beliefs and 
behaviors are amenable to intentional efforts to change or improve" (Hurtado, Milem, Clayton-Pedersen, \& Allen 1999, p. 20).

Because climate is generally defined as the perceptions of all involved participants, establishing a positive climate campus requires the input of all members of an institution (including students, faculty, and staff). Measuring campus climate is a challenge, as thoughts on this subjective topic will vary from person to person. Mayhew, Grunwald, and Dey (2006) state that much of the research on campus climate focuses on the beliefs, experiences, and perceptions of faculty and students, but not necessarily staff members (p. 64). Furthermore, they claim that studies addressing climate and diversity place the focus at an institutional level and the classroom level, but they fail to address what climate looks like within departments (2006, p. 83).

\section{Service Climate}

Some studies have focused on service climate which is is defined as "employee perceptions of how well the university serves one of its major stakeholder groups (students)" (Martin, 2008, p. 157). As a result of the marketing efforts and the "strong focus placed on student satisfaction data," Martin (2008) explains that universities are leaning into the idea of seeing students as customers (p. 155). Within a university setting, students and staff will have many exchanges; determining their level of satisfaction can help the institution by providing a competitive edge if the service is optimal. A strong service climate will emphasize "well-trained employees who have the tools that they require to perform their work and receive the service and support they need from other organizational members so that they are able to serve customers well" (Schneider \& Barbera, 2011, p. 7). Organizational climate involves a perception of experiences 
regarding policies, practices, and procedures within an organization (Schneider, Gonzalez-Roma, Ostroff, \& West, 2017, p. 468).

\section{Climate and Diversity}

Hurtado et al. (1999) speak about climate from a student point of view to purposely elucidate how institutions and their employees can create an inclusive environment. They make a connection between climate and racial/ethnic diversity. They point out that although the general definition of climate involves the attitudes and perceptions of an institution, climate is "linked with a historical legacy of exclusion... and behaviors on campus that include interactions inside and outside the classroom" (p. 5). Thus, the presence of a diverse student body will impact the psychological climate of a university.

Hurtado, Milem, Clayton-Pedersen, and Allen (1998) developed a framework for campus climate as it applies to racial and ethnic diversity. They detail the forces that influence an institution's climate and categorize them in four dimensions: (1) an institution's history of inclusion (or exclusion), (2) structural diversity, (3) the psychological climate, and (4) the behavioral climate (p. 282).

The first dimension addresses the historical context of the institution, whether or not it was inclusive to students from various racial and ethnic groups. The objective is to acknowledge the history and environment of predominantly White institutions (PWIs) and ensure that universities and colleges cultivate a more diverse group of students on campus. Some universities have committed to serve groups that have been excluded from higher education in the past. Historically Black colleges (HBCUs), Hispanic-serving institutions (HSIs), and American Indian colleges (AICs) are examples of schools that 
emphasize the "cultural and academic development of these students and their communities as part of their mission" (Hurtado et al., 1998, p. 284).

Structural diversity refers to the representation of diverse racial and ethnic groups on campus. Research supports that increasing enrollment of diverse students will benefit the student body and consequently improve the climate. Fostering a multicultural environment should be an institutional priority. Schools can address this initiative with help from various student support units on campus, such as admissions and financial aid departments, which can increase access for students from different populations (Hurtado et al., 1998).

The third dimension, the psychological climate, involves both the perceptions and attitudes of members of the groups. In addition to personal characteristics, one's position and power will influence the experiences they have in an institution. In other words, students, administrators, and faculty members will all have different opinions about their perception of campus climate. Hurtado et al. (1998) make recommendations regarding psychological climate including developing strategic plans that will address stereotypes, myths, and biases that affect groups of people. They also encourage that institutions ensure that formal procedures and consequences are in place for harassment and discrimination incidents. Additionally, proper funding, staff, and resources should be allocated for student organizations that support a diverse population. Furthermore, they state that campus climate should be continuously evaluated with the input of all members on campus (Hurtado et al., 1998).

Inside the classroom, faculty members can foster a positive climate by implementing course content that reflects both racial and ethnic diversity. They can also 
encourage students to engage in work that requires them to work cooperatively. Outside of the classroom, the institution can direct its efforts into supporting multicultural programs on campus (Hurtado et al., 1998, p. 294-295).

The fourth and final dimension is behavioral climate, which is marked by the social interactions between the diverse groups of students on campus. Hurtado et al. (1998) acknowledge that historically segregated institutions cannot change what occurred in the past, they can communicate and promote the value of positive, cross-cultural interactions in the classroom, and also outside of the classroom (p. 294). Each of these four dimensions are connected to one another; for example, universities with a prior history of excluding certain groups of students may experience challenges in increasing their enrollment with a diverse population (Hurtado et al., 1998, p. 282).

Addressing these concerns on campus climate can help reduce incidents of discrimination or microaggressions that may affect groups of students. Racial microaggressions are defined as "brief and commonplace daily verbal, behavioral and environmental indignities, whether intentional or unintentional, that communicate hostile, derogatory, or negative racial slights and insults to the target person or group" (Sue, Bucceri, Lin, Nadal, \& Torino, 2007, p. 72).

\section{A Chilly Climate}

Sandler and Hall (1986) detail the history of factors that led to what is referred to as a "chilly" climate for female faculty, female administrators, and female graduate students. Sandler combines existing literature, anecdotes, and campus reports to describe how men and women are treated differently in an academic setting. Although many people believe that discrimination against women in higher education has been 
eradicated, there are several indicators that reveal otherwise. At the same time, Sandler and Hall (1986) claim women primarily work in lower-level fields, explaining that it is rare for women to work as department chairs or deans. Women who work as administrators tend to be found in "low-status areas that are traditionally viewed as women's fields" (such as nursing), or they are in associate or assistant positions with little mobility to move up (Sandler \& Hall, 1986, p. 2). Allan (2011) backs up these claims, adding that female administrators tend to have less status and lower pay than men (p. 2).

Sandler and Hall (1986) explain that overt barriers that once prevented women from thriving in higher education have been replaced with subtle, covert barriers. These behaviors exist between employees, but also within the classroom environment; for example, professors are more likely to call on and make eye contact with male students and women are more likely to be interrupted than men (Sandler \& Hall, 1986, p. 2-3). Male students will sometimes make certain requests to female faculty (such as extra time on assignments or taking a test after it has been administered) that they would not necessarily ask the male faculty (Sandler \& Hall, 1986, p. 15). Although these instances may be perceived by some as minor, they create a snowball effect that can affect the "development of women's self-confidence, academic participation, and career goals" (Sandler \& Hall, 1986, p. 3).

Both Costello (2012) and Greguletz et al. (2019) write about the exclusion that women face in higher education, claiming that they are often left out of important conversations and meetings. Sandler and Hall (1986) explain the "old boys' networks" which are informal circles that take place on and off campus; women are able to partake 
but they may not ever be considered insiders of the group. As a result, women may not be informed of institutional or departmental changes in addition to feeling like they are not part of the team (p. 8). Minority women may have to deal with "double discrimination" in part because they are women, but also because of their race or ethnicity (Sandler \& Hall, 1986, p. 13).

Sandler and Hall describe society's expectations regarding the difference between male and female behavior. Several assumptions are especially made in reference to how men and women balance their work life and their family life. For example, when women leave work early, coworkers perceive that it has something to do with their children. When men leave work early, "the more common assumption is that he has some important matter to attend to, and that his request is justified" (1986, p. 5). Furthermore, marriage and children may be seen as elements that can interfere with a woman's professional life, although marriage and children seem to represent stability for men (Sandler \& Hall, 1986, p. 5).

Differences in communication style may also play a part in the development of a chilly climate, particularly when women speak in a less assertive manner than men. When women speak less assertively, others on campus may perceive women as "less knowledgeable and competent, and their comments as less worthy of attention and response" (Sandler \& Hall, 1986, p. 12). Likewise, women may find that they are interrupted, ignored, and given less tasks or assignments when in group settings such as meetings and committees (Sandler \& Hall, 1986, p. 12).

At the time Sandler and Hall's report was written, women in top leadership positions in higher education was a rare phenomenon. Women were perceived as 
supporting staff because of a "pervasive assumption that leaders are men, and in part because of women's recent entry into the leadership arena...women in administration may face not only doubt but disbelief about their professional status and authority" (1986, p. 14). When female faculty and female administrators are in visible positions, it may create the false perception that equality has been obtained. Having few women in visible positions also leads to more scrutiny and can increase "the likelihood that they will be viewed as tokens" (Sandler \& Hall, 1986, p. 4).

Sandler and Hall provide examples demonstrating how academia devalues women's work and their experiences. There are instances where men and women have the same credentials, yet the women are passed over as "not well qualified" while male professors proceed to become deans (skipping over work experience as department chairs) (Sandler \& Hall, 1986, p. 6). When female administrators adopt a more collaborative leadership style, it may be seen as weak. Programs such as women's studies are deemed "political" or "easy" which devalues women's experiences and "implies that women's perspectives, lives, and accomplishments are not worthy of scholarly study" (Sandler \& Hall, 1986, p. 7). In addition to these existing factors that contribute to the chilly climate, women may find little support and services that would help areas such as work-life balance, maternity leave, childcare, and gender differences in salary (Sandler \& Hall, 1986, p. 4).

A higher education climate that seems to favor men may also affect women as they transition from graduate student to professional educator working in an institution. Female graduate students tend to have less contact with the male faculty members and therefore receive less guidance and support from them, as a result. When students express 
a research interest in a topic that deals with women, they are sometimes discouraged. As a result, female graduate students can feel isolated and devalued (Sandler \& Hall, 1986).

\section{Staff Perceptions of Climate}

Costello (2012) makes a contribution to the area of female staff and uses "climate" as a central theme in one study. She defines climate as "the overall perception and emotion--both good and bad--of employees within an organization" (p. 103). Through a qualitative study, Costello interviewed 16 participants (all staff members) from different departments working in a single university. The women expressed that promotions were more available for men than for women, and that many of the men in leadership positions would remain in their role for long periods of time. Women in staff positions who wish to advance forward professionally within their institution lack the possibility to do so with men occupying these spaces. The organizational hierarchy of the institution leads to invisibility in low-level positions, which may exclude some women from mentoring and professional development activities. Both their gender and their lower-level position in the institution leave women at a disadvantage for promotion (Costello, 2012, p. 100). However, all participants of this study expressed that "the female staff on campus look out for and support each other" (p. 109). Costello suggests further research on climate, as it is described by female staff in other institutions.

\section{Ostroff's Framework on Climate}

Although there is an abundance of literature on organizational climate, I drew from Ostroff's work on this topic to further help organize the results of the study. Using Ostroff's framework, climate can be classified into three categories: Affective, cognitive, and instrumental (1993, p. 61). The affective component includes the interactions and 
relationships among coworkers. The affective component of this theory can include informal groups that are cultivated within the office environment, as well as the collaboration and support that takes place between employees. The cognitive component involves personal development respective to one's job. For example, it includes the encouragement of new and creative ideas, as well as recognition or praise for employee efforts. Finally, the instrumental component of the model is about work processes such as how individuals navigate the organizational hierarchy and the policies and procedures of the institution. The instrumental category can also include promotions and monetary rewards that reinforce good job performance (Ostroff, 1993; Carr, Schmidt, Ford, \& DeShon, 2003, p. 606). In the present study, the women's anecdotes detailing office climate were framed by these three components of Ostroff's theory. Instances of affective, cognitive, and instrumental activities are detailed in Chapter V.

Ostroff, Kinicki, and Muhammad (2012) explain that when it comes to research on climate, it has focused more on the outcomes rather than the factors that lead to it ( $\mathrm{p}$. 654). They agree that, to an extent, leaders play a role in the type of climate that exists within an organization (p. 652). Specifically, supervisors can demonstrate appropriate role-modeling behaviors such as establishing positive interactions with other employees (p. 669).

Ultimately, it is difficult to discuss all aspects of climate, but it is necessary to mention that climate can serve as a "gauge for assessing progress toward the attainment of equity" (Allan, 2011, p. 65). It is a concept that can be measured quantitatively (for example, men and women's salaries) or qualitatively (such as the responses provided by the women in this study when describing their departmental environment, or deeper 
issues such as marginalization or sexual harassment). Although Allan (2011) lists that climates can exist in a variety of forms ranging from "hostile, toxic, and chilly to welcoming, friendly, and supportive," this list is limiting and climate should be described by its participants on open-ended terms.

\section{The Advisor Role}

In contrast to Costello (2012), Lee and Metcalfe (2017) focused on a single group of staff members (academic advisors) and explored their role and duties by studying American and Canadian advisor job descriptions. They define academic advisors as staff members (non-faculty) who provide academic support for college and university students. Some of their tasks include advising regarding course selection, offering career counseling services, providing remedial support, checking student progress for graduation, and other duties related to the overall well-being of the students (Lee \& Metcalfe, 2017, p. 946). After studying several job descriptions, the authors cite some recurring soft skills listed in the postings. These soft skills include examples such as diplomacy, tact, and advocacy for social justice (p. 954). They assert that the role of advisors is "invisible" in nature, and "not fully understood by students, professors, and administrators" (p. 945). This belief corroborates Costello's (2012) claim that staff roles tend to remain hidden within university organizations.

There is little doubt that academic advisors play an essential role for students and the institution as a whole, but there is ambiguity surrounding the nature of the role and who should be performing this function (O'Banion, 1994, p. 10). Determining who will perform the advising responsibilities (whether a faculty member or other employed university personnel) may vary from one institution to another and depend on factors 
such as resources. O'Banion (1994) indicates that some advisors have received graduate preparation for skills such as listening and helping students make decisions (skills that may not be explicitly taught to faculty members who are mostly focused on subject area knowledge) (p. 12). Still, some institutions may prefer to have faculty working in these roles instead of professional advisors who have been trained to advise students and perform all of the functions the job entails.

Stuart Hunter and White (2004) bring attention to the need for an effective advising program in an evolving higher education system. Some institutions are receiving less funding, from both public and private agencies; students are also affected as they may lose scholarships if they do not complete their degree within a certain timeframe (Stuart Hunter \& White, 2004, p. 21). Meanwhile, as the cost of tuition fees increases, an unprecedented growing number of students are also turning to the institutions for guidance and assistance. Academic advising is one resource where students expect "high quality, sustained attention of an institute representative who can guide and mentor them" (Stuart Hunter \& White, 2004, p. 21). The need for efficient personnel in the area of advisement is evident.

In addition to "patience and a willingness to listen to students" (two personal characteristics Stuart Hunter and White deem as necessary for good advisors) they suggest some key factors that are necessary for a high-quality advising program (2004, p. 23). For starters, they recommend a strong mission statement that would effectively communicate the goals of the advising program to the institution and its constituents. Next, the advising program would need to adhere to formal standards and values, such as the ethical practices suggested by NACADA. Additionally, a successful program requires 
advising structures in place that acknowledge the diverse student population of the institution (examples include remediation for students, career exploration for students who are undecided about their major, etc.). Leadership is an important piece of a quality program, especially in large institutions where there may be several managers that oversee advising teams in different units throughout campus. There is also the question of who exactly should be advising the students, because faculty members and professional advisors may be sharing this responsibility. Therefore, staffing should be addressed in building a strong advisement program. Implementing the right technology can liberate advisors from doing certain routine tasks that take away from quality face-to-face time with students during advising sessions. Advisor councils, which can be made up of both advisors and even students, allow members to voice their thoughts on current policies and advocate for change. Both program evaluation and assessment of advisor effectiveness stress the importance of continuous reflection to improve the quality of advisement. Rewards and recognition and advisor development help create incentives for advisor retention (Stuart Hunter \& White, 2004).

Stuart Hunter and White (2004) detail the challenges that exist within an advising program, especially for leadership because there are very few rewards for those working as advisors. They explain that, in some institutions, faculty members (who advise in addition to their other duties) may be rewarded for their advising responsibilities because this activity is recognized and factored into tenure and promotion decisions (p. 24). However, this privilege does not apply to professional advisors who are not on a tenure track. However, the University of Hawaii practices a system where professional advisors are encouraged to conduct research, publish, and apply for grants as part of their advisor 
role. Other types of rewards for advisors may include annual recognition awards, opportunities to travel for professional development, or even a designated parking space on campus (Stuart Hunter \& White, 2004, p. 25).

Castleman and Allen (1995) describe demographic trends in Australian universities and comment on the gender disparities. They claim that from the universities surveyed, women make up $62 \%$ of staff in lower level positions (p. 65). They provide some explanations for these gender differences, mentioning gender biases of the past as well as the fact that some women may build careers after they have children. However, they claim that women (when compared to men) have a harder time being promoted within the institution hierarchy, even when they have dedicated a significant period of time working for the university (p. 66). Through interviews with 50 managers (leaders of academic units, as well as leaders of corporate/operational departments), Castleman and Allen explored the issues of general staff (comprised of men and women, although it is largely female dominated). The interviews revealed implications that affect female staff such as: (a) lack of career growth for staff members, (b) lack of staff development opportunities, (c) lack of promotion opportunities, (d) bias in promotions, (e) masculine culture with too few women in higher level positions, and (f) a lack of recognition and attention directed to staff members (1995, p. 67).

Donnelly (2004) used surveys, focus groups, and interviews to collect data on advisor job satisfaction. All participants were targeted because they were academic advisors, faculty advisors, or administrators working in higher education institutions in Canada and the United States. All participants had previously attended the 2000 National Academic Advising Association (NACADA) national conference. Using the results of 
102 surveys, the typical survey participant was described as a full-time academic advisor working in a public university, making a salary between $\$ 30,000$ and $\$ 39,000$ a year with a master's degree (2004, p. 36). Through purposeful sampling, six individuals who had advising experience were selected for an interview (in order to triangulate the data collected from the survey).

The qualitative responses included advisors explaining that the best parts of their job (such as working with students) are able to compensate for the downsides that come with their role (for example, "politics of office and nowhere to advance"). Overall, the advisors placed less importance on extrinsic motivators like salary and career growth, and more emphasis on intrinsic motivators such as finding meaning and value in their work (Donnelly, 2004, p. 37). “Achievement, recognition, challenge, responsibility, growth, and development" were factors that were listed as contributors to advisor job satisfaction, while job burnout was linked to high student caseloads, poor job training, little recognition, and unclear role descriptions (Donnelly, 2004, p. 38).

Donnelly concluded the study by revealing that advisor job satisfaction is related to a) the use of standards, b), good fit between the academic advisor and the job (mostly in the form of effective interpersonal skills), and c) information on resources. The use of professional standards (whether national or institutional) can help provide role clarity. Regarding resources, advisors will experience more job satisfaction if they feel they have access to accurate and up-to-date information that needs to be disseminated to students (2004, p. 40-41).

Modeling after a pilot program implemented in institutions including Auburn University and the University of Texas, Kent State University developed a career ladder 
for academic advisors. It began with the creation of a new position (the Director of University Advising) which would be responsible for a review of the current academic advisor role. The review was referred to as the $360^{\circ}$ Assessment. The institution was motivated to launch a career ladder for advisors as a way to strategically decrease job turnover and increase advisor satisfaction (Pellegrino, Snyder, Crutchfield, Curtis, \& Pringle, 2015).

Prior to implementation, the university noticed a trend that academic advisors would leave because they wanted to advance in their career, but their advisor role did not provide this opportunity. Some employees chose to leave because they wanted to obtain a job that would allow them to serve as a supervisor. Finally, others would leave due to salary-related reasons.

This initiative was expected to produce certain outcomes including clear expectations for all advisors working in the institution, an avenue for advisors to gain recognition and professional development, enhance both student and advisor relationships as well as the relationships between students, staff, and the institution. The first step involved a small group comprised of the Director for University Advising, a Human Resources representative, and an Associate Vice President. Academic advisors were not present for this group due to "potential conflicts of interest" (Pellegrino et al., 2015, p. 3).

This initiative required both hiring new employees, but also promoting existing employees. The $360^{\circ}$ Assessment created two separate tracks: the Sole Contributor track and the Lead/Mentor/Supervisor track. The Sole Contributor track is for employees who want to continue their advisor duties, with little administrative responsibilities. The Lead/Mentor/Supervisor track is for those who want to practice their leadership skills by 
managing student workers, graduate assistants, and other staff. They may also guide other advisors as part of their role. Setting clear expectations about the different tracks also opened up a conversation between advisors and supervisors regarding advancement. With the organizational change, supervisors could address what is required of advisors to be promoted into higher positions during their employee performance evaluations. By clearly outlining the steps needed to implement this program, the institution now had a model that could be adapted to modify positions in other departments and units (Pellegrino et al., 2015).

\section{Performance-Based Funding}

Public, postsecondary institutions measure their efficiency through a collection of data. Information is gathered on specific criteria such as: the number of degrees awarded to students, graduation rates, the length of time it takes to obtain a degree, as well as the number of credits to complete the degree (Reyna, Reindl, Witham, \& Stanley, 2010). The state allocates and awards money to institutions on the basis of these measures, as opposed to providing funding to colleges and universities using enrollment numbers alone. Although states typically gave money on the basis of enrollment, enrollment is a "poor predictor of overall institutional performance" (Miao, 2012, p. 1). With limited funding from states, institutions must focus their attention on ensuring they meet the metrics.

Academic advisors, alongside all other university personnel, are expected to help the institution achieve these metrics successfully. Although meeting the metrics is a college-wide effort, it is evident that much of the responsibility lies in the hands of the advisors as they have frequent face-to-face contact with the student body. Advisors are 
designated a caseload and this implies that they are accountable for the success of potentially hundreds of students. The advisor role includes messenger duties where they typically deliver school-related information and execute interventions for at-risk students when necessary.

\section{Women in Higher Education}

Allan acknowledges the historical, social, and political events that have contributed to women's status in higher education $(2011$, p. 4). She refers to the historical roots, beginning with Harvard College, when postsecondary education was intended to benefit men (2011, p. 5). At the time, women did not have access to the university. Over the years, women made great strides in the area of higher education. Allan claims that improvements have been made regarding women's access and representation in higher education, but there are still several instances of gender inequity (2011, p. vii). She explains that issues such as finding the right work-family balance, salary differences, and occupational segregation already pose a challenge for women; but these problems are "compounded for women of color, first-generation women, lesbian, and disabled women, who also must navigate the climate-related challenges that emerge from workplaces and learning environments that privilege white, middle-class, able-bodied and heterosexual norms" (Allan, 2011, p. ix). She proposes three key changes that can assist in implementing change: (1) support opportunities that will allow us to learn more about women in higher education, (2) use multiple feminist perspectives to solve gender equity problems, and (3) execute change strategies using the different feminist perspectives (Allan, 2011, p. x). 
Maranto and Griffin's (2011) study emphasizes the chilly climate for female faculty in higher education, indicating that academia is generally male-dominated and also gender-segregated. The tendency to favor men in higher education may be linked to the fact that the tenure timeline for faculty lines up with women's child-bearing years. Furthermore, a professor's work schedule does not always fall in line with the traditional 8-hour workday because of responsibilities such as research assignments (p. 1-2).

Confirming the existing literature on chilly climates for women in higher education, Maranto and Griffin explain that women feel they are excluded from informal networks when compared to men (2011, p. 12-13). The researchers sent surveys to hundreds of male and female faculty members working in one private Midwestern university to measure perceptions of exclusion as well as their perception of organizational justice (this includes issues such as: are decisions being made fairly, rewards given on the basis of performance, proper allocation of resources, and other equity issues, some involving gender). Respondents also had to specify how many faculty members were women and how many were men in their department. Maranto and Griffin (2011) found that, overall, women perceived a chilly climate in the university when they were the minority in their department; the presence of a chilly climate appeared to be true regardless of their discipline (p. 14). The researchers make recommendations for accountability and explain that "exclusion is reduced in departments in which women have greater representation” (Maranto \& Griffin, 2011, p. 16). Other suggestions to alleviate the chilly climate for women include training to foster awareness of informal exclusion of women, establishing a formal mentoring program, and having an evaluation 
method in place so department chairs are responsible for ensuring an inclusive environment for all faculty (Maranto \& Griffin, 2011, p. 16).

Walsh and Morley (2005) explain that women make up a small percentage of all faculty; additionally, they tend to be lower in academic rank and untenured. Women are found mostly part-time roles, work in disciplines that are perceived to be feminine, and work in universities with little prestige (p. 33). Female faculty may also find themselves taking on the bulk of advising responsibilities, which leaves them with less time to pursue other duties such as research (Tack \& Patitu, 1992, p. 36). Women balance their professional lives and their home lives (which may include raising children); they may find little assistance from colleagues or the institution itself, as Tack and Patitu state that leaders tend to be white, married men (1992, p. 44). The authors encourage an exploration of other life stressors that impact the lives of female faculty.

A quantitative study used a questionnaire to determine the job satisfaction of a group of faculty and staff members in one public university in the United States. The Job Descriptive Index was used to measure job satisfaction; this instrument measures an employee's satisfaction in the areas of: “work, pay, promotion, supervision, and coworkers" (Tang \& Talpade, 1999, p. 346). The results supported that there are significant gender differences, specifically in the areas of satisfaction with pay and satisfaction with coworkers. In the Tang and Talpade (1999) study, the researchers suggested that men may value money more, as it contributes toward esteem needs, while women prioritize office relationships because they help satisfy social needs (Tang \& Talpade, 1999). 
The literature states that in the general workforce, women change their jobs more often than men do; in fact, they are more likely to change jobs for reasons such as "work/family conflict [and] poor employee/supervisor relations." Men, on the other hand, are more likely to leave their jobs because they find jobs with a higher salary (Jo, 2008, p. 566). Jo explains that literature on turnover in higher education has predominantly focused on both faculty members and university presidents; consequently, less is known about voluntary turnover of nonteaching professional staff (2008, p. 568).

A study in South Africa surveyed professors and staff members to determine the relationship between job embeddedness, work engagement, and turnover intention. The results supported that both job embeddedness and work engagement was related to less turnover from employees. Those who feel embedded at work have strong connections to their job or colleagues (which makes it harder to leave the role). Work engagement is marked by an attachment and commitment to the organization (Takawira, Coetzee, \& Schreuder, 2014).

One study examined gender differences in work burnout among university staff in Nigeria. In this study, burnout is defined as emotional exhaustion experienced by employees; this can lead to negative attitudes toward coworkers, as well as overall dissatisfaction with the job itself (Adekola, 2009, p. 886). Burnout was first reported in the 1970s in the nursing field, and studies have revealed that it tends to occur in environments with stress and high emotional investment; As a result, fields like social services and education may experience high levels of burnout (Hakanen, 1999). The burnout phenomenon may have far-reaching effects (even impacting organizations as a whole), as studies have revealed that faculty burnout is increasing, and it may act as a 
deterrent for workers seeking opportunities in higher education (Rothmann \& Barkhuizen, 2008, p. 440).

A random sample of male and female staff from ten public universities in Nigeria answered the Maslach Burnout Inventory to measure factors such as emotional exhaustion, depersonalization, and personal accomplishment. Results revealed no gender differences in burnout, as both male and female staff reported high levels of burnout. However, the gender differences that occurred were that female staff reported less personal accomplishment when compared to male staff (Adekola, 2009).

Although Castleman and Allen (1995) did not intend to make their study femalefocused, the results highlighted the issues female staff encounter in higher education spaces. For example, they focused on three female supervisors from corporate areas who all expressed challenges working in their high-level position. All three women commented on the male-dominated culture of senior level positions within the organization, stating that "the whole place is run by men" (p. 68). Another female supervisor explained that hiring selection committees tend to be largely male-dominated, and their decisions hold much weight. In addition, initiatives that focus on improving the position and status of women in universities tend to benefit female academics (faculty members) --not necessarily female staff (p. 69).

Costello (2012) notes that women who work in higher education face many barriers. These obstacles may pertain to "issues of gender, organizational practices, or climate" (p. 99). Research on women in academia concentrates on female administrators and female faculty; consequently, less research focuses on the female staff members working in higher education organizations. Female staff have less of a presence in 
literature, despite their presence and role in colleges and universities. Some staff roles are perceived as entry-level in nature and involve repetitive tasks; examples of these positions include those in clerical staff and support staff (Costello, 2012, p. 100).

One study explored gender equality issues in one state university in Cameroon. The researchers proposed six factors that produce a more gender-inclusive environment: empowerment, co-operation, equity, sustainability, and security. Empowerment exists when women have a voice on campus that allows them to make decisions that impact their environment. Co-operation involves a mutual support between men and women. Equity can be summarized as justice and fairness for everyone and can include nuances such as those found in the language that is used (ex: chairperson instead of chairman). Sustainability occurs in peaceful, respectful working environments. Security means there are set guidelines that protect the rights of working men and women, especially in regard to incidents of sexual harassment (Endeley \& Ngaling, 2007).

Via a questionnaire designed to collect both quantitative and qualitative information, Endeley and Ngaling (2007) gathered data from 185 teachers working in the University of Buea. When asked if they favored the development of women's support groups on campus, about $63 \%$ of the respondents indicated that women's support groups were a valuable asset. They believed these groups could be beneficial for "exchanging knowledge, healthy for university campus life, and a means of helping women become more active, especially in their professional careers" (p. 73).

When participants were asked to discuss the benefits of cultivating a campus that strongly advocates gender inclusiveness, examples included: a positive learning environment for all students, increasing women's self-confidence, better cooperation 
between men and women on campus, equal opportunity, less discrimination, and creating awareness about gender issues that could impact the larger society (Endeley \& Ngaling, 2007, p. 75).

Thomas (1990) indicates that feminist researchers have not sufficiently focused on the sociology of higher education (with more emphasis placed on secondary education and primary education). Thomas proposes that feminists believe that if women are obtaining a postsecondary education, then they are already "successful." However, Thomas advocates that feminists should also be concerned with what happens to women after they enter higher education (1990, p. 29).

Ageism may play a role in the difference between men and women's careers in higher education. Walsh and Morley claim that networking becomes necessary for women in academia, especially in the middle and at the end of their career (2005, p. 20). As men and women progress toward the end of their professional career, "men are promoted so that by middle age a number have reached the highest echelons and a significant number have been promoted above the lowest grade, while all but a few token women languish on the lowest grade throughout their careers" (Walsh \& Morley, 2005, p. 21). When women make progress, they tend to climb at a slower pace and spend more time in their roles (when compared to men); as a result, they may not be considered for certain promotions until they are older (Walsh \& Morley, 2005, p. 28).

\section{Women in Support Staff Roles}

Because the effectiveness of higher education institutions relies heavily on personnel, there is a growing interest in employee satisfaction (Küskü, 2003, p. 347). Academic staff (professors) and administrative staff (those who offer support to the 
academic staff) might work in the same environment (an institution) but have completely different tasks, and consequently, levels of satisfaction. Job satisfaction may depend on variables such as one's organizational loyalty, satisfaction with management, satisfaction with colleagues, satisfaction with the physical work environment (labs, restrooms, etc.), and salary satisfaction (including benefits) (Küskü, 2003, p. 350). One quantitative study in Turkey found that there are significant differences in levels of satisfaction for administrative staff when compared to academic staff across the dimensions, excluding management satisfaction (Küskü, 2003).

In tracing the history of women's roles in higher education, Cullivan (1990) claims that institutions undervalue both women and support staff in institutions, revealing that "neither role has a base of true academic power" (p. 9). She provides more background on the development of support staff explaining that although most of the institution's functions used to be in the hands of faculty, faculty had to change as a consequence of student growth. Factors such as the GI Bill and the 1950's Baby Boom required a response from universities; specifically, there was a need for additional employees to "oversee activities unrelated to the primary university missions of teaching, research, and service as performed by the faculty" (Cullivan, 1990, p. 10).

Cullivan makes a distinction between professors and staff members, indicating that faculty members require the proper academic credentials while support staff are usually "minimally qualified person[s] with the best match to specific job competencies for the least amount of money" (1990, p. 10). Cullivan's assertion echoes other claims in the existing literature that staff are at a disadvantage when it comes to salaries. Furthermore, staff members do not have the benefit of tenure, yet they are expected to 
supplement and support the work of faculty members by providing assistance in areas like advisement (Cullivan, 1990, p. 11).

Cullivan frequently states that higher education is a male-dominated field where women work in support staff roles or low-level administrative roles. They are hired for these positions because they are considered roles that require "nurturing" behaviors and also because placing women in these roles reflects "male attitudes about appropriate female fields of endeavor" (1990, p. 12).

Cullivan concludes with recommendations that staff members need to work closely with both faculty and administrators, collaborating on school events, but also to have a voice in decisions that affect the institution overall. According to Cullivan, a group effort will open up communication and lead to "new levels of professional respect among all groups" (1990, p. 13-14). Cullivan poses a rhetorical question: "Are staff positions devalued because women are in them, or does the organizational structure define the generally low value of staff positions?" (1990, p. 12).

\section{Power and Leadership}

Kanter addresses the influence of power within organizations; she explains that having access to both resources and information (as supervisors do) leads to efficiency and being able to accomplish more tasks. She indicates that managers with power are more likely to delegate work and reward employees for a job well done. By definition, "power is the ability to get things done, to mobilize resources, to get and use whatever it is that a person needs for the goals he or she is attempting to meet" (Kanter, 2008, p. 166). 
When power is monopolized, it implies that one person within the organization holds the most influence. However, Kanter (2008) provides an alternative solution: more can be accomplished when employees are given "more autonomy, more participation in decisions, and more access to resources" (p. 166). In other words, when power is distributed amongst the workers, the organization can get closer to meeting its maximum potential in efficiency.

Powerlessness, on the other hand, tends to lead to a managerial style that is ineffective, bossy, and comes across more like a dictatorship than true leadership (Kanter, 1979, p. 69). Kanter discusses staff members, stating that their roles are useful for easy, "routinized administrative functions" and "involve little innovative decision making" (1979, p. 75). Additionally, staff members have little mobility in terms of growth, unless they have already acquired experience working in higher positions (with management or supervision).

According to Kanter (1979), powerlessness can produce negative outcomes for staff members. Because staff professionals "are often seen as adjuncts to primary tasks, their effectiveness and therefore their contribution to the organization are often hard to measure" (p. 78). Consequently, staff members may receive less visibility and recognition than other organization members for these reasons. Because of a lack of power, staff members may respond in a way where they create a division within the organization. They perceive that they are "the only ones who can control professional standards and judge their own work" which in turn creates "false distinctions between themselves as experts and lay people, and this continues to keep them out of the mainstream" (Kanter, 1979, p. 78). 
Allan presents the idea that women and men may use different approaches when it comes to leadership styles. She provides an example, stating that women are sometimes described as more collaborative when compared to men. If this is the case, then an increasing number of women in leadership positions may result in a shift in norms and a shift in climates. Both mentoring programs and professional development opportunities may be helpful in this initiative. (2011, p. 109).

\section{Relational Aggression}

Beyond limited growth opportunities and lower salaries in higher education, women may also face conflict between colleagues in the workplace. When examining workplace bullying, Namie and Namie (2009) stated that "women target women in 71\% of cases, targeting other women 2.5 times as frequently as they target men" (p. 6). If women in support staff positions (which tend to be female-dominated) wish to grow professionally into leadership positions (which tend to be male-dominated and limited), then competition for the same upward-bound jobs can emerge between coworkers. Allen and Flood (2018) explain that there is a lack of information on conflict between women working in higher education. They state, "although there is a dearth of research examining women in higher educations' experiences with RA [relational aggression], professional sabotage, and the lack of support from other women, our data suggest that these are important areas of exploration" (p. 20). Keashly and Neuman (2010), make a similar claim by stating that, "although much research has been done on workplace aggression and bullying over the last two decades, academics have paid relatively little attention to bullying in their own institutions" (p. 48). Walsh and Morley (2005) mention a "double bind" situation in which women may receive backlash when they attempt to 
make themselves more visible. They state that "behavior such as assertiveness, selfconfidence, and self-advertisement, which is praised in men, may be criticized as unfeminine and risk alienation from women colleagues" (p. 18-19).

Relational aggression is an indirect form of bullying that is more closely associated with women rather than men. It occurs when an individual intentionally tries to emotionally harm someone else "through purposeful manipulation and damage of their peer relationships" (Crick \& Grotpeter, 1995, p. 711). Relational aggression is nonviolent in nature, but it is intended to damage the social relationships between people. It can manifest in many forms, but is typically characterized by emotionally harmful actions. Some examples include "socially aggressive behaviors, such as gossiping, social exclusion, social isolation, social alienation, talking about someone, and stealing friends or romantic partners" (Crothers et al., 2009, p. 102).

Using a questionnaire and semi-structured interviews, Allen and Flood (2018) collected information from 34 female assistant professors, associate professors, as well as administrators who work for North Carolina public and private higher education institutions. Participants were asked to describe instances of "aggressive treatment" from a coworker or a supervisor. Categories that emerged from the data included:

"exclusion/ignoring; gossiping/spreading rumors; professional sabotage; and taking credit for others' work" (Allen \& Flood, 2018, p. 17). Allen and Flood explicitly assert that despite the growing number of women in higher education institutions, there are challenges found in "building and maintaining positive relationships with female colleagues" (2018, p. 14). 


\section{Forming a Sisterhood}

Vaccaro (2011) suggests that women in higher education can challenge and fight against gender inequities such as institutional sexism through supportive interpersonal relationships with other women (referred throughout the article as a "sisterhood") (p. 27). Using a case study approach, Vaccaro focuses on Mountview, a private university, and examines three groups/organizations formed by women working as faculty, mid-level managers, and high-level administrators. Data were collected through a combination of official group documents (such as mission statements and meeting agendas), an openand-closed-ended survey regarding the women's group experiences and their thoughts on feminism, as well as a follow up interview. Although their experiences and perspectives were highly varied, the two themes that emerged were that the women primarily joined the groups in order to fight institutional sexism and that their group goals included forming a supportive sisterhood.

Responses from the women in Vaccaro's (2011) case study were mixed, with some expressing a close bond within the group, but a lack of community in the university as a whole. Many indicated that women's mentoring programs (whether formal or informal in nature) were valuable. These groups were an avenue through which women could find "a way not only to survive, but also to thrive in a sexist campus climate and male-dominated hierarchy" (Vaccaro, 2011, p. 34). Other women reported that individual personalities may contribute to the lack of on-campus support. For example, one woman responded that society has led women to distrust other women (p. 35).

To create an inclusive working environment, Vaccaro insists that women need to work collaboratively to fight issues like the glass ceiling, low pay, and sexism. However, 
she recognizes that collaborative relationships are challenging when the interactions between the women are already tense and complicated to begin with. She encourages an open discussion where everyone can talk about these issues such as distrust and tensions to diffuse conflict (2011, p. 43). It is imperative to learn more about women's differing perspectives on campus in order to move toward the community sisterhood described by Vaccaro.

Alternatively, the formation of tight-knit groups can also be detrimental for employees in certain circumstances. Kanter (2008) proposes that some coworkers join together and develop a countersystem in which the less advantaged employees engage in "gossip, joking, and ridicule at the expense of the advantaged" (such as the individuals found at the top of the organizational hierarchy) (p. 150). Kanter explains that these peer groups of people with little opportunities to grow (mostly secretaries and clerical workers) tend to close their membership off to others, comparing them to "adolescent gangs, developing norms of mutual aid and loyalty" (2008, p. 150). In these groups, members may find it difficult to leave (such as by gaining a promotion) because it may be perceived as being disloyal to the other employees (Kanter, 2008, p. 151).

Research suggests that mentoring can be an effective strategy that can assist women's career mobility, and conversely, a lack of mentoring may limit their career advancement (Allan, 2011, p. 107). Mentoring involves a relationship between two or more people, but at least one individual "provides guidance, support, knowledge, and opportunities for whatever period the mentor and protégé deem this help to be necessary" (Wasburn, 2007, p. 58-59). Whether they are strategic and formal or spontaneous and informal, mentor programs may benefit in the retention of employees. However, the 
success of the program relies on a few factors such as the sharing of common goals, personalities that fit together, and luck (Wasburn, 2007, p. 59). Formal mentoring programs tend to benefit workers at the start of their career, but this type of assistance can be helpful for people in later stages of their career as well (such as in the case when they perceive their career has reached a plateau) (Allan, 2011, p. 109).

\section{Homophily}

Homophily is a phenomenon that explains that friendships are formed because of the similarity between individuals (Hafen, Laursen, Burk, Kerr, \& Stattin, 2011, p. 607). According to the concept of homophily, people come together through shared interests, activities, and opinions. As a result, friendships that are created are marked by stability and limited conflict. Friendships that are made between individuals with few things in common are likely to be short-lived (Hafen et al., 2011). Homophily can refer to individuals sharing the same gender, race, ethnicity, age range, socioeconomic status, religion, or educational backgrounds. Geographic location also plays a role, as we tend to have frequent contact with those who are in close proximity (McPherson, Smith-Lovin, \& Cook, 2001, p. 429). Research on homophily concentrates on what brings people together, and less is known about the dissolution of connections between people (McPherson et al., 2001, p. 435-436).

\section{Theoretical Framework - An Ethic of Care}

Carol Gilligan (1993) writes about the psychological development of women, their relationships with others, and the differences between men and women's perception of the world in her book, In a Different Voice. She explains that men and women (because of socialization) have different experiences and perspectives from childhood 
that can have lasting effects in adulthood. For example, childhood activities that are traditionally associated with girls (like hopscotch) are not outright competitive in nature; the lack of competition helps maintain peaceful relationships between the girls involved. Additionally, young girls engage in play by creating small, intimate groups of friendships. Being included in a group is thought to lead to developing more empathy and sensitivity toward others (p. 11). She states that "the sensitivity and care for the feelings of others that girls develop through play have little market value and can even impede professional success" (Gilligan, 1993, p. 10). The nature of more competitive game play is commonly linked to boys, and this "male model" is perceived as advantageous, at least in the case of achieving "modern corporate success" (Gilligan, 1993, p. 10). However, Gilligan emphasizes that human behavior is largely standardized and based on the male experience, as well as men's interpretation of research. As a result, when women "do not conform to the standards of psychological expectation, the conclusion has generally been that something is wrong with the women" (1993, p. 14).

Carol Gilligan's ethic of care is built on the theory pioneered by Lawrence Kohlberg, a psychologist known for his ideas on moral development. Kohlberg proposes six levels in the evolution of moral reasoning; in order to determine one's current stage, a fictional dilemma is presented and the individual is asked to explain how they would handle the conflict described in the scenario. At the core of Kohlberg's theory, there is an emphasis on the idea of justice when seeking conflict resolution (Gilligan, 1993, p. 25). In essence, Kohlberg associates "moral maturity" with individuals who turn to an ethic of justice (Gilligan, 1993, p. 27). In contrast, Gilligan provides an alternative explanation, asserting that 'the voice of 'care' and the desire to maintain relationships are far more 
powerful explanations of behavior than an attachment to justice" (Lovell, 1995, p. 62).

The notions of justice and chare should not be viewed as a dichotomy; these two concepts are different options and individuals may be socially conditioned to lean more toward one than the other.

Gilligan's work emphasizes maintaining close relationships and an ethic of care, in which "rests on the premise of nonviolence - that no one should be hurt" (Gilligan, 1993, p. 174). The title, In a Different Voice, is intentional; both men and women can switch between an ethic of care or an ethic of justice when dealing with issues of morality (Gilligan, 1993, p. 2). Through interviews, the female academic advisors in my study described their experiences with other women and revealed the presence or absence of this "ethic of care" in their work environment. I looked for recurring themes, such as women forming small, supportive groups with each other, or a sense of disconnect among themselves.

Gilligan describes that competitive situations "threaten the web of connection," specifically for women (1993, p. 44). On the basis of the literature on women in academia, several factors may contribute to the development of competition between female staff. Men hold several leadership positions and make many of the hiring decisions for promotions. Women may want to move up, but find obstacles along the way, such as limited positions for them to grow into. Gilligan urges more research on women's adult development, but she is adamant that their experiences are shared in their own terms. In other words, Gilligan wants women to share their own stories through their own voices as they navigate their experiences in a "patriarchal world" (1993, p. xii). As a consequence, she believes this will reveal new perspectives on relationships and 
interconnectedness (1993, p. 173). Therefore, ethic of care was used as the theoretical framework for the present study. This theory was tested in a unique context (a large, public university) with a carefully-selected group of participants (female advisors working in a majority-female department).

The concept of an ethic of care is, as Gilligan describes, "the tie between relationship and responsibility, and the origins of aggression in the failure of connection" (1993, p. 173). My study allowed women to talk about their experiences with fellow female colleagues, whether they are positive experiences about sisterhood, support, and solidarity, or negative experiences with conflict, aggression, and competition.

\section{Justifying the Research Problem}

Walsh and Morley explain that higher education is "hierarchized in terms of strongly institutionalized hegemonic masculinities" with mentoring opportunities favoring men over women (2005, p. 21). Although some women choose to stay in the same role, others may find themselves left out of networking opportunities or professional development options. When compared to faculty and administrative pay, staff members tend to earn less pay and they are already marginalized with fewer opportunities to advance within the organization. Knowing that female staff may be at a disadvantage in terms of visibility in research, pay, and professional growth, it is important to bring their voices and experiences into the conversation to call attention to the barriers placed in front of them. Costello specifically calls for further research on female staff and suggests a focus on "the culture and climate of different institutional types such as 4-year residential, commuter, and community colleges" (2012, p. 112). The eight academic advisors in my study represent a portion of the entire staff population 
working in one university. The literature claims that advisors face issues of visibility and lack of professional growth, especially in comparison to professors. While faculty members enjoy benefits such as tenure, sabbaticals, and promotion opportunities, academic advisors trail behind in status, power, and pay (Murray, 1987, p. 51). Still, advisors are expected to be credentialed, sometimes requiring a Master's degree in order to be hired, and demonstrate a knowledge of school policies and resources. They are the “links between students and the institution's other support services such as tutorial programs, testing and counseling, and financial aid" (Migden, 1989, p. 64).

Although faculty members have a clear pathway for promotion, the pathway for professional growth may not be as straightforward and linear for academic advisors in higher education institutions. Both the GSI and performance-based funding have emphasized the vital role of academic advising in increasing student success. The GSI, an intervention plan geared toward increasing student graduation within a specific timeline, sparked organizational change at the institution I selected for my research. The GSI lead to a "professional advisor model" where academic advising was the responsibility of "master's-prepared professionals." As a result of the initiative, 69 advising lines were added in the span of 5 years in order to meet the large volume of students. In addition, the academic advisor position was restructured to create a pathway of six levels in which employees could grow professionally and increase their salary (Robertson \& Pelaez, 2016, p. 145). Similar to the way faculty members can advance through the tenure process, academic advisors at this institution also had multiple levels they could aspire to grow into. 
Allen and Flood (2018) contribute to the literature on relational aggression by exploring the presence (or absence) of sisterhood in higher education. They explain that the same women "who have complained for decades about unequal treatment from men now perpetuate many of the same problems by turning on other female colleagues" (2018, p. 12). Allen and Flood provide a theoretical framework (relational aggression) and a mixed methods approach to studying interpersonal relationships between female professors and administrators working in higher education. My research focused on a different demographic. Instead of faculty members and leaders, I will focus on the social interactions among female academic advisors (non-administrative, non-faculty) in female dominated work environments and learned how they perceive their departmental climate (whether leaning toward a sense of sisterhood or the feeling of conflict and aggression). Research on organizational climate relies heavily on employee surveys using observable behaviors (Schneider et al., 2017, p. 468). My research, qualitative in nature, used interviews to provide a descriptive account of climate. Looking at the interpersonal relationships among the women is important, as the relationships are "important factors in establishing an appropriate working environment and in motivating people to do a good job" (Tack \& Patitu, 1992, p. 40). The use of semi-structured interviews in the present study was intentional; every participant was treated as an individual and the results are not generalizable by design.

The topic of gender equity runs the risk of "being understood in reductionist ways that fail to acknowledge differences among women" as much of the research on this gendered issue may concentrate on the experience of "white and economically privileged women" (Allan, 2011, p. 3). Thus, there is a need to highlight the experiences of women 
in various age ranges, and from diverse racial, ethnic, and socioeconomic backgrounds. Although they shared many characteristics (several of the interviewees were Hispanic women in their 20s, with similar educational backgrounds), they are not treated as a homogenous group; each of the women were encouraged to share and highlight their professional identity.

\section{Summary}

The chapter begins with a brief overview explaining the gender inequities that exist within the overall workforce. Next, the literature review explores several interpretations of climate, specifically in the higher education setting. Allan insists that universities are "microcosms of society" in that they both represent and contribute to the norms of our culture. Thus, inequities found in higher education can have a larger impact when they transcend into "learning environments, quality of life, and career satisfaction of both women and men studying and working in academic institutions" (2011, p. 3). Because there is a need for more research on the experiences of female staff in higher education, my research concentrated on exploring departmental climates and the relationships between women working in one public institution. Academic advisors were chosen to narrow the population, but also because of their deep involvement in student retention and graduation rates. They directly impact institution metrics, which are important for this public university to receive funding. Furthermore, their primary duties tend to be similar across different institutions and regions. Although the results are not generalizable to the larger public, some of the themes explored may apply to men and women working in this support staff role. 
The literature review provided some insight on healthy relationships that establish between women in the form of a sisterhood, as well as information on how office tensions can escalate into relational aggression. The intent was to show a range of office dynamics that may emerge between staff members in higher education. The chapters also provided context for the advisor role, the typical duties of the job, as well as the current affairs of higher education that directly impact advisors.

The bulk of the literature review concentrated on the varying definitions of climate (in the classroom, on campus, organizational climate, service climate, etc.) and women working in higher education environment. Carol Gilligan's literature on ethic of care provided a theoretical framework to guide the study; the interview transcripts were intended to reveal whether or not the women experienced strong interpersonal connections in their immediate work environments. The following chapter discusses the methodology I used and a justification for the use of the paradigm. 


\section{CHAPTER III}

\section{METHODOLOGY}

Chapter III details the procedures used in the present interpretive qualitative study and justifies the methods with support from authors in the field. It includes a description of the sampling technique (snowball sampling), the data collection method (one-on-one interviews), and how I handled ethical concerns (such as the use of a consent form). Chapter III also addresses the specific criteria that were used to select eligible participants for the interviews. I conclude with a brief summary of my personal interest in the topic, which addresses biases and assumptions I had prior to conducting the research.

\section{Research Design and Methodology}

The current study highlighted the voices of women working as academic advisors, including their day-to-day interactions with their fellow female colleagues within their department. Because looking at work relationships is a highly contextualized topic dealing with sensitive information, the study gathered qualitative data to understand the complex dynamics taking place. Guba and Lincoln emphasize that human behavior "cannot be understood without reference to the meanings and purposes attached by human actors to their activities" (1994, p. 106). In order to focus on the women's individual experiences, I conducted semi-structured interviews, which allowed me to explore issues in depth. Through a series of open-ended questions, the academic advisors were able to articulate their perception of their workplace, as well as the actions of their colleagues. The data collected resulted in a descriptive, interpretive qualitative study that examines the interpersonal relationships occurring among female academic advisors working in a single higher education institution. 
The intent of the research was to highlight women's stories about events in their work environment. The women were encouraged to make meaning of their own day-today experiences, personal anecdotes, and interactions with coworkers. Through these descriptions, I would be able to explore their departmental climates as a result. The present study drew from the principles of interpretive qualitative studies to showcase the various perspectives. Interpretive qualitative research is commonly found in educational research. With an interpretivist paradigm, data are drawn from sources including interviews, observations, or documents (Merriam, 2002). It is primarily meant to "focus on the construction or co-construction of meaning within a particular social setting" (in my study the setting is a large, public, research university) (Davis, 1995, p. 433). The goal of interpretive qualitative research, according to Davis, is to (1) present assertions and (2) verify assertions (1995, p. 447).

The methodology of the present study primarily drew from the qualitative techniques and recommendations of Sharan Merriam. According to Merriam, the researcher is interested in learning "how people make sense of their lives and their experiences" (2002, p. 38). Results are achieved by analyzing how individuals interpret their experiences, make meaning of these experiences, and construct their world (Merriam, 2002). Merriam explains that meaning is a social construction that results from individuals interacting with the world around them and unlike quantitative research, one's reality is not a "fixed, single, agreed upon, or measurable phenomenon" (2002, p. 3). The qualitative approach helps both define and understand the phenomenon and places weight on observed variations (Elliott, Fischer, \& Rennie, 1999, p. 216). 
Although all of the participants in the present study were full-time, academic advisors for undergraduates in one institution, the qualitative approach acknowledges that there may be multiple realities as a direct result of the women's different perspectives, experiences, backgrounds and departments. The women were asked to actively interpret their relationships with other female advisors in their department, and additionally include a description of their workplace environment. Consequently, the current study used the principles of constructivism; this is an underlying premise of interpretive qualitative research and "the key philosophical assumption upon which all types of qualitative research are based is the view that reality is constructed by individuals" (Merriam, 1998; p. 6, Merriam, 2002, p. 37).

Participants were selected from a public metropolitan research university in Miami, Florida, with over 56,000 students and Carnegie highest research activity (R1) designation, after receiving approval from the institution's Institutional Review Board (IRB). The institution offers Bachelor, Master, and Doctoral degrees. The study targeted female staff (specifically, academic advisors) as Costello (2012) advises the population is a rich resource for future research (p. 112). All women were full-time employees, as parttime advisors have fewer hours scheduled than full-time workers. Having less work hours may lead to less opportunities for social interactions with other colleagues (as opposed to full-time advisors working alongside other full-time female advisors). The advisor role was defined for the present study as non-managerial because the main responsibility involves helping students and not the supervision of other staff members. Men were not included, as the study concentrated on the experiences of women in the academy. Additionally, Carol Gilligan insists in her book, In a Different Voice, that research should 
focus on women's perspectives, especially in their own words. Women that were selected for the study came from departments where there were more female advisors than male advisors (women making up at least $60 \%$ of the total number of advisors). As a result, the study is not representative of all departments within this institution.

A total of eight female academic advisors were interviewed in this study. Although all women work for the same institution, and they are all located in the same campus, they came from seven different departments. They all shared the characteristic of being full-time, female academic advisors working with the undergraduate student population. In addition, they all worked in an environment comprised of mostly female, and not male, advisors. Although I initially wanted to focus on interviewing women from 2-3 different departments so that I could gather a more comprehensive view of departmental climates found in the institution, I was unable to achieve only 2 or 3 departments caused by the unpredictable nature of snowball sampling. By the end of the study, I spoke to eight women from seven departments (two of the women worked for the same department). Consequently, I did not have the opportunity to compare and contrast how different women perceived the climate of a single work environment.

Because the sample size of advisors is small, this study is not generalizable to the larger population at this institution. However, to address concerns regarding my sample, I interviewed women of different ages, and selected participants with varying years of advising experience. I also spoke to women with different job titles, which represented different job responsibilities and salaries (ex: Advisor Level 1 versus a Senior Advisor). With qualitative research, the goal is not necessarily to target a large number of participants, but rather "to sample broadly enough and to interview deeply enough that all 
the important aspects and variations of the studied phenomenon are captured in the sample" (Elliott \& Timulak, 2005, p. 151).

\section{Data Collection Sample}

The selection of participants was not random, because I employed the snowball sampling technique. Snowball sampling is a strategy used in research when there are recruitment challenges (such as gaining access into certain communities) (Sadler, Lee, Lim, \& Fullerton, 2010, p. 370). It involves selecting an individual (who already meets the participant criteria for the study) that can tap into his or her network and find others that meet the desired criteria (Sadler et. al, 2010, p. 370). The sampling technique is believed to be an efficient and inexpensive way to gather participants, and especially helpful in small communities that may be hard to target (Sadler et. al, 2010, p. 370).

I purposely sought female advisors working in departments that were made up of predominantly female advisors. It was necessary to use the criterion in order to properly address the research questions. Because it was difficult to get access to the demographics of every department at this university, the snowball technique allowed me to speak to specific women who met the criteria. In addition to these benefits, the snowball sampling technique may have a built-in sense of trust between potential participants (as they are being referred by colleagues). As a consequence, participants may be more willing to speak to the researcher (Sadler et. al, 2010, p. 370). Some of the women may have felt more comfortable being interviewed because we had a mutual contact.

I gained initial access to my interviewees by first reaching out to a woman currently working as a full-time academic advisor at the university. Because I work in higher education, I had the advantage of having several acquaintances at the university. 
Once I had my first participant, I then asked her for a referral who also met the criteria of the study. I repeated the procedure and asked my second interviewee to provide a referral, and the process continued until I had my sample of participants who were willing to interview. Each of the advisors was asked (prior to scheduling the interview) if they worked in a department where female advisors are the majority. I intentionally sought women working in departments where female advisors outnumbered male advisors to concentrate on female-dominated environments.

Initially, I completed seven interviews with seven women; however, five of the women had under two years of advising experience. In order to address the issue of having a skewed sample, I purposely sought an additional academic advisor with several years of professional experience in academic advisement. By the completion of the data collection process, three of the eight women had over two years of advising experience.

\section{Semi-structured Interviews}

Semi-structured interviews were conducted face-to-face with each participant. With the face-to-face interviewing technique, the researcher has a topic they will focus on, and questions are generated beforehand, but there is room for flexibility in responses (Rubin \& Rubin, 2011, p. 31). The questions went through several revisions prior to conducting the interviews to find the right balance that allowed for direction and focus on the topic at hand, but also left room for the women to elaborate on issues that they found relevant.

Drawing from the technique of Gilligan, interviewing allowed me to "follow the language and the logic of the person's thought" (1993, p. 2). I used the snowball technique to gather my interview subjects (which resulted in a total of eight women). The 
interview questions are provided in Appendix A. Although major themes of the study such as competition and sisterly support were not explicitly revealed prior to the interview, the nature of the questions touched on these topics. Even when describing the study to potential participants, the words competition and support were intentionally omitted so as not to sway the participants in a certain direction. Probing questions were used to encourage more detail in responses, especially when the women needed clarification on the meaning of the question (I encouraged them to interpret the questions from their own perspective, being careful not to impose my pre-existing beliefs on them).

The synchronous nature of the face-to-face interview allowed me to ask other questions that were not necessarily written down but were used as a follow-up to the responses they provided. As a result, I made some revisions to my interview questions upon completion of some interviews, because I would learn something new that I could bring into my next interview. In contrast to quantitative methods, qualitative research focuses on verbal responses to open-ended questions. Because it is marked by flexibility, each interview should be treated as a unique experience (Elliott \& Timulak, 2005, p. 149150). Lead advisors, their role, and the advisor promotion process were topics that were not pre-planned, but they emerged organically through the interviews. The nature of interpretive qualitative studies allows for changes in the interview questions because it is believed to be a cyclical process. With data collection and data analysis, "the study often changes directions in terms of the questions being asked and the theoretical perspectives brought to bear on the study" (Davis, 1995, p. 444).

Qualitative research strives to be "richly descriptive" that includes not only participants' direct quotes, but also descriptions of the context in which the study is 
taking place, the background of each participant, and perhaps even their respective interests (Merriam, 2002, p. 5). All of the information helps situate the interviewee's perspective. Following Merriam's suggestions regarding qualitative information, the direct quotations in Chapter IV will provide the reader "with a depiction in enough detail to show that the author's conclusion 'makes sense"” (1998, p. 199).

Interviews were conducted in a space where the participant felt most comfortable; I offered to work around their schedule and agreed to interview at their place of work, if that is what they preferred. Interviews did not have to be conducted on-campus, because that could have affected the responses of the interviewee. However, six of the eight women were comfortable interviewing in their own office, some of them during their work hours with coworkers sitting in the room next door. Interviewing at the workplace was beneficial for the study, as I was able to interact with the women in their natural setting. Conducting the interviews in their departments also allowed me to better understand their descriptions of the physical proximity of the advisors in their workspaces, and gave me the opportunity to view relevant artifacts, such as advisor awards or degrees displayed in their offices.

Since the interviews took place face-to-face, I observed "social cues, such as voice, intonation, body language, etc.... extra information that can be added to the verbal answer of the interviewee on a question" (Opdenakker, 2006, p. 3). As stated, many of the women preferred conducting the interview at their place of work, and they did not appear uncomfortable discussing potentially sensitive topics (such as competition at work, as well as their relationship with their immediate supervisor) in their workspace. 
Before the interview, each participant was asked to sign an informed consent form and all received a brief explanation of the purpose of the study. The consent form used in the study was approved by the IRB and it is included in Appendix B. Those who did not wish to participate after the explanation would not be part of the study (however, all eight of the women agreed to continue). All participants were informed that their responses would be recorded and transcribed later using the NVivo program. They were allowed to ask questions about the process before beginning in order to address possible concerns. I eliminated identifying information including their names (pseudonyms were used in place of their real names), job titles, and the names of the departments participants work for ensured confidentiality. Although for demographic purposes, I asked for their ethnicity and their highest degree earned, I decided not to reveal this information in the results of my study because the details had the potential to compromise their identity. I also asked about their marital status, but this was also omitted because the focus of the study was about their professional experiences. Participants were told that they were able to opt out of the study if they were uncomfortable at any stage. All participants were interviewed once (ranging from an hour to an hour and a half, depending on the responses that were given and the time they had allotted in their schedule).

\section{Data Analysis}

Interviews were recorded and transcribed verbatim with the permission of each participant. Data collection and analysis took place simultaneously. After each interview was completed, the data analysis began starting with the transcription process. Emerging themes were explored with the help of NVivo software. Using software to code the data increased the rigor of the study and provided me with an avenue that ensured my work 
was both systematic and organized. For first cycle coding, I used NVivo as it "draws from the participants own language" and it is necessary to get an authentic look at the culture and lived experiences of the women working in their departments without imposing biases or assumptions (Saldana, 2009, p. 66). I used axial coding for the second cycle; axial coding allowed me to organize and create new labels from my first cycle coding and make conceptual categories (Saldana, 2009, p. 160). In axial coding, the researcher creates a conceptual model and determines "whether sufficient data exist to support that interpretation" (Hoepfl, 1997, p. 55). The process was inductive in nature, as I collected data in an attempt to find concepts that connect to my research questions.

In my initial draft of my results, I focused on themes that helped answer the three research questions. These themes included department climate descriptions, evidence of conflict, and evidence of support as described by the women in their own words. Although other themes emerged during data analysis, they were not related to the established research questions. However, upon review, I returned to my data. The other themes were later added to my results section; they provided an in-depth look at the experiences of these eight women and encouraged me to examine other issues that occurred in their workspaces.

The research drew from Merriam's recommendations on qualitative studies; therefore, the data analysis process used certain guidelines. According to Merriam, data analysis is "the process of making sense out of the data. And making sense out of the data involves consolidating, reducing, and interpreting what people have said and what the researcher has seen and read-it is the process of making meaning" (1998, p. 178). Specifically with interpretive qualitative studies, the process of analysis requires 
"identifying recurring patterns" (which may come in the form of categories or themes, for example) (Merriam, 2002, 38). All assertions should be supported with evidence, such as quotes or descriptions (Davis, 1995, p. 446).

Keeping the research questions at the forefront, I wrote the results using the women's direct quotes. It was necessary to keep the dialogue in its original form, as I tied concepts together using a constructivist paradigm, which mean the ideas are "emerging from peoples' social practices... and existing largely within people's minds" (Yazan, 2015, p. 138).

\section{Data Integrity}

I used Tracy's (2010) criteria for qualitative research to ensure data integrity in my study. Tracy notes eight categories for strong qualitative research: “(a) worthy topic, (b) rich rigor, (c) sincerity, (d) credibility, (e) resonance, (f) significant contribution, (g) ethics, and (h) meaningful coherence" (p. 839). Several of these categories guided my study.

Research on academic advisors is both timely and relevant, as higher education institutions are relying on performance-based metrics for university funding. To determine specific areas that need assistance or policy change, "states collect data from all public, postsecondary institutions to report on a set of common measures of college completion" (Reyna, et al., 2010, p. 1). High student enrollment is a priority, and consequently, academic advisors play a critical role as they are inextricably linked to enrollment initiatives and procedures. In addition to fostering an advisor-student relationship beginning as early as orientation, retaining these new students each year requires input from all university personnel (including faculty members). However, 
faculty members often have several other responsibilities other than teaching in the classroom, such as committing to service, research assignments, or writing grants. As a result, many retention projects fall on the hands of the academic advisors who are seeing students on a day-to-day basis, year-round. There is an ample amount of literature on the retention of students, but this study contributes to the worthy topic of the retention of academic advisors. An increasing number of students in higher education will require an increasing need for staff and academic advisors. In addition, the present study contributes to the topic of female staff in higher education, which Costello (2012) insists is an area that should be explored.

I was intentional in practicing sincerity as I revealed my biases beforehand, both in the process of writing about my study, but also to the academic advisors. Two of the advisors knew me professionally prior to our interview. They knew about my extensive background advising students from different populations. The other advisors learned about my advising experiences as I shared information during the interview process. I did this with the intention to build a connection, and to let them know that I understood their role and I could relate to some of their experiences with undergraduate students. I explored possible limitations prior to the study, as well as after it was conducted.

I engaged in some practices specifically for credibility purposes. First, I was careful to let the women tell their stories in their own words, without my input or biases overshadowing their experiences. Second, although I used computer software to transcribe my interviews, I listened to all eight interviews and made manual edits to ensure that the words were transcribed as accurately as possible. Finally, I initially interviewed several women with only a few years of advising experience. However, as I 
was nearing the end of my data collection process, I intentionally targeted women who met my criteria and had more years of advising experience to make my sample more representative of the diversity of staff working at the institution.

To ensure rigor, I engaged in self-reflection throughout the entire research process, especially when the results seemed to negate my initial expectations. Elliott and Timulak (2005) corroborate that qualitative research requires "constant critical selfreflection and challenging skepticism with regard to the analysis methods and the emerging results" (p. 152). The women did not have many anecdotes to share that revolved around the topic of conflict, as I had originally assumed. Instead, the women's stories largely focused on the strong coworker friendships that have been cultivated in their department. I included a list of the codes that were generated in the analysis process in chapter IV.

The results in the following chapter are the advisors' tales, word-for-word, taken from the interview transcripts. With my study, I hope to make a significant contribution to the existing literature by providing the women's perspectives on what works or what does not work in building positive working environments and relationships between women in large female-representative departments.

To ensure ethical practices, all of the advisors were instructed that they could opt out of the study at any time, and they could "pass" on questions that dealt with uncomfortable or sensitive information if they felt the need to. On the rare occasion that an advisor stated that she wanted certain information off the record, I explained that any "off the record" content would not be included in the results. I did not reveal the names or departments of the academic advisors, and I did not share information among the women. 
Each woman was given a consent form prior to the beginning of the interview, and they were given time to review it and ask any questions so I could address concerns before we commenced.

\section{My Position as a Researcher}

I approached my study with fourteen years of experience in higher education, with a background in both private and public institutions. Seven of those years were spent working as an advisor in some capacity, guiding different populations including ESOL (English for Speakers of Other Languages) and GED (General Education Development) students, first time in college (FTIC) undergraduate students, and students with documented disabilities. My professional background not only inspired my research interests, but it also helps me understand the language, processes, and experiences expressed by the participant academic advisors. As a result, I am able to actively coconstruct (alongside the participants) the meaning behind their stories. In addition, this connection allowed me to access the first and second academic advisor who referred me to other advisors through snowball sampling.

For nearly two years, I was employed as a Senior Academic Advisor; this role required a Master's degree and offered a higher salary than employees with an Academic Advisor title in this particular institution. Senior Advisors are responsible for incoming FTIC students, from orientation until graduation, remaining in constant contact with each student. Each Senior Advisor is assigned a caseload of students (with numbers reaching over 1,000) and advisors are expected to plan a two-year course sequence for each student by meeting with them one-on-one. The disparity in salary and the distinction of job duties between these two roles (Academic Advisor and Senior Academic Advisor) 
were topics often brought up in the office, sometimes leading to tense interactions. Some employees voiced their opinion that the creation of the Senior Academic Advisor role directly led to conflict and tension.

There was a perceived sense of favoritism, with a select group of Senior Advisors continuously being placed on hiring committees, being asked to complete specific projects, and making decisions that impacted the rest of the team. Despite the enhanced pay, the Senior Advisor role had high levels of turnover with some citing bullying (being excluded or being the subject of rumors) and burnout as reasons for their departure (I eventually resigned, leaving behind a caseload of 1,400+ students). Furthermore, seven of the nine Senior Advisors in my department were women, making this a majority-female group.

Further adding to the tension, those who aspire to grow beyond the Senior Advisor role may face issues of job stability once they get promoted. The shift from a Senior Advisor position to an administrator position brings a salary increase, but also an annual contract which may or may not be renewed at the end of each year. As a result, some employees may be left without a job. Job insecurity may make some individuals hesitant to grow; some may want to challenge themselves with a higher position, but they fear the risk of becoming unexpectedly unemployed. At the same time, because there are relatively few administrator positions in the college, there seems to be much competition for these positions when they are open. Several of the advisors would apply for the same positions.

As a result of these events, I cannot deny my emotional investment in this project. My personal experiences drove me to focus my study on exploring departments where 
women outnumber men and allow these participants to share their own stories (welcoming both positive and negative stories). Although my negative experiences led me to quit the advisor role, I recognize that the eight women I interviewed had their own unique stories of the profession and I was happy to give them the platform to share them.

I opted to conduct my study at a different institution, which I felt would give me a different perspective and reduce my biases. I approached the study with a genuine curiosity, welcoming the women's stories and wondering if they would dispel the beliefs I had about the role. In order to avoid imposing my own perceptions from previous experiences in the data collection, I was intentional in crafting my probing questions. I focused on asking follow-up questions that highlighted both the emotions and perceptions of the women in their own words. In the few instances where participants asked for clarification regarding the questions, I encouraged them to interpret the question as openended and that they could answer the question as they felt appropriate. The interview questions were frequently reviewed, making sure there was a balance between the topic of conflict and the topic of support.

My intention with this research is to provide an outlet for women in academic advising roles to share their voices. I heard from women who may perceive themselves as invisible, are overwhelmed seeing students and working toward demanding university metrics, or simply feel left out of important conversations and administrative decisions. My study acknowledges that their work is both appreciated and necessary in the higher education field today. 


\section{Summary}

Chapter III provided literature that explains the methodological choices used in this interpretive qualitative study. The paradigm was chosen because there was a focus on women's individual stories, and my purpose was to help them co-construct their reality, using their own words. Snowball sampling was used to recruit participants because I had existing contacts to advisors working in the institution. Reaching out to my professional acquaintances gave me access to meet other women who met the criteria for my study (full-time academic advisors who work for departments that currently employ majorityfemale academic advisors). A total of eight women were interviewed (spanning from 26 to 49 years in age, and 11 months to 5 years of advising experience). I used face-to-face semi-structured interviews to collect the data and many of the meetings were conducted in the women's own offices.

I referred to Sarah Tracy's (2010) suggestions regarding qualitative inquiry in order to address data integrity, specifically addressing a worthy topic, ensuring rich rigor, practicing sincerity, justifying my credibility, offering a significant contribution to existing literature, and abiding by ethical rules.

Sharan Merriam's work on interpretive qualitative study protocol primarily informed my research, due to the focus on descriptions of the women's work environment and coworker interactions. I provided background information on my work experience as a female academic advisor in higher education that helped inspire and motivate my research interests. 


\section{CHAPTER IV}

\section{RESULTS}

Chapter IV provides the data collected in the form of excerpts of direct quotes from the women who participated in the study. From April 6 to November 12, 2019, I conducted eight face-to-face interviews with eight female academic advisors. Together, the advisors represented a total of seven different departments in one public, four-year institution. Two of the women worked together in the same department. The first two advisors I interviewed were acquaintances I had known previously in a professional capacity. These advisors referred me to other qualifying women who were willing to be interviewed. The interviews ranged from an hour to a maximum of an hour and a half. Each participant was asked where and when they preferred to be interviewed, and if they agreed to be recorded on audio.

The gender breakdown of the office (how many male advisors and how many female advisors in the department) and even the total number of advisors in the office were omitted because this information may help identify the participants. The following table provides background information for each of the interviewees: their pseudonym, age, job title, and how long they have been working as academic advisors (at the time of the study). If at any point during the interview, they expressed that something should be off the record, I assured them that it would not be included in the study. 
Table 1

\begin{tabular}{|c|c|c|c|}
\hline Name & Age & Job Title & $\begin{array}{c}\text { Number of years in role (at } \\
\text { the time of the interview) }\end{array}$ \\
\hline Melanie & 29 & Academic Advisor 1 & 1 year \\
\hline Giselle & 27 & Academic Advisor 1 & 1 year \\
\hline Chloe & 29 & Academic Advisor 1 & 11 months \\
\hline Kimberly & 30 & Academic Advisor 1 & 1 year and 5 months \\
\hline Jacqueline & 26 & Academic Advisor 1 & 1 year and 6 months \\
\hline Ginger & 49 & Manager & 5 years \\
\hline Gia & 37 & $\begin{array}{c}\text { Academic Advisor 1 } \\
\text { currently in the process } \\
\text { of becoming a level 2) }\end{array}$ & 2 years and 6 months \\
\hline Viviana & 39 & $\begin{array}{c}\text { Senior Advisor } \\
\text { 4 years and } 8 \text { months }\end{array}$ \\
\hline
\end{tabular}

At the conclusion of each interview, the audio recorder was shut off and the researcher and participant engaged in a short conversation to debrief and discuss the nature of the interview questions. Participants were able to express how they felt about certain topics and to reflect on the experience overall. Some of the women took the postinterview opportunity to reiterate any topics they preferred be omitted and be kept off the record. I felt it was appropriate to share some of my own advising experiences after the interview, in part to help build a trusting relationship, but also to show them that we had some commonalities.

The NVivo website provides a service which can take a digital audio file and convert the recording into a written transcription. I used this transcription service for the benefit of saving time (each recording was fully transcribed in under ten minutes). I played the audio and followed along with the transcript, manually making edits that were made due to software error. This procedure increased the accuracy of the transcription of the advisors' verbal responses. The final edit of the transcription was then exported into the desktop version of the NVivo program to begin the coding process. 
Using NVivo, I read each transcript and highlighted major themes (creating a node for each recurring theme). I transcribed and coded each interview one at a time, as they were completed. This allowed me to continuously reflect on the questions and the responses, so I was able to make revisions to the interview questions as necessary. The following includes excerpts that pertain to the main themes of this study: department climate as described by the women, evidence of conflict, and evidence of support among female colleagues. Additional data led to the creation of a few themes that were not necessarily related to the research questions, but they were relevant to the experiences of women working as academic advisors. These themes included: plans for growth, relationship with supervisor, conflict with supervisor, skill-building, role expectations, and advisor value. A list of all codes generated from the analysis process is provided in the following table. 
Table 2

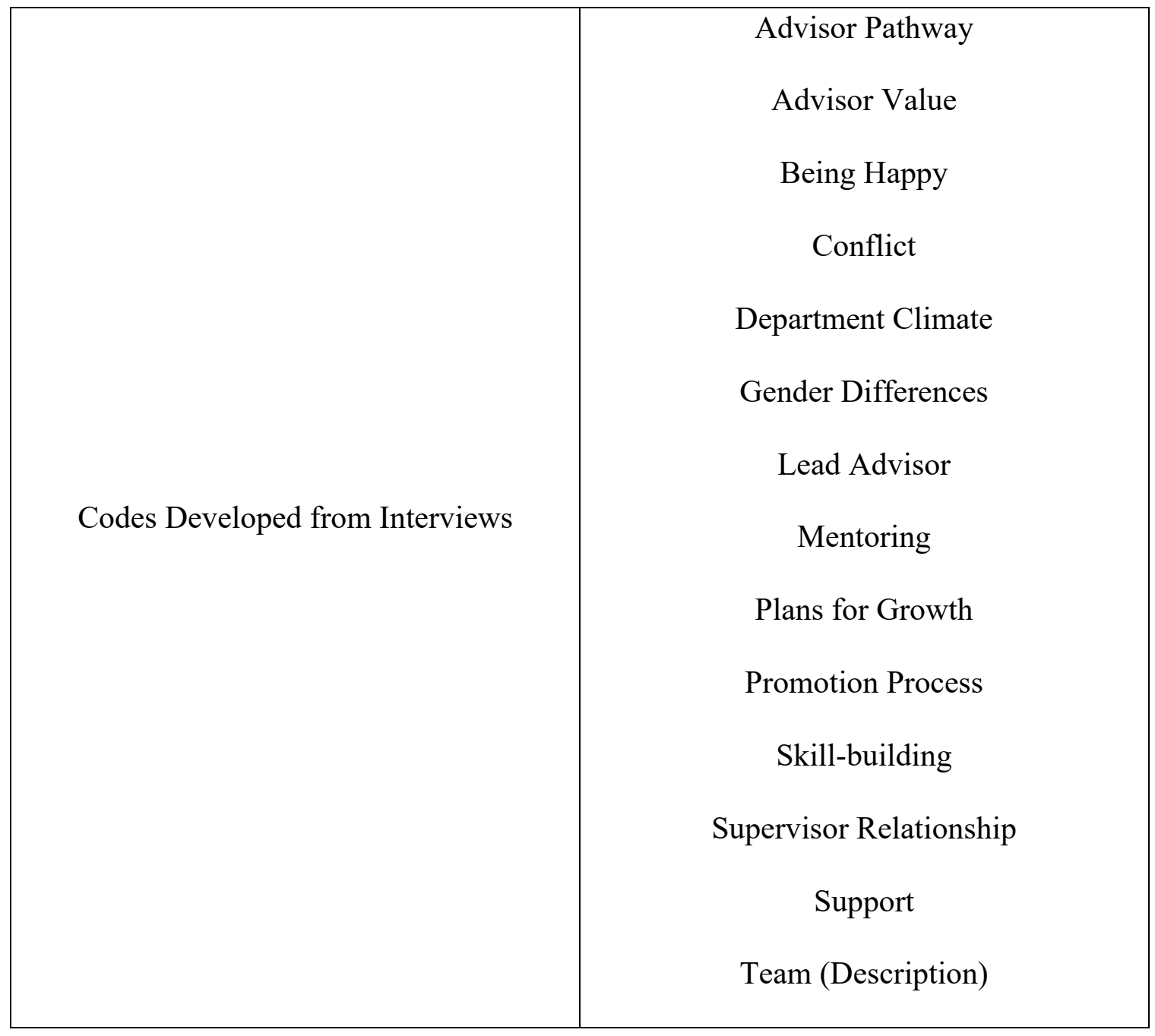

\section{Department Climate}

Kimberly consistently referred to her team and her department as instantly welcoming and she believes her boss, in part, fosters this.

"From the moment we met each other, it's like something about us [the team] clicked. I'm guessing it's our supervisor in the first place because she gives you that vibe of "everybody's welcome."

Kimberly believes her supervisor is a key figure in creating and maintaining a warm, work environment. Kimberly explained that her boss will arrange individual 
check-ins with each academic advisor for 30 minutes throughout the semester. These individual meetings are supplemental to group meetings where all of the advisors assemble together as a team. During individual check-ins, Kimberly feels comfortable enough to express personal issues, sometimes unrelated to work. In our interview, Kimberly reveals some recent, health-related concerns that led her to ask for time off at work. Not only was her boss receptive to the requests for time off, but the individual meetings provided the opportunity to have private conversations where Kimberly's supervisor demonstrated concern and care for Kimberly's health.

Exploring the departmental climate through indirect inquiry involved asking questions about how the team treats new hires.

"So you get hired and they train you. You get to see all of us work because you get to shadow all of us. You see my style, you see someone else's style. So you try to come up with your own style, but you don't have to. In our department we have like an open door policy so it's always open to questions."

Jacqueline also works for a department that engages in periodic group meetings and individual meetings. Kimberly, like Jacqueline, appreciates these individual meetings with her supervisor. When asked what she feels she receives from these individual meetings, Jacqueline states:

"I think a lot of mentorship because maybe you're having an issue and you don't know how to handle it. Sometimes when I would ask her a question like I'm having an issue with a coworker or something, then I would bring that up and she would help me."

Regardless of department climate, supervisors may find individual check-ins can be helpful. These meetings may create safe spaces for advisors to discuss and work through issues that may be affecting their job performance or job satisfaction. This may 
be a way for leaders to keep their finger on the pulse of the department, potentially reducing or eliminating conflict when it starts to emerge.

Gia referred to her small team as a family; however, she states that her department did not always feel this way. In fact, she used to believe her team was disconnected (prior to an intervention initiated by an administrator). About a year ago, leadership stepped in and arranged a staff retreat specifically for this department. The entire office was closed for one day and the staff was directed off-campus in order to talk about what was going on internally. Gia describes the events that took place:

"It was amazing. We all talked about everything that is on our plate so we had to write down everything. And people cried...I was looking into maybe moving on because this wasn't going to work that way that it was at that moment. It was bad and he [the administrator] fixed it. We just needed the right stuff. That's all there was and we got it. Because we saw everyone vulnerable. Everyone got to express how they really felt. And there were tears and there was resentment that was voiced. It was so honest and transparent."

The fact that the office closed for an entire day demonstrates that leadership prioritized addressing concerns and fixing the issues that were plaguing the work environment. Although performance-based metrics such as student enrollment are important for this institution, this staff retreat sent the message that employees are valuable to the overall running of this university, too.

This study explores the factors that bring coworkers closer together. All of the advisors were asked to describe what they believe helps build bonds in the office. Jacqueline offered an explanation and talks about the activities that took place in her department:

"Our offices were in the same hall so we would eat lunch together, do everything together in terms of like paperwork and stuff. Sometimes I would go to the conference room to sit down and do it together even though we weren't talking. We would just hang 
out. You know we're still working but we really were together and just working on messages and emails."

A shared space in the office provides the opportunity for advisors to sit and get work done together, as opposed to having all advisors separated in their respective offices. For Jacqueline in particular, this is a chance to be collaborative, but there are other benefits involved. She referred to this location as a "community coworking space" and explained that advisors would invite the others to join in if they wanted to. Jacqueline gives her perspective on the advantage of this shared space:

"That provides a stress relieffor us as well because you're not in your office by yourself because that can be isolating. You're there and you're like 'Oh my god, these messages!' that you have to get through. I think it can be overwhelming."

Some of the women expressed a friendship that extends the physical confines of the office. For example, Melanie described occasions where a small group of coworkers go to lunch together:

"So we don't hang out that often, but we might go to lunch together. I think a couple of times we've actually gone out after work. So it's not that we go out very often...we do keep in touch. We have a group chat...our group chat that we talk throughout the weekends. So we have a pretty close relationship in that regard for us."

Other women described their take on the ways that bonds and friendships are built within the walls of the office. Giselle emphasizes the importance of downtime in the office that allows the advisors to connect and share.

"So we are, for the most part, close. So I can go to any one of them and ask for help and I feel like they're' willing to help. We have a good office relationship, like we set aside some time to just chat maybe at the end of the day. We ask about how our weekends were, we talk about our families, and it's not strictly work-related communication."

Not every department will lend itself to organic team-building or bonding opportunities. Chloe discusses how the nature of the advisor role keeps her busy and, 
consequently, prevents her from interacting with her coworkers. She describes her advisor role as independent, as opposed to collaborative (four of the eight advisors described the advisor role as collaborative). Chloe explains:

"Most of the time you're in your office doing appointments with the student. It's collaborative in the sense that it's very supportive where we're all trying to help one another but sometimes a day goes by and I don't get to see the other two advisors who are on the other side. A day goes by so fast and we're all sucked into our appointments that we don't even see each other. So in that sense, it sucks just because sometimes you're just tied to your chair and the only place you go is the bathroom or a water break. I like seeing [people] face-to-face. So in that sense, that's something that I'm not a fan of."

Chloe reminds us that advisors tend to be busy throughout the day, even going as far to say that the few times she can step away from her desk, it is to use the restroom. Based on her description, Chloe may wish to have a collaborative working space, like Jacqueline, that would give her the opportunity for more interactions. Chloe continued to explain how the independent nature of the work can lead to other issues in addition to isolation.

"I guess that's why a lot of advisors say that they feel like they're undervalued. I think maybe that's one reason. Cause everybody has an idea of what you're going through but nobody's really seeing it. Only if they're close to you, they can hear it, but nobody's really seeing it as much."

Here, Chloe briefly touched on issues of invisibility that seem to plague staff in certain positions. The work is being done, but perhaps is not being acknowledged. When asked how her department can shift from an "independent" culture to a more unified, cohesive culture, Chloe suggested the following:

"I think having more meetings between us...I feel like sometimes it's just once or twice a semester. I feel like we need more of that, even just to vent or talk about all the little things that are going on because we just get little bits and pieces. With my neighbor, she's my immediate contact so I pretty much know everything that's going on with her 
because of proximity. I don't entirely know what's going on the other side [of the physical department]. So I think that's probably a start."

Chloe clearly longs for a stronger connection with her coworkers, expressing that she wants to know more about them. However, she is limited by the fact that they are physically spread out within the department, but they are also frequently busy with students. When asked to further discuss what she feels she is missing from her work environment, she expresses a desire to have downtime to be able to sit with a coworker, just to talk.

"Because you spend so much time at work. You spend like eight, nine hours at work. You're spending more time here than basically at home because during the weekday, by the time I get home and I'm with my husband it's really like six [p.m.] to ten, maybe eleven. If we make it past 10. So you spend a majority of your time here."

As mentioned earlier, both Jacqueline and Kimberly call attention to the value they place on those frequent face-to-face meetings between advisors and their supervisors. Meetings of this nature may not always be possible and can depend on several factors such as the supervisor's availability (due to busy schedules) and the number of staff members they are responsible for. It may be more difficult to have individual meetings when they have many advisors working on their team. For this reason, smaller teams may be ideal to help build stronger bonds.

Leaders may be interested in cultivating a culture of a strong team identity. The academic advisors were asked to describe the department dynamics that exist on the occasion when a new advisor is hired. Giselle described a tradition in her department in welcoming a new employee on the team:

"[They are received] very well. We usually have a lunch where the whole team gets together-- not formal, and we just talk about the pros and cons of advising, but in a very joking way. And then the new advisor trains with mostly every single advisor... They 
[the new advisors] get to see your style, your personality. I think that one-on-one with each advisor is helpful when they transition into their advising role because you've already had that conversation with each one. Whereas, if you just train with one or two advisors, you're kind of a stranger to the other advisors because you haven't had that time with them."

In addition, managers can help develop an inclusive climate by allowing team members to make hiring decisions. Gia expressed how she appreciates being a part of the discussion.

"Everyone who's hired here, my boss always asks us to step in and voice our opinion. Me and the other advisors. She always asks us 'Hey, you want to sit in for the interview?' or 'Do you want to help me with this?' I mean, every single person that comes in here, every single person. I love that because it affects us directly especially if it's an office assistant or the recruiter. It not only gives us a sense that our opinion matters, it just helps the flow better. The chemistry."

Allowing all members to provide input in hiring decisions promotes equality between employees. This also reduces chances for conflict to arise when one person (or a small group of people) control the decisions that impact everyone in the office.

Viviana perceives that leadership is the main force that contributes to a positive working climate. There is a balance between being an employee and also about being "human." Her administrative team fosters the following environment:

"We are professionals. These are the expectations, but you're also a human. I know you have a family, and I know your mom is sick, or I know you have children. So I've always felt like a human. I think that's always relayed to the whole team. There's always compassion."

When discussing what keeps her happy at work, Viviana has concrete examples:

"I'm not micromanaged so our calendars are all visible to each other. Let's say I had a meeting. No one is asking 'Where's Viviana?' because there is a sense of professionalism and the expectation that I get my job done. It is a very positive culture both from the admin and the team. As far as I know, there is no drama." 
When Gia was asked to describe the office climate, her word was "family." In her department, the employees receive individual recognition on their birthdays. They engage in conversation whenever there is downtime at work.

"Every month when it's someone's birthday, we throw them a little birthday party. We pull names at the beginning of the year every year and whoever's name you get, you have to buy them their birthday cake when it's their birthday. It's monthly. We celebrate everyone's birthday. And everyone takes mental health breaks. They walk around the building and talk...You need to get up out of your desk for a second and just get some fresh air. We're big on that. And then it works because we have great conversations. We know everything about each other's families."

Gia understands that this kind of closeness is more likely to exist in small departments, and not larger ones. She refers to large departments on campus, some having 40-50 academic advisors ("There are people within those departments that don't know each other and that floors me.")

Because Gia is the only advisor who was in the middle of changing her status from advisor level one to advisor level two, I took the opportunity to ask her a few additional questions that applied to her unique situation. I was interested in learning how her coworkers treated her promotion.

"They want me to just go up all the way up. I think what helps for our dynamic is that we are all in different fields. We're not competing against each other at all. None of us are competing against each other and the way that we advise is completely different, too. I think that helps too. That's a good reason why we get along."

Gia confirms that she does not perceive competition within her immediate surroundings and acknowledges that their diverse educational backgrounds and degrees are an asset in department dynamics, but also when it comes to advising the students. This is reminiscent of the idea established earlier that highlighting the advisors' 
individual strengths can help contribute to a positive department climate because all employees will have the chance to be acknowledged.

"I notice the people who don't clap for other people. How do you see someone do something outstanding for their career or their education and you don't say congratulations? The biggest helping factor is the way that we all respect each other. All of us have pursued some kind of higher degree and we're all always supporting each other to do so and congratulating each other when we accomplish any little thing."

Several of the women described positive interactions with their supervisor (all of the advisor's supervisors were female). Melanie referred to her supervisor's previous experience as an academic advisor. Melanie values that her supervisor understands the nature of the advisor role, a role that has been described in the literature as invisible and not fully understood (Lee \& Metcalfe, 2017, p. 945).

"I think that definitely shaped her approach to it [leadership style]. Because she's been in the trenches, so to speak, like she's seen the ground-level-work that we do...She's very knowledgeable, and she's sensitive, and she knows what will happen."

She provided an example of a time when her boss stepped in to show support.

"I remember last summer when it was my first year and I was doing orientations. I think it was the first orientation I ever did by myself...So by ourselves, we will have rooms of about 20 [undergraduate] students...She [Melanie's supervisor] actually went with me, to that room to help me advise. That, to me, was a huge thing. Like, ok, she's got my back. She's here with me."

When the supervisor has background knowledge of the advising role (and furthermore, steps in to help when needed), this can shape a positive working environment for advisors who are feeling overwhelmed or overworked. At minimum, the advisors may feel they have a superior that can relate to them. older,

Ginger is distinct from the other advisors that were interviewed because she is holds the title of "Manager" instead of Academic Advisor and works mostly from home. 
Despite her title, she explains how her role still involves advising students, just in a virtual capacity (via phone calls and emails). In her words, she states that she has no direct reports working under her, so her role does not entail supervision. She insists that although she works remotely, she still has significant interactions with her coworkers (some who work remotely as well). Much of these interactions take place through instant messaging through What's App, a messaging platform available on smart phones. When asked about her face-to-face interactions with other coworkers, Ginger revealed:

"I'm the oldest one there so I kind of self-exclude cause they're new and I don't have time...I think they invited me a couple of times [to lunch] and then they stopped inviting me...I may have turned them down too much because I don't like going out...That's what I mean by self-isolate...I don't have money for that. You guys are, I don't know, living with your parents or something.... That was the kind of difference like I'm paying a mortgage and your life is different and that's ok."

A few of the advisors in the study made reference to the fact that their close friends at work were similar to them in age. Ginger acknowledges that her age difference is likely a factor getting in the way of her work relationships.

Finally, in relation to department climate, it is worth mentioning that three of the eight advisors discussed the topic of professional development and how it fits into the culture of the institution. Chloe feels that the university lacks professional development opportunities; she stated that it has been over a year and there have been no talks of a conference. According to Chloe, she has inquired, but it never goes anywhere. She feels this is unusual, given that she works in higher education. In contrast, both Ginger and Giselle believe the institution offers several opportunities for them to learn new things. Furthermore, Giselle feels truly valued when her supervisor sends her workshops, as she felt her previous institution did not encourage continuing her education. Stuart Hunter 
and White (2004) encourage the use of professional development and professional travel to help recognize and reward exceptional advisor work. This may help motivate Chloe who commented that sometimes the work advisors do goes unnoticed.

\section{Conflict}

Although the initial intent of the study included exploring relational aggression between advisors, this was not directly stated to the interviewees. The term aggression may carry a heavy, negative connotation. In order to avoid leading the women with biased questions, I used the word "conflict" instead. When asked about potential conflict in the office, some women described instances of tension between coworkers. Four of the eight women expressed ambiguity surrounding advancement for advisors, with two women referring to the process as "vague." For example, Jacqueline reveals:

"It's very vague and it's actually been expressed within the department that people want a clear-cut way on how to grow. And it's just like 'Oh you need to do more projects, you need to do more this.' But people have been doing that and not getting promoted versus people who aren't doing that and have not been going the extra mile that other people have and they have gotten promoted. So it's very unclear on what the parameters are. And I think that's a university-wide thing."

As previously explained, the organizational hierarchy of this institution provides opportunities for advisors to advance from an Academic Advisor level one position to a level three position in sequential order. Each promotion includes new job responsibilities as well as an increase in salary. However, when attempting to explain the promotion process, many of the women did not know what it takes to move forward. Melanie, the first advisor I interviewed, mentioned this issue:

"I think that causes the most frustration. It's like there is not a clear answer in terms of how the advancement takes place." 
From that interview forward, I asked all seven of the remaining women about their understanding of the promotion process, how one can achieve a promotion, as well as what job duties each advisor level entails.

Kimberly has read the job description for a level two advisor, and she feels she already meets the criteria, despite still being a level one advisor.

"They have advisor level one, two, and three and based on the description of each of them, I can tell that I'm doing work of an advisor two but again I'm advisor one. You see, it's always that we don't have enough money to give everybody a promotion. But again, I'm doing work for that specific title. I don't see the promotion easily in this department."

Giselle tried to further explain the responsibilities that pertain to each advisor level:

"Academic advisor one is your basic advisor and you're just seeing students. Advisor two's are doing a little bit more projects and then advisor three is your senior advisor...they're probably like project leaders. So they're a little bit less student interaction, more working on projects and how to better make that communication with the department and the advisors. Yeah, I'm not 100\% sure that's exactly how it works but that's my understanding."

Chloe attributed professional advancement to external factors outside of the academic advisor's control:

"So it's interesting because I think it's also kind of based out of luck in a way because there's only so many spots that are available. There's only so many academic advisor two's, academic advisor three's. So it's until someone goes that the spot becomes open. So that's why I say it's kind of like luck and seniority. So that's why I say I really love academic advising but it's one of those things that if I don't really see myself moving up then you move out."

Melanie suggests that seniority plays a role in advancement from one level to the next. But she also mentions gender issues that may be influencing professional growthor at least that is the perception in the office. 
"There's also this perception that the boys are advancing more because one of the boys is advisor [level] three. But mind you, he's been here the longest. To be fair, I know there is a perception that he doesn't do as much as the rest--which might or might not be true. I'm not sitting in his office, so I don't know what he's doing. But at the same time, that perception, I get that it might or might not be accurate. But also, he's been here the longest. So it makes sense that he would have advanced the most."

Melanie continued addressing the perception about men in the office gaining certain opportunities but offered an explanation.

"Ongoing rumblings in the department is that only the boys get the opportunities. That has been kind of the ongoing thing. But again, my personal experience has been that it's not necessarily accurate. It is more that nobody else is really stepping up to it. So that's why only the boys get the opportunities-- because they are the only ones who are assertive enough or who are like 'I'm gonna do it.' And then they get it"'

Gia is in a unique situation when compared to the other academic advisors; she is in the process of growing from a level one to a level two advisor. When the interview began, she stated that she was working on the paperwork to formally make the transition. When asked about this process, Gia reveals that she needs to write a letter explaining all of the advisor level two duties she currently performs. Although she is in the middle of this process, she expresses uncertainty regarding the initial steps.

"I'm assuming it has to be on based on a recommendation of a superior."

Although she is the only one of the eight advisors that is currently going through the motions to advance, she is still unable to provide a clear, confident answer.

Finally, it is Viviana (my last interview, a Senior Advisor who has successfully grown within the institution) who delineates recommendations regarding growth in the advisor pathway.

"There is a rubric out there and it sort of outlines the responsibilities, but you still need supervision because you're learning the ropes and the policies. As time goes on, those who take on more initiatives and do extra projects and volunteer...the more you get involved and you put yourself out there so when it's time to be evaluated, you highlight 
and you emphasize those roles that you've taken and hopefully you get promoted to level two."

Many of the other women provided responses that indicate that they also wish to grow within the academic advisor pathway, but they have limited information regarding what is required of them to advance. Advisors may be given opportunities and assigned to lead projects (by way of their supervisors); this gives them a chance to highlight their strengths and exercise leadership skills that are not always included in the advisor role. Viviana stresses that advisors need to find the opportunities to stand out, however, this can be a double-edged sword. For example, these opportunities can also become catalysts for conflict in the department. Melanie describes the department culture when someone is given the directive to lead a project:

"Sometimes conflict arises because there are not a lot of opportunities [to be leads]. When they come up, there's almost this culture that nobody necessarily steps up for it. But then when somebody does step up for it, there is this culture of like 'Oh, how did you get that? How did you get to do that?' Well, because I volunteered and nobody else did...So that is one of the things where I said there are little conflicts everywhere."

Melanie later added that others might perceive her willingness to volunteer for leadership opportunities as her doing it to "look good." This perhaps implies that her work is seen as performative (to be noticed by her supervisor) rather than genuine in nature. While on this topic, I decided to ask about her future career plans. When asked if she is thinking about growing into leadership, she responds:

"Yes potentially. But most likely not in advising--not because I don't like advising-but because there's very few opportunities in advising...We have a huge team and there's only so many administrators that you can have. There's only so many administrative positions for me to go into...I've only been at this for a year. So it's not something that will happen anywhere in the near future." 
Two of the women explained that they are inclined to lean toward conflict

avoidance. When Melanie was asked if she had felt any conflict between coworkers in the office, she stated:

"Not really or at least nothing that sticks out...I'm very conflict-avoidant. So there may have been situations like somebody might have raised an issue and I didn't because I tried to avoid conflict like the plague which is probably not good."

Similarly, Chloe felt that she had seen conflict present itself in previous jobs, and now actively avoids it:

"I feel like I've seen it through different jobs. And that's something my mom always taught me: She's like 'quedate calladita' ("stay quiet" in Spanish) and it's true just because, you know, what for? Why add more fuel to the fire? And I don't know, I just think to me, it's something that just looks really bad. You're talking about one person and then, you know, you're being super nice to them and to me it just looks very two-faced."

Although Chloe does not perceive conflict in her current department, she acknowledges previous work environments that included conflict. In this case, her interpretation of conflict at work includes people talking about others behind their back. However, in the same interview, she goes on to describe incidents she has experienced with her lead advisor. A lead advisor in this context is defined as a level two or a level three advisor working in the same department. These individuals have likely been working there longer and have been promoted.

Chloe provides a brief explanation of the chain-of-command:

"It's pretty much like a chain. So Academic Advisor 1 's first checks with their Academic Advisor 2 (their leads). If they [academic advisor level 2] don't know, then they usually ask a 3 or our Director."

She explains her interactions with her lead advisor in the following quote:

"Not so much conflict... with one of my lead advisors I would say maybe sometimes you don't see eye to eye. It wouldn't be conflict. Maybe just like the way she 
goes about things could be handled a little bit differently...or like the way she comes off, sometimes it could be, I feel, like a little bit better."

With a few probing questions, Chloe provides an example:

"I think like if something isn't done right then it just comes off the wrong way. Instead of being more of a learning experience, it's more scolding. That's how it comes off, like more condescending. Let's say I made a mistake on a form, and she lectures me like 'Oh, how could you make this mistake? You know that this is a requirement.' Like going on and on and on about something that was just a mistake. It is what it is. So I think focusing too much on what the issue is instead of just moving forward and looking toward a solution. I think sometimes she makes it a point to bring you down."

It is necessary to make note of the fact that although lead advisors may be a few levels above those in academic advisor one positions, they are not considered managers in the sense of having formal leadership responsibilities. Consequently, this situation may be ambiguous in terms of the presence of a power dynamic between the lead advisor and Chloe. Lead advisors may have seniority and be able to answer questions that advisor level ones may have, but they are not a substitute for an immediate supervisor.

Chloe acknowledges that the lead advisor's communication style may be coming from a place of stress or frustration. Additionally, the advisor reminds me that the lead advisor has more responsibilities than an academic advisor level one. The advisor chooses to assess the experience as situational and not personal. Due to the high volume of students, mistakes can happen due to human error. However, leaders may play a part in setting the tone of the environment when situations like this occur. Melanie explained:

"Our boss doesn't look to blame us for things that happen because sometimes errors may happen, or things might go wrong and it's not necessarily anybody's fault. I really appreciate that about her. She doesn't look to assign blame."

Melanie makes reference to the impact of stress on the work environment, specifically addressing how the department responds to high-stress moments. What may 
be interpreted as conflict, Melanie refers to as "friction." Still, she acknowledges that stress can affect inter-office relationships.

"I think our team is pretty cohesive. So I think the dynamics might change but it might just become more exclusive. So it might be more of a reaction like protect each other and stick more together. So I think under higher stress that might be the reaction to become closer-knit which may not necessarily be a positive thing because even though cohesion is good you also need to have a healthy degree of flexibility to change. It's good that we maintain that team identity but at the same time it can lead to moments of friction or clashes between ourselves. Or it might lead to friction with administration."

Literature on occupational burnout indicates that it tends to occur in high-stress environments, and also in education and service industries (Hakanen, 1999). Although the women did not mention the term burnout in the interviews, some of them alluded that the nature of the job can create pressure and emotions.

"I think the fact that we have to collaborate often forces us to have to get to know each other. Because sometimes we will work on an event or a project or something together and it's emotionally charged. So we see that vulnerability and each other's emotions."

Giselle acknowledged that there are times in the department where people are not always getting along. However, she labeled these incidents as "hostility" and assured that these moments are rare in her office.

"The woman advisors that I work with closely I would say have grown to a great friendship. But for the rest of the team, there has been a lot of cattiness at times. There has been, not necessarily competition, it's more of 'Why do you get to do this and I don't?' or 'Why was your answer this and mine was something else?'... 'Why did you get more time off than I did?' or 'I requested around that time, too. Why did you get it and I didn't?' ... Sometimes there is a little bit of hostility. Very little, but it's so hard to describe it when your day-to-day, for the most part, is good. There are some days you're not getting along with some."

Giselle hinted at moments of perceived differential treatment at work that might be the reason for conflict in the department. However, situations like these can be 
addressed and perhaps alleviated through face-to-face group meetings (assuming the members are transparent and wish to settle issues together).

Although Ginger primarily works remotely, she periodically visits the department.

Talks of cliques did not come up frequently throughout the different interviews, but Ginger

describes their presence in the office:

"We definitely have little cliques. For better or for worse, but my coworker complained about it. Poor girl. That's why she quit because she sees these bad things and she just can't let go of them. And they hurt. They do hurt."

Jacqueline also brings up cliques that exist in her department. She notes that she witnessed cliques were more common among groups of women than groups of men and some groups were more at an advantage than others. When asked to elaborate on what she believes her leadership can do to eliminate harmful cliques, she revealed that sometimes the managers themselves are enmeshed in the cliques.

"I think they can't because of the relationship between some of the other administrators. There's even cliques that include some of the administrators. So they can't. It's like just impossible unless they get a whole new staff. Like it's literally impossible to do."

Jacqueline describes the nature of some incidents that have caused some tension in the office.

"Sometimes you would say something, and it would get back to an administrator. You can say something like 'I have a lot of messages' but it's not because you're not doing your work, it's because you have a lot of messages. And it would get back to your administrator. They tell you, 'Oh I hear you're overwhelmed.' So you see how the words were twisted. So you have to watch yourself and what you say sometimes."

Jacqueline acknowledges that this was a select group of advisors and they would sometimes target others in the office. 
As established, several advisors have expressed uncertainty in the pathway to professional advancement. They are aware that a promotion to academic advisor level two or level three is accompanied by a salary increase. At this institution, salaries and employee titles are accessible through a website. Two of the advisors refer to this specific website, www.floridahasarighttoknow.myflorida.com, where anyone can log in and access public records in Florida. One can search for information, such as an individual's salary and job title, assuming the individual works for the state government or a state university. Ginger expresses her negative feelings toward the site.

"It kills the soul...My one coworker, she's always bringing it up because they [administrators] make so much money. They make much more money. Well, they're in a role, they have a title. I don't care how much money they make but their title indicates that they have some responsibility."

Ginger explained the discontent her coworker experiences regarding the disparity in pay between advisors and their leadership.

"I try not to look at that [website]. Once I learned about it, it was a rabbit hole. Oh, it's terrible. It hurts... The discrepancy in pay It's terrible. It's constantly being referred to."

However, Ginger seems to be upset more over a lack of clearly defined roles, and less so when it comes to matters of money.

"Let's just clarify who's responsible for what, you know. Like I said, I don't know what they're [administrators] responsible for because there's a huge lack of transparency in our unit."

Ginger continues to reveal more of her feelings regarding salary differences (this will be addressed later). 


\section{Support}

When describing office climates, support between the women emerged as a recurring theme. Some women described stressful events, occurring either their personal or professional lives, and the support they felt when sharing these moments with peers. For example, Giselle revealed:

“...there's been times I've been very stressed at work. Maybe I had a student who was extremely rude. I've gone into their [coworkers] cubicles crying, and I feel so comfortable doing that. I let it out and then I can go back to work. In and out of work, I can rely on them... We 'll go out every now and then. We'll go to lunch, breakfast...It's nice to have that emotional support, that connection to your co-workers because I could tell them anything and everything and I know that it will stay with them. So if I have to vent about something that happened at work, or that happened with my family and it's straining my day, I can talk to them and feel a little bit better the rest of my day."

Giselle provides several other examples in which she feels supported by coworkers:

"We'll go to professional developments together if we have to present...They're always willing, like 'I'll do it with you. Don't worry about it. We can work on this together and we'll grow together in this process.' They're always willing to go above and beyond and help me professionally whether it is maybe trying to get a message across to my supervisor--even the simplest of tasks like that."

She refers to this as emotional support that goes beyond the walls of the office and exists out of work. She explains communication between them takes place every day, mostly through text messaging. On the other hand, Chloe (who has already described her situation as very isolating) does not feel she can turn to her coworkers for emotional support. She offered her take on the lack of connection:

"I haven't felt it so much here...I feel it's just like a proximity thing. The way that everything is set up, we're all just physically separated and a lot of what we do with our students is very, very independent. In my last job, it wasn't so much that way. My direct supervisor was right next door and I had an amazing relationship with her." 
She emphasized the connections that develop out of close proximity between advisors but adds that the nature of the job keeps her busy with students and does not allow her to get much face-to-face time with her peers (according to Chloe, she currently has over 600 students on her caseload). As a result, she admits that she cannot think of someone she would consider a "good friend" at work. When asked what she believes may foster closer relationships with coworkers, she explains having more meetings (more than once or twice a semester) would allow them to share what everyone is going through (even if it's just to "vent about all the little things").

Giselle acknowledged the pride she feels from peer recognition; this peer recognition is a direct result of the close physical proximity of the advisors in her department. The physical location and closeness provide more opportunities for meaningful interactions.

"Since we are in an open space, we do hear our advising sessions and if I'm doing a good job, my coworkers will let me know. Like, 'you know, that was a good job.' It makes me feel good. So if I'm advising a student, my two cubicle neighbors can hear my advising session and then at the end of the session, sometimes we'll go into each other's cubicles and talk...And a lot of times we'll tell each other 'Man, that was a really good point. I want to use that next time.' That makes me feel valued."

While on the topic of value, Melanie discussed some of the most rewarding moments of her job come with recognition. This recognition does not have to be formal in nature, nor strictly public or private, as she detailed that it is valued whether it comes from her peers, her supervisor, or from the students.

"In general, we get a lot of recognition from each other. So we really make a point of appreciating each other and making sure that we let our colleagues know all that they do. They let me know, or I let them know that we have each other's support. That we work as a team. We have a very strong team identity so that definitely makes me feel valued. I think our supervisor...she's very good. She acknowledges the things that you're doing and she acknowledges the things that are going well. Like she's very, very good at 
that. So that also helped me feel like I do a job that matters. With students, it's a little hit or miss. But you do have those students that say 'You helped me so much. You answered my questions.' And that is wonderful to get that feedback from students especially in our roles where $90 \%$ of the time we're seeing students."

Some of the women stated that they felt support in the little moments, and not necessarily in grand, public gestures. Gia described what happens when she engages in public speaking events at the university.

"I have colleagues that show up. If not, they'll come in here [the office] before they see me go off to the lecture and they're like 'Hey, you're going to kill it today. You're going to be great.' You know, it's those little, tiny things. They really help... You have to get to know people. You're going to work with them. You can come in lock yourself in your office all day and not talk to anybody, but don't expect to feel good or feel supported."

Although the term "sisterhood" was not explicitly mentioned in the interview questions so as to avoid swaying the advisors into answering the questions in a biased way, some statements seem to indicate a presence of sisterhood between intradepartmental advisors. Though it may be difficult to put into words, Giselle attempted to explain the relationships:

"We all want each other to become the best versions of ourselves that we can be...[this] is why we help each other. I think the care that we developed for each other, wanting to be there for one another...I don't really know how to explain. It's like I can see it in my mind, I can feel it, why I care for them. Why? Because I know they are capable of so much. Whether it be in this role, I want them to succeed. I want us to grow together...If you're not in higher education, it's hard to explain to someone outside of higher education why you like what you're doing and you why you do what you do. I think with them it's so easy to express our love for students, our love for helping these students grow. And I think that's why-- the same reason why I want my students to grow, I want them [coworkers] to grow up to be the best."

Because Viviana is a seasoned advisor who quickly advanced along the advisor pathway, she assists newly hired advisors by serving as a mentor. She describes some of the activities she partakes in, despite being busy with her day-to-day advisor duties: 
"I haven't been mingling as much as I should, with the exception of my mentees. I have 2 mentees... We have a mentorship program for new advisors that lasts about four to six months. We have discussions and we have lunch with them, or a coffee like once every two weeks, or once a month. I try to keep those connections because they're new."

According to Viviana, Senior Advisors working in this institution are responsible for this additional duty. For new hires who have a hard time networking, being part of this mentorship program may give them the chance to organically establish connections with other employees.

Jacqueline frequently used the word "community" to describe her team of 6 advisors. She believes the closeness is, in part, due to the fact that they are a small department. She elaborates that a small team allows you to get to know each other with "significant interactions" but a larger team would not make way for these opportunities. When asked to describe how these connections are built, Jacqueline explained the circumstances surrounding the academic advisor role that may help foster relationships in the workplace.

"We often vented to each other. Advising can be very taxing because you're getting that from students all the time...that emotional baggage. So sometimes you get students coming in and they're crying. Being able to unload that on a co-worker helps...Feeling overwhelmed with everything that needs to be done, as an advisor...Like you have 50 emails and you there's a policy to answer them within 48 hours, and you also have a day full of appointments. There's literally no time to do anything. Talking to someone about it who also feels the same way is helpful in a judgement-free territory."

Jacqueline continued to advocate small team sizes, indicating that close relationships are not easily cultivated in larger groups. When asked why she believes smaller teams can bring more success in achieving camaraderie between coworkers, she explained:

"It's probably because you have more of an ability to speak because there's less people at the table. You have more of an opportunity to build friendships... relationships 
with people in your team, versus if it's 20 people on the team, you can't possibly know everyone well. So it's easier to have that 'community feel' with everyone. And you know who's at the table because if you had 20 people on the team, you probably don't know everyone. You know who they are but you probably haven't had significant communication or significant interaction."

Based on her response, it would seem that Jacqueline feels deeper relationships are created in smaller groups because everyone is able to have a voice. When it comes to larger teams, Jacqueline has her beliefs:

"There's a lot of invisibility. Those larger teams can lend itself to that. Different personalities too, because extroverts are more likely to speak out in a big meeting versus a smaller team, you're more likely to speak your mind. It's just a conversation versus a huge crowd."

Fewer people in one department allows people to get to know each other on a personal level, in addition to being work colleagues. This, however, relies on the assumption that the members of the department are willing to be open with each other and get closer. expressed

Ginger, like Jacqueline, also spoke of the benefits of a smaller team. She her ideal size for a team, drawing from her counseling background, explaining:

"I think I learned this from my classes, you know, small group counseling. It's 5-7 [people] max. If you get to 7 it starts to get crazy so really 5 is the most conducive number for small group bonding."

Though she refers to small groups in a counseling setting and not necessarily in higher education, the implication is that larger groups may lose focus, or perhaps miss out on the $\mathrm{x}$ factor that leads to strong connections and team identity.

Jacqueline seemed to suggest the presence of a sisterhood in her department, referencing the fact that her department is made up of mostly women. 
"I know females in general they're very nurturing... because you can say something even if it's crazy and they're not going to shut you down. You know they'll let you down easy and be like 'well, that's not a good idea.' They're not going to be like 'that's terrible, why would we do that?' So it's kind of safe. I don't know, I guess it's like a mom thing."

The advisors were asked, in their opinion, what factors may help cultivate support between female coworkers. Melanie expressed the idea of highlighting individual strengths. For example:

"When new people come in, offer them support. Train them. Give them the tools to do their job. I think when you're given the tools to do your job, you know what you're doing, and it's an environment that feels nurturing, then those relationships form naturally. Sometimes you just get lucky with a team that people will mesh well together and that works out. I think part of it is fostering an environment where employees are supported and talents are nurtured. For example, one of my colleagues, he loves photography. So whenever we have to do projects that involve pictures or that involve recording, usually that's something that he will get involved in...So giving people the opportunity to use the talents or the skills that they have even though they may not necessarily be advising skills...I think that fosters an environment where people will kind of coalesce together."

Kimberly (who works in the same department as Melanie) echoed a similar sentiment, as she discussed that everybody is welcome to take on a project (or several projects). She thinks that, as a result, no one feels as if they are superior to other peers. She also agrees with Melanie in the sense that their supervisor seeks out individual strengths. So, if an advisor possesses a specific talent, that advisor will be asked to work on a specific project or provide suggestions and opinions on tackling said project. Supervisors may also take this opportunity to pair employees in a way to generate mentorship opportunities, where advisors can benefit from each other by learning new skills or best practices. This mentorship can organically create more leadership opportunities for advisors interested in showcasing their skills.

Kimberly described examples of how her team shows support: 
"My colleagues, no complaints. They are very helpful. I remember the last time I had to be at the doctor unexpectedly, they were willing to see all my students even though we were in peak season. So my colleagues are awesome. We get along very well which is good because that's one of the things that that's keeping me here... We're like a family here."

When asked what she likes best about her team, she states:

"I think it's the willingness to help each other out because you don't find that often. This is not my first [place of] employment. I used to work somewhere where it's like, "everybody for themselves."

She provides other examples that demonstrate the camaraderie that takes place in her department. Her coworkers act as a practice audience for Kimberly to deliver presentations (a skill that is required for her job, but she admits still makes her nervous). When she was dealing with some health concerns, her fellow advisors were willing to see the students on her caseload during peak season. Recently, Kimberly's coworkers nominated her for a university advisor excellence award, giving her public recognition. However, upon recollecting this event, Kimberly refers back to her coworkers expressing:

"It wasn't that I'm winning this, it's like everybody's winning this because we're doing it as a team."

\section{Additional Themes}

Through coding, other themes were identified in the analysis process aside from those defining and describing climate, conflict, and support. The women in this study also talked about their "five-year-plans," the interactions they have with their direct supervisor(s), and the importance of advisors within the world of higher education. The following details the additional codes that emerged in this study. 


\section{Plans for Growth}

A Master's degree is required for the advisor role at this institution, but a few of the women stated that they are pursuing a doctoral degree. Melanie recently began her coursework this Fall semester and potentially sees administration in her five-year-plan after graduation. She expressed some ambivalent feelings regarding her future in advisement, seemingly contradicting herself as she answered a question regarding her long-term career plans.

"I'm not quite sure. I don't know if I will still be an advisor. I might because, to be honest, I really enjoy it and it's a really solid entry level kind of role and I genuinely enjoy working with the students. I might still be an advisor."

When asked to predict how much longer she thinks she will remain an advisor,

Melanie once again expressed some uncertainty:

"I would say at least another year, at least. One more year, maybe more, depending on how things shape up. Opportunities. I'm always looking for opportunities for growth. But at the same time, I'm cautious not to overwhelm myself. I will be starting up the [Ph.D.] program in the Fall so I definitely want to have that stability. And the team I have right now is a really good team. To me, that's very valuable. I have a great boss. So with all of these things, unless something radically changes, I don't see myself being in a rush to transition out. But at the same time, I don't see myself advising for the next 10 years. It's kind of a balance where I don't want to get too comfortable to the point where I'm stagnating. But at the same time, I do want to give myself the space to grow to Level 3."

At the time of the interview, Melanie had been in the advisor role for only one year but she acknowledged that she keeps an eye open for advancement opportunities. However, she demonstrates that her connections to her colleagues and supervisor act as incentives to keep her in the department.

Melanie is not the only advisor thinking about continuing her education, as Chloe expressed a desire to enter a doctoral program soon. Gia is already enrolled in a doctoral 
program and is currently trying to juggle her full-time advising job, part-time adjunct work, and finishing her Ph.D. As an incentive, the university provides tuition benefits for employees who want to return to school. Aside from the financial benefit to completing a degree at the institution in which they work (in the form of saving money on coursework), the advisors have the added convenience of being able to go from work to the classroom and remain on the same campus. These women are going beyond the minimum requirements for their role and considering avenues that may arise after completing a Ph.D. degree.

Later in the interview, Melanie explained that she finds the advisor role is limiting for individuals who wish to grow within higher education. She confirmed again that being an advisor may be a way to start a career in academia, but it is narrow in terms of long-term career prospects.

"I would say there is a lot of shifting about in advising especially...I think advising is, again, kind of built as an entry-level role like I mentioned earlier. The opportunities for growth are not that great. So if you want to advance, chances are you're going to have to walk away from advising. If you want to advance, there is not a whole lot beyond going through the whole advisor 2, advisor 3, and then what?"

However, Melanie also believes that there is a lot of shifting in the higher education environment overall, especially with nonadministrative positions.

"That might just be my experience so far, but I feel like people change roles a lot. If you're leaving your job within four or five months, there is a problem. But typically, people don't stay in their roles for more than a couple of years. That has been what I've seen. If you are very established administrator, you're probably going to stay, but entrylevel positions...I would say there is a lot of shifting about advising especially. I see a lot of people who either move laterally to another advising position or move and do a coordinator or a manager role somewhere else within higher ed[udcation]."

According to Chloe, her department has seen high levels of turnover in the past year that she has been working there. 
"From what I've heard, the atmosphere wasn't the friendliest before I got here. I feel like there's a lot of fresh, new faces. So it's a little better now. From what it sounds like, before, this [department] was very, very divided."

When I asked for her perspective regarding the reasons why people have left the advising role, she offered her explanation:

"You know, the work that we do is very time-consuming. It does take a lot out of you. I feel like you have to really, really love it. I feel, if after a while, you're not moving up, then I could see why people job search and move on to something else."

Giselle, like Melanie, has been in her role for a year. Also like Melanie, she is already thinking about what her professional future holds for her:

"So in five years, I hope to maybe be a Senior Advisor. Honestly, on my way out hopefully. Maybe pursue another area in higher education or an administrative role, like an Assistant Director, maybe. You know, nothing too crazy but I probably see myself out of advising in five years."

Despite being in the role for a short time, a few of the women don't see advisement as their life-long career. Giselle reveals:

"I would say five years is how long I want to be in advising. I think I say five years because there's not much growth other than Advisor 1, 2, and 3. I love that student interaction that you have as an advisor, but if I'm being quite honest, the pay isn't what I see myself getting with a Master's degree."

When the women expressed an interest in pursuing a leadership role, I followed up by asking them what was appealing about being an administrator. Like Giselle, Chloe believes that becoming a supervisor will give her access to responsibilities that can make an impact on both the institution and its employees. However, she also brings in the element of how she would treat her staff, referencing how she would handle disciplinary matters. Chloe had previously described how her lead advisor could address discipline in a more effective and gentle way. 
"I think being able to have a say in terms of different policies and procedures. Obviously, you have more say in that [as a supervisor]. I think, as a leader, one of the qualities that I like about myself when I've trained people or when I've trained my students--even if they've made mistakes. It's not so much about the mistakes, but them learning from it and kind of moving forward. So I'm really, really big on not trying not to be condescending...You know that to me is probably the most valuable thing."

Chloe may have strong feelings regarding leadership because she has previous experience in a supervisory position.

"As an Assistant Director, I supervised full-time staff members...I supervised a group of student interns which would be, roughly, like 10 - 12 students. So that part I really enjoyed and that's something that I'm not able to do within this role. So like I said, if I'm not able to grow here, that's something that I'd be looking for."

Giselle also expressed interest in growing into leadership, and her motivations seem to be two-fold:

"I think it's being able to solve, or maybe 'solve' is not the right word. I would say, to fix problems that maybe I can't [solve] right now. So let's say I have a problem with a student. All I have to do is basically reach out to my supervisor and something gets done, right? I feel like although I want to help my students right now I can't to my fullest potential because I don't have that authority. I also feel like being in a leadership position and also having that advising background I think it would be useful in helping the other advisors be happy in their advisor roles. So I think also part of the leadership role is how to keep advisors happy in their role...Sometimes I feel like, in my previous roles, my leadership have forgotten what it was like to be in this role."

When asked what would make Giselle happy (specifically, things that are in her supervisor's control) she stated support ("that feeling of 'I have your back no matter what'”) and encouragement to pursue career growth through professional development opportunities. The relationships cultivated between the advisors and their respective supervisors were another recurring theme explored during the analysis portion of the study. 
Kimberly believes leadership is appealing because it would give her access to learn more about the inner workings of higher education. Right now, she finds that being an advisor is narrow in terms of the role and its functions.

"The staff that's above all of us go to meetings that we can't go to. So you learn more about the university as a whole instead of just 'Hey, you need to meet with students. You need to graduate students. '... Here you go to professional development, and to all of those things you could do to help students. But you don't know the university as a whole-what's going on."

Kimberly appears to want more involvement in matters that are directly related to the university, not just dealing with daily student interaction. Furthermore, her comment about the pressure to graduate students might be alluding to the pressure that is placed on meeting certain university metrics. Despite wanting to work as an administrator someday, Kimberly admitted that her current advisor role is not helping her grow in that direction.

Viviana offers a different perspective; she feels her current senior advisor role is preparing her for a future in administration.

"Ever since I've acquired this role, I've worked closer with admin[istration]. I attend, not the 'important,' important meetings but I do attend meetings that are relevant to my major area so that I could disseminate that to the team."

Because Viviana has been able to work her way up the advisor pathway, I took the opportunity to discuss how some of the women working as level one advisors (such as Kimberly) would appreciate having more input in departmental or institutional matters. Viviana, who has previously been in their shoes, offers an explanation:

"Obviously my knowledge of the major is a little more extensive than a [level] one. So if they [administrators] need feedback, like 'Does this make sense from an advising level when you're redirecting students? What would this look like?' I can provide that information rather than someone that may not have that experience. So although I can relate to those sentiments because I said 'I wish somebody would have told us what's going on.' But now from the other side it's like, it's complicated enough up here. The information has to be very clear before we can disseminate it to everybody else 
before we start getting a can of worms of questions. So that can't happen with a million voices because it will never get done."

Viviana has the advantage of experience and she can see the issue from both sides. She feels that only certain individuals attend certain meetings for the purpose of streamlining communication. She receives valuable information from these meetings and delivers the relevant messages back to her coworkers. This perspective may be useful for advisors who are still in level one positions who aspire to grow within the advisor pathway. Although they may feel some frustration and limitation in their current role, Viviana can serve as a role model and provide clarity to other advisors due to her professional growth. In her position, she can already see new hires who have potential to advance forward professionally.

"I can see, from my perspective, advisors that are 'out there.' They're jumping on all opportunities. I can see this person is going to make it far faster than others that are...not complacent, but just doing that day to day, coming to work, seeing students, following these deadlines that are given. So I can tell from the position that I am in, those that are wanting to shine."

Ginger is open to exploring several different options in her career, not just an administrative role.

"I think if I were to move away from Miami, I would have more of a chance of getting into a higher-level role. I don't know if I really want that headache or not...I've thought about teaching. I know I can always fall back on teaching. I kind of have aspirations to be kind of like a mentor. Just to be able to help others in the field. I'd love to be a director to do that."

Gia talked about career options outside of the advising realm, but unlike the other women in this study, she is not interested in the administrative side of higher education.

"My boss would always tell me, 'You know, one day you can be a Dean, you can be a Director... You're still going to have your PHD. You can still teach.' And I would always say no because I hate all of this bureaucracy and I love my students. I really, 
really love my students. I love watching them learn. I love watching them have epiphanies. I love dream-building with them."

Gia's department is smaller in personnel than the other departments that I was able to explore in my research. Because there are few employees in this department, she is asked to take on tasks that go beyond the standard duties of an advisor. She was the only one of the eight women to refer to the advisor role as "administrative." It is possible that she feels she is already doing the work of an administrator; perhaps that is why she would like to scale down her responsibilities and solely work with the students one-onone. This might be why Gia does not wish to grow into leadership; in fact, she expressed a desire to grow within the academic advisor role. She made a joke about going beyond a level three advisor role.

"Yeah. I'm not interested in it [being a leader]. I'm really not. When I speak to my students as a professor, about leadership, I always try to remind them that everybody feels like an imposter at all times [laughs]. Everybody's winging it and everyone is learning...I want something a little more humbling, I think...I tell everyone I'm going to be Academic Advisor Six one day because I love advising. I really love advising. I don't want to be responsible for anyone. I don't like those positions of power."

\section{Relationship with Supervisor}

As mentioned above, Giselle's boss has previous advising experience. Giselle described her relationship with her supervisor, indicating that they are geographically separated, with her boss working in an entirely different building. Despite the physical distance (in a study where proximity has been a recurring theme in creating and maintaining positive working relationships), Giselle commented that her boss is always accessible via email and strongly promotes open communication. 
Chloe previously expressed disappointment in the lack of face-to-face

opportunities with her coworkers. However, Chloe also informed me that she has limited chances to speak with her direct supervisor, as well.

"I think it's interesting since I don't really interact with her on a day-to-day basis. She's technically my supervisor on paper at the end of the day. She kind of has the final say, but for training purposes and the day-to-day, we have our lead advisors who are here who kind of act more like our supervisors."

In Chloe's department, the lead advisors (again, those who are working in level two or level three positions) step in as seasoned advisors who can manage day-to-day issues and concerns of the office. Chloe posits that this may happen more often in larger departments with many employees, where the immediate supervisor is not always accessible due to other work commitments.

"Technically, they [lead advisors] are not our supervisor, but they are just because of the immediacy...As a director, even like an assistant director, you have a lot on your plate. You're in and out of your office. You have a lot going on. So it's kind of more streamlined...There's a lot of questions that the lead advisors can answer."

As a reminder, Chloe is the advisor who expressed instances of conflict between her and a lead advisor in her department.

Several of the women have expressed that they value the positive interactions they have with each other in their day-to-day moments together. Kimberly describes her boss as another member of her cohesive team. Her boss encourages open communication for the entire team (often initiating it herself) which may help bring the group closer together.

"She will text or e-mail saying 'Hey, we need to get together as team to catch up to see how everybody's doing. ' Just for that. You know, just to see how we're doing. "

Kimberly believes her supervisor does a lot of work behind the scenes to help 
keep the advisors on the team happy. However, she knows that there are some things that are beyond her immediate supervisor's control.

"She always listens to us. We do talk a lot. We always bring our concerns to her and she fights her way. She's always, always fighting fires, which is great. We love that about her. She is very understanding...Let's say you're interested in something. She will let you explore that. But again, she does have somebody above her so she might agree but that doesn't mean her supervisor will."

Viviana, the Senior Advisor, who expressed that her leadership is one of the biggest factors in establishing a positive environment gave an example of the open conversations that take place in the department:

"They [the supervisors] know that we're here to grow. So if I am looking for another position, I feel comfortable enough to knock on the door and say 'Please don't kill me, you know I love you. I applied for this position.' And that's not easy in any other job. In other jobs you don't want your supervisor to know that you applied for other positions. In meetings, the supervisor says 'Listen, I know you're here but you all want to grow. We know people leave, it's OK. I want you to grow. I I support you. I'm the first one to support you.' That's part of setting the culture."

\section{Conflict with Supervisor}

Although the results indicate that the majority of the advisors self-reported relationships with their supervisors that are warm, close-knit, and encouraging, this is not the case for Ginger. Although Ginger brought up elements that would fall under the theme of conflict, her negative experiences surrounded the relationship she had with her supervisor and not her peers.

"It's a bitter pill. I'll share my bitter pill that I still work on. So I came on board with eight years of advising experience already under my belt. There was an advisor who had been there for eight years, so we were pretty much contemporaries... She got the Associate Director [position] and I got Manager. I didn't feel like that was recognizing what I had done. And I didn't do anything about it."

Ginger recalled the events that led to a coworker getting a promotion over her. As mentioned earlier, Ginger is well aware of the website that details employee salaries. 
Based on her following statements, it is clear that she has complicated feelings about the monetary value that is assigned to the advisor role.

"Now she's Associate Director and she's making significantly more than I am. I actually have to restrain myself from really looking at what she's making because it's disappointing and that's not the value of the work that I do. That is what I really have to focus on and I think that has been a thing that I have gained over the years."

Ginger touched on issues that concern advisors in higher education; here she drew attention to issues involving low pay, especially in relation to administration in the same field.

When asked about incidents about sabotage, Ginger shared that although she does not experience these feelings with coworkers, she feels it may be occurring with her supervisor:

"Sabotage...I wonder about my Director sometimes. If she's trying to get rid of me. I've been there so long. I butt heads with her sometimes you know. It's been a lot better since I've been at home."

Ginger stated that she works at home in order to accommodate the department needs (allowing for more advisors to work for the department to serve a growing number of students, but in a virtual capacity in order to address issues of space in the office). However, if supervisors see growing tension in the office, they may want to consider having advisors work remotely.

\section{Skill-building}

A few of the women are thinking ahead about future administrative roles they wish to obtain. The women were asked how their current position contributes to their future professional plans. The following excerpts detail the skills they feel they are 
gaining while occupying the advisor role. Melanie describes the interpersonal skills, as

well as the networking opportunities that come with advising:

"I feel that it gives me the space to develop as a professional so I'm learning skills like advising skills. If you're in a student-facing role, you need to learn how to talk to students and I think having that experience is valuable. The populations we work with can be challenging because they're undergraduate students...Sometimes they are a high risk [student]...I also think it's a great opportunity for networking. So being in a place as big as [institution name], I get to meet a lot of people. That can potentially open the door later on, especially if you're interfacing with different colleges, it may open the door if a position opens up."

Giselle also mentions the tactful communication skills one cultivates in this field, and hints about the holistic nature of the advisor role:

"You're working with students day in and day out. And although you're an academic advisor, and you're helping them with their academics, there's so much more to students. When they come in and they're struggling with a course, they're going to tell you much more than just about the course. I think starting in advising definitely develops you to really know how to work with students and really know how to communicate with them. And I think that in advising, you learn a little bit of everything."

Chloe thinks the role is helping her fine-tune her critical thinking skills, as well as helping her learn more about the institution and its policies. This can be valuable if she chooses to remain working for this university.

"I think this is a job where I have learned the most in very, very little time--which I absolutely thrive in... You have to know a little bit about everything because we work with so many students...Every student is so different and has so many different unique backgrounds. Every student is super different from what I've seen. And there's certain things that you can make exceptions for and you just have to be very familiarized with a lot of things. A lot of rules. A lot of procedures. Sometimes there's exceptions depending on $X, Y$, and $Z$. I think with my critical thinking skills, it's helped me out a lot in the sense that I will question so many things because students will come in with a question and it turns into like me asking them 10 questions back...It's like the art of asking questions and trying to figure out what's going on. I think that's something that I will take with me wherever I go." 
Kimberly, like Melanie and Giselle, pinpoints the communication factor, but also describes the customer service skills that come with the territory of the interactions between advisor and student:

"You learn a lot from this position. You learn how to deal with other people. Any professional in this world has to learn how to get along with other people. How to speak, how to talk to people. Because we cannot speak rudely to our students, even though sometimes they're pretty rude, but we cannot do the same thing to them. So I think it's kind of preparing me to have those honest conversations and then at the same time be humble about certain stuff."

\section{Role Expectations}

The literature on advising addresses the uncertainty that lies within the role as far as who should be doing which functions. Ginger explains her frustration regarding the way

tasks get delegated to academic advisors.

"The faculty are sending us things, and then the Provost, and then our deans. It's like, don't you guys know that we're doing something? But they don't get it. Especially the faculty. The faculty really gets on my nerves because they're just as much in contact, if not more, with these students. The funding has gone to create all of these advising positions, so there is this explosion in [school name]. I don't know how other schools are, but I really feel like it is exploding in other schools too, where they're just hiring and hiring advisors. But there's this lack of clarity on how far we can go with these advisors. What are we supposed to do? There's all this disorganization."

Viviana stresses the various duties academic advisors currently take on in today's

higher education climate. Her day-to-day responsibilities go beyond listing the credits required for graduation:

"We don't just advise for classes. When we have an appointment with a student, we're talking about potential mental health issues when they're telling you that they can't focus, or that their mother just died. They're talking about submitting a medical appeal because of their cancer like the one I had the other day. They're being sexually harassed by a classmate. They're not passing and they're in the wrong major. We're having this whole discussion that really involves some degree of counseling skills to help the student as a person and help the student academically. A lot of people don't realize that we're doing all of this. They think that the students come in and we're prescribing classes 
again... and now we're addressing career. We're addressing career and graduate school. So in a 30-minute session, we're trying to cover a lot of things."

Costello (2012) indicates that entry level jobs, such as the roles that make up the support staff in higher education, may be repetitive in nature. This is especially true when academic advisors have hundreds of students on their caseload that they are responsible for. Gia described one of her functions that has become very routine:

"When I'm doing my summer emails for new students, I constantly have to tell myself 'Be specific. Don't rush through this because this is their first time. It's your onehundredth today, but this is their first time.' So I try to just copy/paste but also look through it and make sure that I answered some questions. So I constantly have to tell myself to stay enthusiastic because it's not their fault that my other 200 students ask me the same question."

Academic advisors and supervisors should be able to join together and brainstorm solutions that can eliminate some of the routine, but necessary, tasks that take away from quality time with the students. Alternatively, reducing the number of students on each caseload may enhance the relationships that are built between advisor and student. Gia's comments remind us that the role of the academic advisor is ultimately largely serviceoriented.

Gia refers to meetings where all academic advisors in the institution gather together. She feels this meeting gives her a different perspective of the advisors, seeing them as more "human" than just workers.

"They put us in this huge room. It's 700 people in there. So it's one of those rooms and they'll fill it up and we'll always have guest speakers. And I love when it's the question-and-answer session at the end of the talk. You realize 'Wow, look they're humans, they're not robots.' Because sometimes an advisor is like 'No, we just need to get this done. Ok, sorry, I ran out of time.' We don't have time to be human, right? It's just prescribe, prescribe, prescribe and send them on their way." 


\section{Advisor Value}

Viviana and several other advisors brought up the topic of advisor salaries.

Because Viviana has been advising for almost five years, she has been able to see

firsthand the salary increases that have been put in place for academic advisors at this institution.

"So it [advisor salary range] has gone up because the university at some point realized their value. The GSI was the initial fuel that started putting us in the spotlight. That's what made everyone realize their value because before either the faculty advised, or students advised themselves. Even now I would say that many faculty members still don't know our value. We hear it all the time. 'The advisors are not experts in this department' or 'Go see a faculty advisor.", GSI.

Ginger has witnessed firsthand the changes that occurred with this institution's

One of the changes standardized the pay that advisors receive, regardless of which school they work for:

"Prior to the GSI initiative, all of the colleges were paying advisors differently so you could be an advisor in Psychology versus an advisor in Business. Same exact job, same exact level, [the school of] Business was paying them about ten thousand dollars more a year."

Viviana credits the GSI for drawing more attention to the importance of a

professional academic advisor:

"They [faculty members] don't know the processes, the systematic processes, of what we do to make sure students are on track. I think it is a lack of awareness of all our duties and responsibilities and the ones that really do know say 'You guys are awesome.' But then the ones that don't... they don't really see the value or don't really recognize the work that we're doing for the university, or for the student, or for the department. I think it's because this whole professional advising thing is very new."

\section{Summarizing the Results}

The women's stories appear to indicate that several different factors can contribute to a positive working climate in departments with large female representation. 
Some of the academic advisors focused on the benefits of quality face-to-face time with their supervisors, and also with each other. Conversations in the office allow for bonding opportunities, even when the dialogue is not necessarily work-related. Having a say in group decisions that impact the department overall, such as in the process of hiring new employees, was also valued. One department was able to make a significant change (for the better) in terms of departmental climate, by intervening with a staff retreat to bring the team closer together and diffuse the existing tension. A diverse team (made up of individuals with different educational backgrounds, of various age groups, race/ethnicity, and sex) can create a more inclusive environment. All of the women hold their supervisor in high regard; an approachable boss with experience in the advising field can be very relatable and motivating. In fact, many of the women attribute the success of the department, including the amicable relationships that form in the office, to their leader.

The fact that the women feel they never receive a clear answer on how to grow within the advisor pathway seems to be an influential factor that causes frustration and conflict. Advisors are seeing others being promoted, but they receive little guidance that will help them make their own advances. The women are given some chances to demonstrate their leadership skills when they manage a project, but these opportunities do not come around very often. High periods of stress (such as during peak times, or orientation season) might lead to conflict for some departments. Perceived favoritism from the boss can lead to feelings of resentment from employees who feel they are not being treated fairly. Salary, particularly salary transparency, appeared to be a catalyst for tension in the office. Aside from these concerns, the women did not report many instances or feelings of competition with their intradepartmental coworkers. In fact, when 
asked if they ever applied for the same job as a coworker, the vast majority of the advisors responded, "no." However, many of these concerns may apply to departments of all demographics, not exclusively in majority-female departments.

Although conflict was minimal, support between the women was found in abundance. The advisors described examples of solidarity, such as when it came time to present at workshops. The women would show support by offering to present together or giving their colleague the chance to practice their public speaking skills until they build their confidence. Some of the advisors expressed that support was demonstrated through peer recognition, whether it came in the form of verbal praise or an award. Acknowledging each other's strengths can be beneficial for the department, as special projects can be completed using individuals' expertise. When the advisors feel overworked and stressed, they turn to each other's offices to vent. A few of the women expressed that smaller teams are more conducive for bonding opportunities, as personalities get to shine individually, and there is more of a chance to get to know each other personally and professionally. Lead advisors show support to incoming academic advisors through a mentoring program. All of the advisors are responsible for a caseload of students. When advisors take time off of work for personal reasons (such as medical leave), they rest assured knowing that their colleagues are willing to step in and take on some of the work.

Aside from themes associated to the research questions regarding departmental climate, conflict, and support, other themes emerged through the conversations we shared. In discussing their current advising role, we touched on their career aspirations; consequently, an additional theme was the women's plans for growth. Many of the 
advisors seem themselves in administrative roles in the future. A few are thinking of pursuing their doctoral degree or are already in the process, especially since their place of employment offers tuition reimbursement. Although the focus of this qualitative study was to explore the relationships between coworkers on the same level, two additional themes about relationships emerged: the relationship with their supervisors, as well as conflict with their supervisors. Positive relationships between advisor and supervisor included mentorship, while conflict with a supervisor involved questions regarding what administrators actually do that warrants their high salaries.

The results chapter concludes with three more themes: the skills that are gained through the advisor role, role expectations, and the value of the advisor role (specifically discussing how those not working in advisor roles view and treat those who choose to work in this role. The women touched on how their current role can help them professionally in the future. They clarify that advising duties go well beyond recommending classes and building a schedule. 


\section{CHAPTER V}

\section{DISCUSSION}

\section{Summary of Study}

This interpretive qualitative study focused on the lived experiences of female academic advisors. The objective was to look at the relationships they have with other women in a work environment that may privilege men (in terms of promotions, visibility,

and salaries, for example). Through snowball sampling, I conducted eight interviews with different women who detailed their daily work lives (including their normal, day-to-day responsibilities) their career aspirations, and their relationships with others in the office (including their supervisors). There was a focus on the relationships they have with other women in their department, in order to examine the idea if a large female presence influenced the dynamic of the office.

This chapter addresses the research questions as determined by the women's interview responses, provides conclusions, discusses how the theoretical framework (Carol Gilligan's ethic of care) is applied in this study, and explores what can be done differently in a future study (given the current limitations that impacted the research). Before discussing the implications of the results, a reminder of the research questions is in order:

1) How do female academic advisors in majority-female departments describe their intradepartmental climate?

2) What factors are associated with competitive workplace climates among female academic advisors in departments that are primarily female? 
3) What factors are associated with supportive workplace climates among female academic advisors in departments that are primarily female?

\section{Climate}

Because Maranto and Griffin (2011) described that women in higher education perceive a chilly climate when they were the minority in their department, this study purposely examined department climate when women are the majority. Advisors were encouraged to describe their office climate in a manner that was open-ended. The study was exploratory and intended to look at how these women perceived their workspace (the environment where the majority of their interactions take place). Most of the interview questions were written specifically to address work climate, and they were carefully constructed in a way to avoid personal bias from the researcher. The interview questions addressed topics such as the relationship between the advisor and her supervisor, challenges that the advisors had encountered in their career, a description of their role in the department, how long they wanted to stay in their advisor role, and their perception of their overall work environment. Summarizing Costello's (2012) interpretation of climate, it is "the overall perception and emotion— both good and bad—of employees within an organization" (p. 103).

A diagram was created to reflect major themes that emerged during coding, in respect to the research question regarding department climate (Figure 1). These themes included: Individual and Team Meetings, Group Hiring Decisions, and Collaborative/Shared Space. 
Figure 1

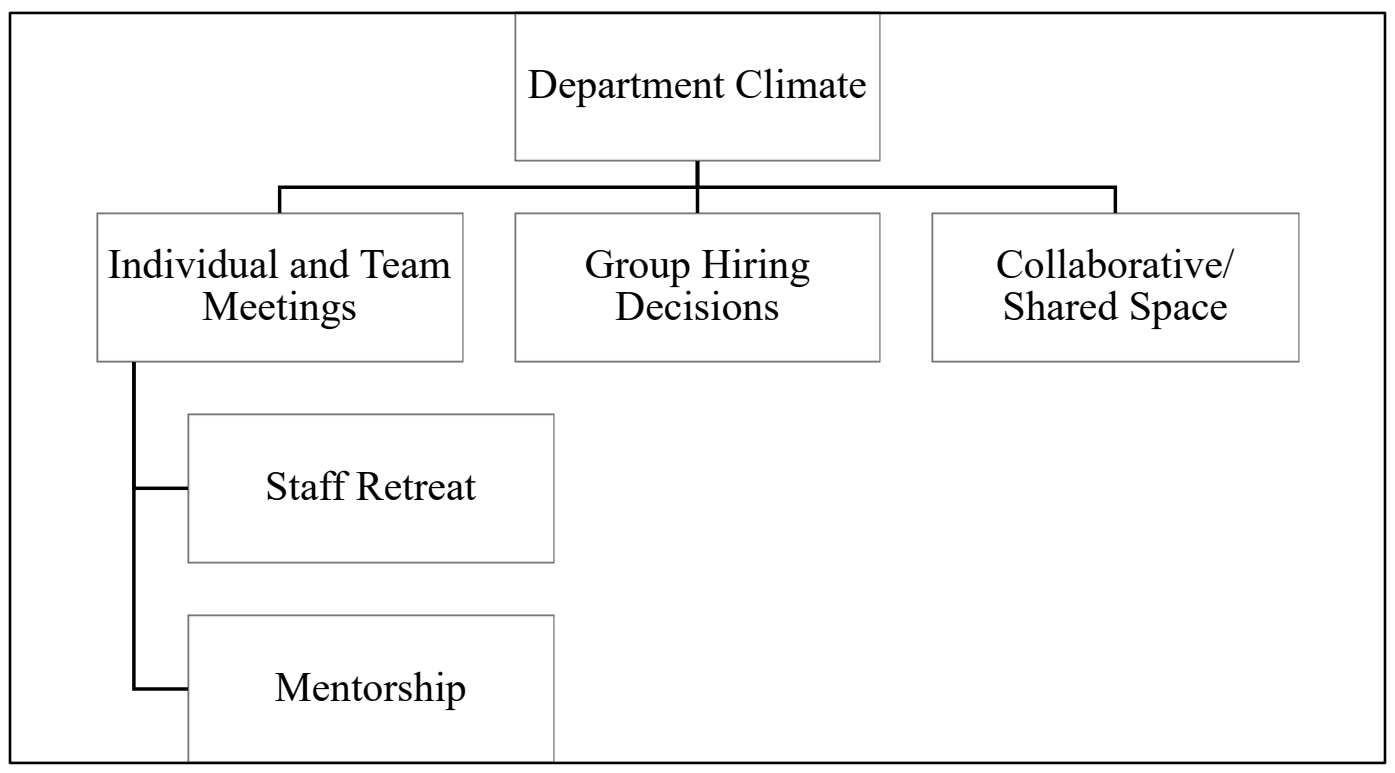

Based on the descriptions provided by the women interviewed, the factors listed above contributed to their department climate in a positive way. For the most part, the women perceived that they worked in a warm, open climate marked by positive interactions with their colleagues. Several of the women made reference to frequent meetings, both with their coworkers and one-on-one with their boss. For some, these meetings were a chance to receive mentoring from their leader or just to catch up (on topics that were both work-related and personal matters). For Gia in particular, the staff retreat that ultimately brought the entire department closer was extremely valuable as it changed the climate completely. Being taken into account when adding other members into the team was also highly appreciated as it demonstrates that everyone has an input. According to Jacqueline, a shared working space for advisors who wish to spend time together allows for productivity and camaraderie. 
Using Ostroff's (1993) framework, I created a diagram of the women's descriptions of their department environment in reference to the three categories of climate (affective, cognitive, and instrumental) (see Figure 2). This theory was tested in the context a single, public university, but specifically to frame the stories coming from seven departments made up of primarily female academic advisors. Ostroff (1993) referred to the affective component of climate as the interpersonal interactions in an office, including positive and helpful working relationships between coworkers and leaders. The cognitive component includes an individual's professional growth, such as improving skills and an emphasis on creativity. Finally, the instrumental component deals with the organizational procedures and organizational hierarchy, such as knowing who to turn to in order to maintain an orderly environment.

Figure 2

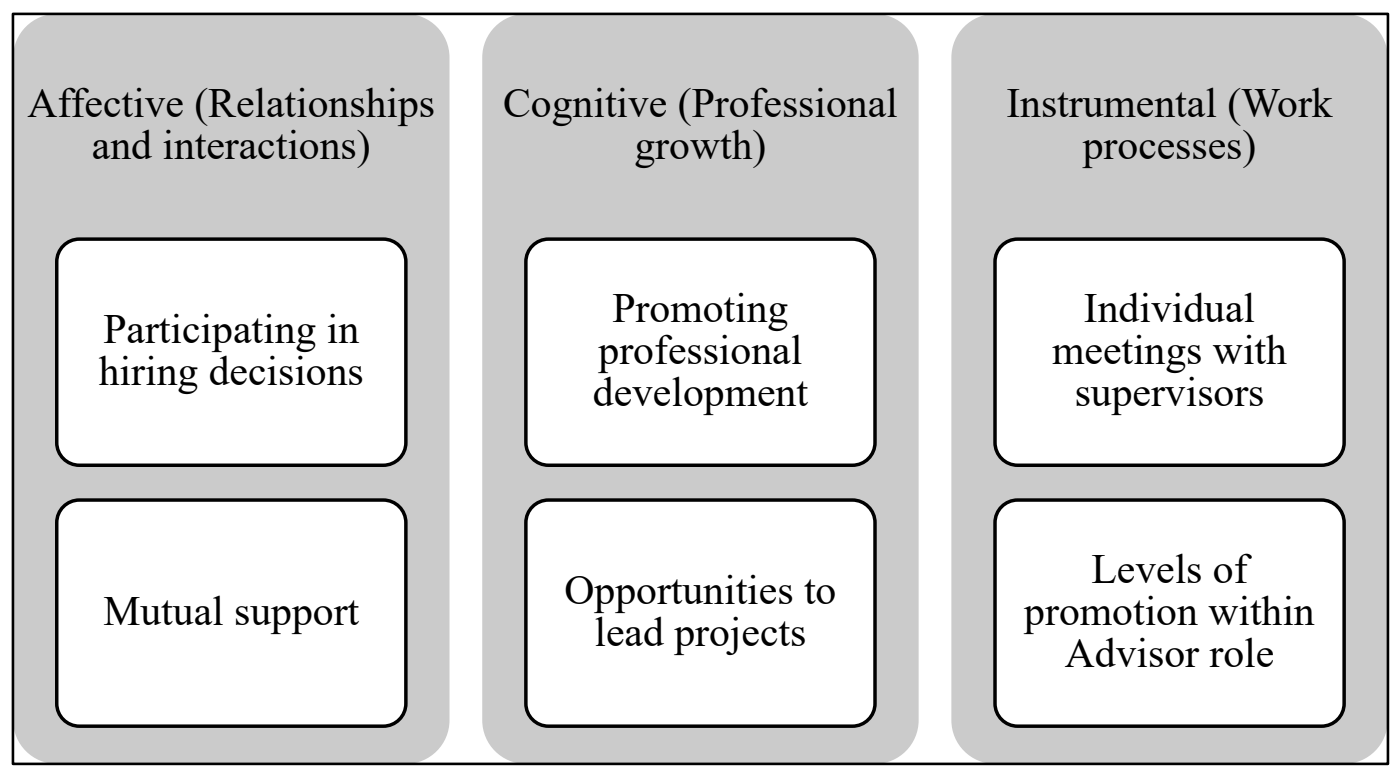

This theory was tested in a single university with a few departments representing the institution. Summarizing the results, some of the advisors expressed the value of 
building bonds in the office (the affective component of climate), which appeared to develop through their face-to-face interactions with each other. Although many of the women expressed satisfaction in this area through descriptions of their positive work relationships, Chloe yearns for more connections in this office. Many of the women stated that they will likely pursue a leadership role within higher education, making it clear that professional growth (cognitive component) is important to them. The university not only offers professional development opportunities (which supervisors sometimes encourage staff to complete), but it also offers the incentive to complete another degree with tuition benefits. A few of the advisors in this study are making use of this perk. Finally, it appears that several of the advisors would benefit from learning more about certain work processes, specifically in learning what it takes to grow within the advisor role. The instrumental facet seems to be where most of the advisors are the least satisfied. Leaders can address this concern and improve the working conditions (specifically in this area) by providing clear explanations regarding promotions (within the advisor pathway or the pathway leading to administration).

The results of this study contributed to the existing literature on climate by offering an in-depth look at select departments in a single institution. Specifically, the study used direct quotations from female academic advisors working in departments where women represent the majority group. Their descriptions of the interpersonal relationships that take place in the office (with their supervisors and their colleagues) reflect their perception of their work environment. This includes their propensity to get to know each other better and support one another personally and professionally. The advisors' interpretations of climate are also defined by the levels of communication that 
occur (either face-to-face or off-campus through various social media platforms) between coworkers.

\section{Conflict}

The interviews with the eight academic advisors did not reveal many incidents of conflict, tension, or bullying in their departments. The advisors were asked questions regarding how the department receives new hires, what happens when the women express a different opinion to the group, if they had ever applied for the same position as a coworker, and were specifically asked if they had ever been excluded, sabotaged, or the subject of office rumors.

Chloe mentioned that she has witnessed tension between coworkers in a previous role, which as a result has made her avoid situations at work that may lead to conflict. Ginger spoke briefly about existing cliques in the office that negatively affected a coworker (the coworker eventually quit), but not Ginger directly.

As far as evidence of conflict in their respective offices, some themes that emerged included: Ambiguous pathway for professional growth, Lack of leadership opportunities, and Salary transparency (see Figure 3). 
Figure 3

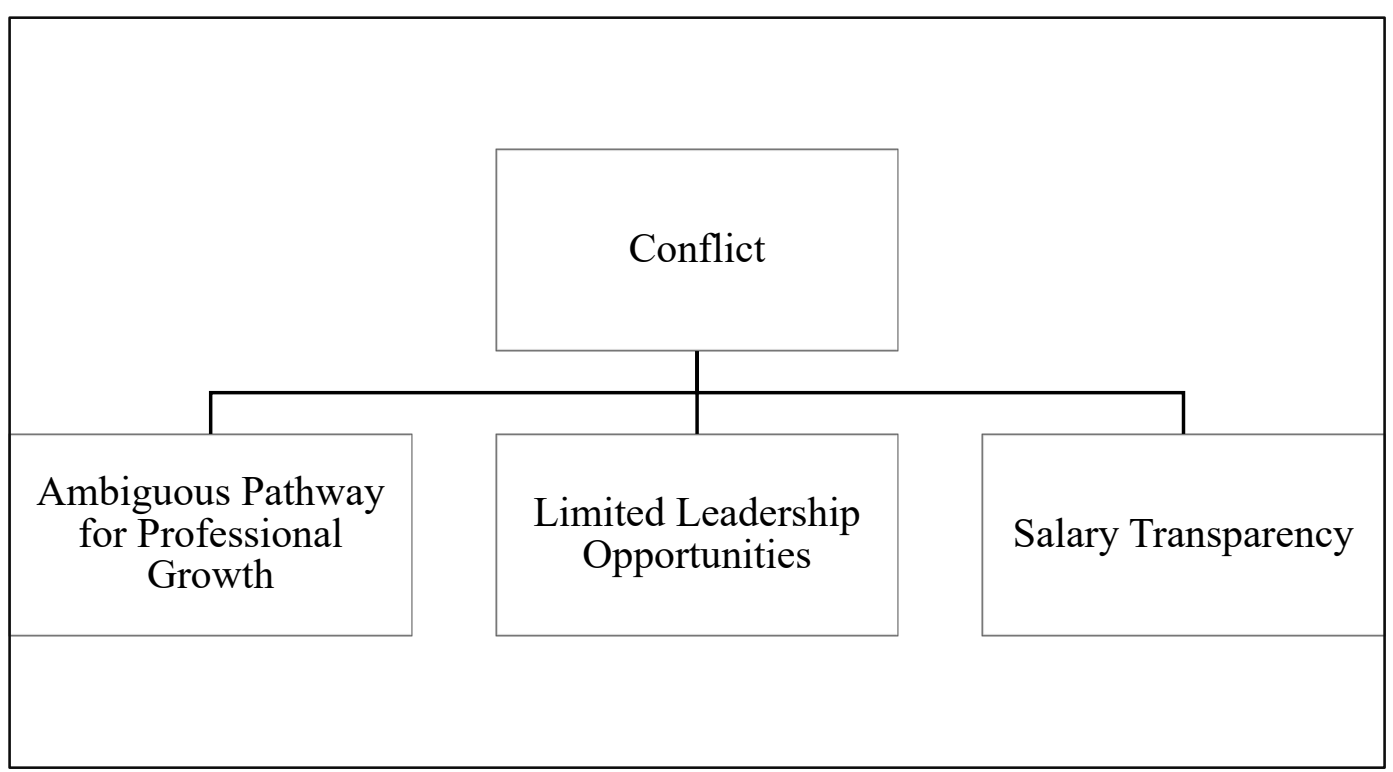

Although tension between coworkers in an office setting may be difficult to eradicate, there are certain factors that can be addressed. For some of the women in this study, they expressed disappointment and frustration when describing what it would take for them to grow from a level one advisor to a level two advisor. They may experience negative feelings when they watch colleagues progress along the advisor pathway, when they feel that they have already been doing the duties of a level two advisor already. This frustration can be remedied if leaders are vocal and transparent regarding the pathway to promotion. It may be more effective if this topic is covered in a group setting, where all advisors are able to ask follow-up questions and get a sense that everyone is on an equal playing field. Managers should focus on providing clarity regarding promotions, as well as acknowledge the advisors who are already demonstrating capabilities that may lead them to be promoted in the future.

In addition to group gatherings, one-on-one meetings between advisor and supervisor may also serve a purpose. Viviana mentioned that advisors who wish to grow 
can talk about their successes during their individual performance evaluations with their immediate supervisor. This is also their opportunity to discuss important topics such as career aspirations in a private setting. However, this requires a certain level of trust (and transparency), as not all employees will feel comfortable talking about their plans to move upward. Viviana happens to work for a department where the supervisor openly acknowledges that she wants her employees to grow. For those advisors who wish to stay in the field, they can use these individual meetings to communicate their interests, strengths, as well as their challenges; this will also reinforce the idea of being treated as a "human" (as Viviana expressed).

Some of the women mentioned that conflict can erupt when coworkers begin to compare salaries - which they are able to do by clicking through a website. Ginger expressed some dissatisfaction with advisor salaries, especially in comparison to what the leaders are making. This is in line with the literature regarding advisor pay, as advisors typically make less than faculty [and administrators] (Murray, 1987, p. 51). The website cannot be eliminated by supervisors, but it provides more incentive for leaders to be clear when informing advisors about how they can earn promotions within the advisor role. Supervisors may also use this opportunity to remind the advisors that there are other benefits that can be used, such as tuition reimbursement to complete another degree at the institution.

Academic advisors who want the chance to show their leadership skills may have to be vocal themselves, specifically talking to their supervisors about this request. If the opportunities to lead projects are few and far apart for advisors, then they may need to be more proactive either by asking to lead or creating their own initiatives and projects. 
Supervisors should be careful when making the decisions regarding who leads and attempt to spread the responsibilities in order to avoid claims of favoritism between supervisor and advisor. Managers should also be cognizant of cliques that exist and be sure that they do not give off the impression that they belong to any group (such as the instance described by Jacqueline in her department), as favoritism can lead to resentment and a toxic environment for the team.

\section{Support}

In addition to exploring tension or conflict in the office, the women were also asked to describe the relationships they had with other female advisors in their department in order to determine if they felt support from one another. Other questions probed about the advisor role (is it more independent or collaborative, for example), how they envisioned their ideal work environment/team, their daily interactions with coworkers, and whether or not they turn to their female coworkers for personal or professional support.

Through these questions, the themes aligned with support include: Proximity, Small teams, and Nurturing relationships (see Figure 4). 
Figure 4

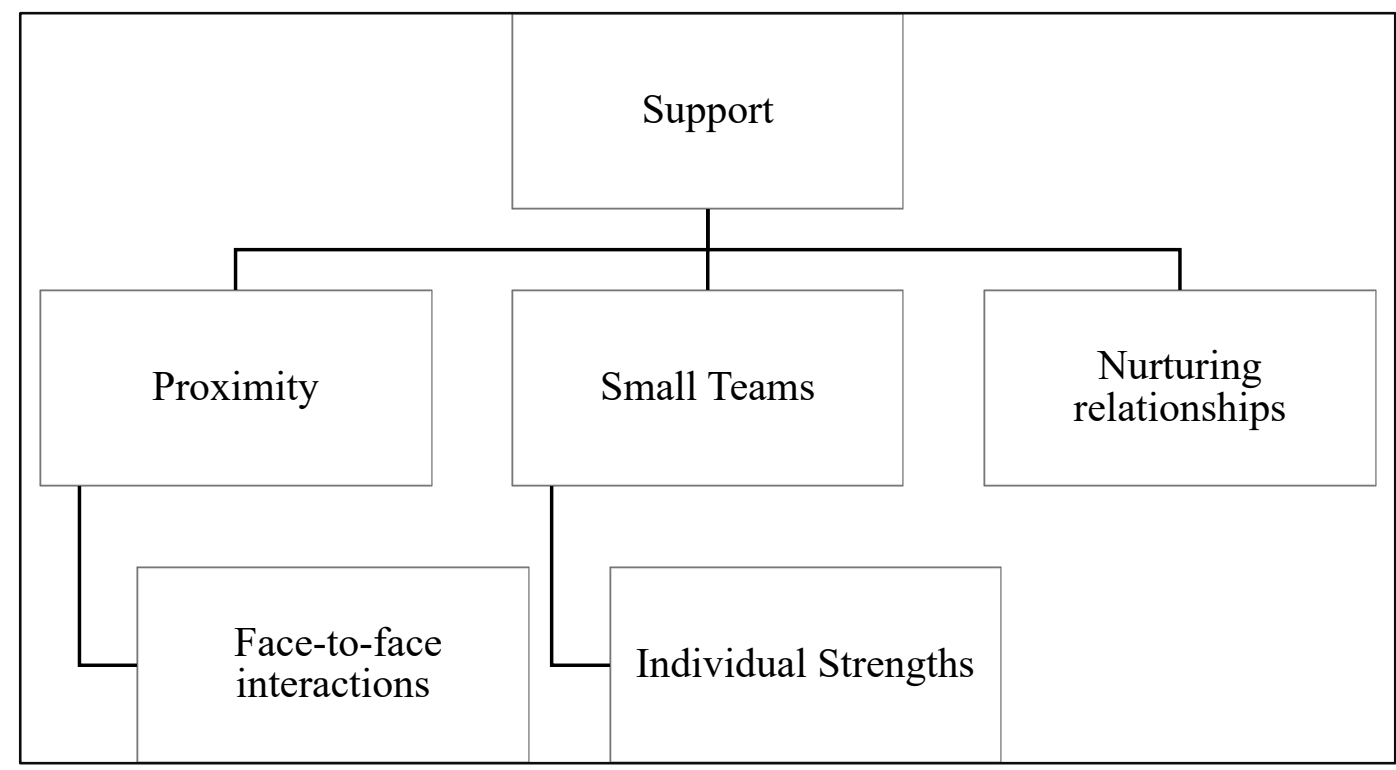

As previously mentioned, the results of this study can contribute to literature on higher education. Although this study focused on female experiences, the conclusions drawn may apply to departments with a different demographic. Supervisors especially may see the benefits of increasing face-to-face interactions (both between supervisor and employee and between coworkers), allowing members of the department to have a say in hiring decisions, and designating a shared space in the office that will welcome coworkers to collaborate (or work on independent tasks, together). Additionally, when there are instances of conflict or tension in an office, having the opportunity for more face-to-face interactions with supervisors may help advisors seek assistance on dealing with issues that are leading to said conflict. Managers may be a valuable resource when employees need help with conflict-resolution. 


\section{Conclusions}

\section{Support or Competition}

Allen and Flood (2018) explain that women may view each other as competition, especially when it comes to achieving positions of leadership in higher education.

Additionally, Kanter describes that "great opportunity — the promise of ever-increasing status and power-can breed competitiveness" (2008, p. 163). However, the women in this study did not express feelings of competition amongst their own coworkers. The institution itself may be acting as a factor in the lack of reports of competition. These women work for a large university which may offer several opportunities for career growth and promotions. The advisors may not necessarily be competing for the same jobs because they may be thinking about growing in other departments, other schools (within the university), or even in other campuses (as this institution has several campuses). It may be that I perceived more incidents of competition in my experiences as an academic advisor because the opportunities to grow in my institution appeared to be few and far apart. Additionally, my colleagues and I were very similar in terms of professional experience and educational backgrounds. When the occasional promotional opportunity became available, several of us met the qualifications.

Part of the objective of this study was to explore instances of relational aggression that occur within the office. Although the women were not given information on relational aggression (the term was not even mentioned in the interviews), they were all asked to recall events in which they may have experienced professional sabotage, social exclusion, or whether or not they had been the subject of rumors at work. These questions were intentionally asked because each of these examples represent relational aggression 
in action, (Crothers et al., 2009). The women did not report instances of these situations in their current role. Instead, the terms they used in their interviews were "hostility," "clashes," "friction," "tension," "conflict," and "cattiness." It may be the case that perhaps the women truly did not perceive relational aggression in their workplaces, or it could be that they did not feel comfortable sharing this information with the researcher.

The women who wish to stay in the field of advising know they have the chance to advance along the advisor pathway and make professional and financial gains as a result. This may decrease feelings of stagnation (and conversely, increase job satisfaction) that may arise when employees find themselves in the same position for years. Furthermore, beyond level one, level two, or level three advisor, employees in this university may venture into positions holding the titles of program coordinator, or program manager, for example. If the women wish to shift over to hold administrative roles, they can climb up the ladder by first becoming assistant directors before they are promoted as directors. These positions will bring new responsibilities, more exposure, and potentially an increase in salary as well. For some of the advisors, these positions may be steppingstones needed in order to acquire the director positions several of these women aspire to have in the future.

Should these women continue growing into administrative positions, they will not be placed on an annual contract. Although I have heard my own colleagues express fear over job stability due to contracts, this is not the case for the women I spoke to. Perhaps because they have several avenues through which they can grow professionally, coupled with a sense of job security, there are few reports of competition (at least from the eight women I surveyed). 
The $360^{\circ}$ Assessment implemented at Kent State University (KSU), which created two separate tracks for advisors (one that is more student-oriented, and one that is more administrative), shares some similarities with the organizational structure at the institution in which the research was conducted. Advisors in both universities can expect to grow within the role, gaining both new responsibilities and a new salary. The $360^{\circ}$ Assessment required a revision of job descriptions to clearly indicate role expectations. Additionally, with these two tracks, advisors can have open conversations about where they want to take their career. If this institution would adopt the model used at KSU, advisors would be able to candidly discuss their career aspirations with their supervisor, including the topic of whether their interests lean toward administration or primarily student affairs.

\section{The Role of the Supervisor}

All eight of the academic advisors in this study have a female supervisor. Jacqueline goes as far as describing her supervisor as a personal mentor. Jacqueline had both the privilege of proximity with her supervisor, and a positive relationship with her supervisor. Being within close quarters to her boss, Jacqueline had more opportunities for face-to-face interactions with her. Because they had a good working relationship to begin with, these interactions remained positive. Proximity may not be beneficial in relationships that are already toxic or weak.

Several of the women gave evidence that their supervisors demonstrate support to the advisors. Leaders show support by providing opportunities for individual check ins which allow advisors to talk about personal things in their lives that can affect their work (such as medical or family-related concerns), or to discuss future professional plans (such 
as moving up within the organization). This may also be a time to address other concerns, such as job burnout, which eventually may lead some employees to resign from their roles. Some of these topics may be uncomfortable to bring up, but supervisors can improve the situation by creating a safe space for employees.

In some cases, academic advisors are physically separated from their supervisors. There are instances where immediate supervisors are working on a different floor or in a completely separate building than their employees. Furthermore, this university has satellite campuses where advisors may be working in a different location than their direct boss. Advisors who are physically distant from their supervisors may have less opportunities to lead projects, less likely to be picked for a promotion, or feel invisible in the system.

Costello (2012) discusses that the organizational hierarchy of higher education may foster issues of invisibility for some positions. In this case, it is not simply a case of job position but rather issues of job location. Advisors are at a disadvantage when their boss works in a different office. Advisors may be overlooked and inadvertently excluded when opportunities to lead projects arise in one location and not the other. This can affect their job growth opportunities in the future. If they are rarely given the chance to demonstrate their skills, they may be passed over for promotions. In addition, any issues that affect the office climate negatively may go unresolved for long periods of time because they have limited access to their manager. For these reasons (and more), it is imperative that advisors get sufficient face-to-face time with their immediate supervisors.

While on the topic of leadership, Kanter (1979) states that powerful managers are those who successfully delegate work to their employees, provide opportunities to reward 
staff, and help them grow. Many of the women in the study described instances of receiving personal recognition (in the form of an annual advising award, for example), having personal strengths highlighted, and being given opportunities to lead the team on projects. These examples may lead to positive outcomes within the workplace, as Kanter states that organizational power grows when it is shared $(1979$, p. 83).

\section{Becoming Visible}

Chloe, one of the few who describes her job as more independent than collaborative, refers to issues of invisibility in the advisement role (Lee \& Metcalfe, 2017, p. 945). She explains how other advisors feel that their work is "undervalued" because it is not always seen or recognized by others. With the Graduate Success Initiative, it is evident that advisors play a major role in helping students meet the necessary requirements to graduation. However, Chloe claims that advisors still feel underappreciated. Advisors can fight issues of invisibility by finding alternative ways to become more involved within their institution. Stuart Hunter and White (2004) indicate that advisors should be encouraged to conduct their own research or write grants; the benefits are two-fold as it may help the advisor build their resume and set them apart from other advisors as well as bring attention and funding to the institution. There is potential to transform the role of the advisor so that it is not seen in the traditional way: simply prescribing classes and making sure students graduate on time.

Stuart Hunter and White also explain how the presence of a campus-wide advising council can assist in creating an inclusive environment for academic advisors. According to the researchers, they believe the council can "serve as a venue for recommendations for change in policies and procedures" that pertain to these staff 
members (2004, p. 24). This could empower the women of my study who feel that they have little say in university-wide initiatives that impact them directly.

Kimberly explained that she attends workshops and professional development opportunities on campus that are intended to promote advisor skills, such as communication and customer service. It is reasonable to assume that this institution wants to help employees develop their interpersonal skills in part because of an emphasis on service climate. This refers to the student's level of satisfaction with the service they are receiving from the school and its constituents. As advisors, some of the duties include delivering messages (both positive and negative in nature) to a caseload of students (often reaching in the hundreds), motivating them to connect to the campus and its resources, and most importantly, encouraging them to continuously enroll until graduation. This is all necessary to help the institution meet the metrics to receive adequate funding and resources.

However, institutions can invest in their employees and offer workshops or programs that would benefit advisors who are considering other administrative opportunities. There may be academic advisors who aspire to grow into leadership but are uncertain about how to frame their transferable skills that are gained in their current role. The fact that their supervisors were all women who worked as advisors first is encouraging, but the women might need a little push to take their career to the next step. This may help increase employee loyalty, as they will seek advancement opportunities within the university, instead of venturing outside the organization. 


\section{The Supervisor - Employee Relationship}

Like Jacqueline, several of the women in this study also express a positive relationship with their directors. The female supervisors may serve as role models, especially for those advisors who aspire to grow into leadership positions in the future. Several of the women believe their immediate supervisor has a hand in setting a positive climate at work. Although it was never overtly stated, I believe the healthy relationships between the advisors and their respective directors assist in the retention of academic advisors, despite issues that arose in the interviews (such as perceived invisibility, low pay, and feeling undervalued).

Some of the directors had previous advising experience before they became managers; this may encourage the academic advisors that they have the potential to follow a similar trajectory. A few of the women stated that they are considering growing into management positions for various reasons including wanting to help students in a different capacity and being more involved with the institution. It appears as if some of the women, such as Kimberly, are yearning for the chance to wield "power" (as Kanter defines it). Although many of the advisors expressed that they are, for the most part, content in their role, some can already see themselves changing roles in the near future.

Supervisors may want to consider delegating some of the managerial duties in the office by having academic advisors be responsible for some staff. For starters, having student assistants or student interns directly report to certain employees may allow advisors to dip their toe in the leadership waters. Chloe has prior experience as an assistant director, leading about 12 students, and she ideally would like to have a role of this nature again in the future. 
The interviews garnered some information on the women's supervisors. Some of the directors mentioned appear to be practicing Kanter's idea of sharing the power within the workplace. The advisors who sit in on hiring committees, who attend meetings with upper management, and those who act as first responders to other advisors whenever they have questions are already demonstrating a form of power that may actually benefit the entire department in terms of effectiveness.

Evidently, the supervisor is largely responsible for setting the tone of the office environment. Managers would benefit from ongoing trainings that focus on best practices that foster an inclusive climate for individuals from diverse backgrounds. Based on the women's responses, leadership support is another key factor in establishing a positive work environment. Policies and procedures are expected to change in education, for reasons that are social, political, or economic in nature. These changes may impact advisors, as they may be expected to increase their workload (whether it is by attending more orientations, adding more students to their caseload, or maximizing outreach efforts by engaging in "call campaigns") in addition to their existing duties. In these moments especially, leaders should send a clear message that the workers are fully supported and valued.

\section{Evidence of a Gender Inclusive Environment}

Castleman and Allen (1995) explore issues of gender for staff members working in higher education institutions. They discuss issues of bias in promotions, as well as a lack of growth opportunities for women. Melanie mentions how some people in the office perceive that a male coworker was given the promotion of a level three advisor (the highest level one can achieve within the advisor role in this institution). Although the 
reasons for his promotion cannot be determined, rumors exist that he does not do his fair share of the work in comparison to his peers. Endeley and Ngaling's (2007) research provides recommendations to create a more gender inclusive higher education environment which may help reduce or eliminate perceptions of a gender bias.

Some of the departments show evidence of empowerment taking place, especially in the departments where supervisors make advisors active participants of the hiring process. Senior advisors who provide mentorship can influence change within a department, as they can pass down their best practices and ideas to new advisors.

Empowerment involves a sense of control and autonomy, and advisors who are appointed to lead a project are able to practice these skills with the full support of their supervisor.

\section{Faculty and Advisor Collaboration}

There was a discussion about the advisor role versus the faculty role, and how each position involves student interaction. Viviana claims that faculty are considered the experts in their field, so faculty members believe they should be handling some of the advising affairs or that they may have some knowledge that advisors lack. However, the professional advisor model makes academic advisors the primary point of contact for students.

Institutions can initiate a collaborative effort between faculty members and advisors, where specific advising responsibilities can be delegated to each group. For example, academic advisors can be in charge of orientation, outreach, and registration duties, and faculty members can serve as mentors that step in once students are nearing the end of their educational career. Once students have completed pre-requisites and are 
taking courses in their major, they may start to contemplate their next move: starting their career or starting graduate school.

According to Viviana, academic advisors are currently responsible for providing course recommendations, career exploration advisement, and assistance with graduate school admissions questions. On top of it all, the expectations are that these topics must be accomplished within a 30-minute advising session. While advisors strive to provide quality service, it is difficult to deliver adequate information in all of these areas in such a short amount of time. Faculty members can use their expertise in the field by providing guidance in the form of pointing students in the direction of internships and jobs. They can also shed light on graduate school, their first-hand experiences, as well as the requirements needed for admission.

The students will benefit from having an additional resource, aside from their assigned advisor, and there will be less of a divide between faculty and academic advisors working in the same institution. A sense of shared responsibility can impact institutional climate by connecting various members of the organization. This may even lead to potential collaboration between faculty and academic advisors in the form of research publications.

\section{Mentoring}

Vaccaro's (2011) research supports the benefits of women forming mentoring groups (both formal and informal) within the university community. Some of the women in this study seemed to create their own informal mentoring groups in their departments, perhaps not even realizing that they were doing it. Examples of this include the women turning to each other when dealing with a difficult student, presenting together at 
workshops, helping others practice and improve their skills, training new hires, and even seeking emotional support from peers when going through challenging situations outside of work.

Some groups are more formal in nature and intentional because as Viviana explained, the institution designates seasoned advisors to serve as mentors for new advisors. Viviana can be a valuable source of information for these individuals, not just because of her knowledge of advisement processes or overall university policies, but to demystify the promotion process. Experienced advisors who have climbed the ladder can help the new advisors practice their strengths, and also highlight the qualities that will later make them more likely to be promoted. Mentorship at this institution is a worthwhile practice that is sustainable, beneficial, and should continue. An institution that largely promotes from within may make these advisors more likely to stay.

\section{Ensuring Diversity}

Because I used the snowball sampling technique to gather participants, I was able to learn about the existing friendships between some of the women. Two women knew each other as colleagues working in the same department. Several of the other women were referred because they were friends from graduate school, some even from the same program.

Although I omitted certain demographic information from the final write-up for privacy reasons, seven of the eight women I spoke to identify as Hispanic. Four of the participants were women in their 20s. Five of the women hold a Master's degree in the same field (Higher Education Administration). Based on the principles of homophily, it is 
possible that their friendships with similar women (in ethnicity, age, and educational background) exist in part because people from similar groups tend to bond together.

Although homophily may be beneficial in cultivating and maintaining friendships, this may not be as beneficial for the workplace. Diversity of employees may benefit the office for several reasons. For starters, hiring individuals from different racial and ethnic backgrounds, and ages may eliminate the presence of harmful, exclusionary cliques that may form from similar people. Second, employing people with different degrees can make an office more well-rounded and address more student needs. Advisors with different educational backgrounds can bring a different perspective, which may help a student who is torn between different majors (as an example). Third, hiring people with different degrees might reduce feelings of competition between coworkers, especially when there are limited positions to begin with. Employees with similar degrees and similar work experience may be vying for the same positions and have similar aspirations for their professional pathway.

Managers may even consider hiring academic advisors who hold professional experience outside of higher education. An individual with experience from a different field may bring new ideas, practices, and contacts (local or otherwise) that can benefit the institution. This may build new connections between the school and the surrounding community.

Hiring a diverse team will help managers identify and continue nurturing employees' individual talents that make employees feel valued and appreciated. This also fosters a culture where colleagues work collaboratively, and maybe even benefit by learning from each other's strengths. Pairing two employees together, where one can train 
the other to develop a particular skill, can ultimately benefit the department overall by increasing efficiency and productivity.

\section{Ethic of Care}

According to Carol Gilligan, an ethic of care prioritizes connection between individuals; connection is "primary and seen as fundamental in human life (1995, p. 122). The theory of ethic of care was used as a theoretical framework for the study, specifically to look at relationships between the women (as they were described in their own words). Gilligan's research on ethic of care can be summarized as an emphasis on relationships, the use of communication to resolve conflict, a responsibility for others (Gilligan, 1993, p. 30). As a result, women may use these qualities in "group problem solving, consensus building, and democratic ways of managing operations" (Ballenger, 2010, p. 5). In this study, an ethic of care may appear as empathy, cooperation, open communication, appreciation, and mutual respect between people. These eight women provided glimpses of their work lives that (I believe) gave evidence of an ethic of care in their office environment.

Several of the women believe their supervisor has the power to set the tone for a positive work climate. This can be accomplished in different ways. Gia is grateful to be involved in hiring decisions, often being asked to sit in during interviews to meet the potential candidates. Her coworkers are also invited to give input, giving other members of the office an opportunity to express opinions and treat the hiring process as a group decision. This is a form of mutual respect, demonstrated by the director, as she wants her employees to have a voice in something that will undoubtedly impact everyone. 
Six of the eight advisors chose to conduct the interviews in their own office. I expressed a willingness to meet them wherever they felt comfortable and I initially assumed that several of the women would choose a different location (possibly offcampus) for privacy reasons. However, their choice to discuss potentially sensitive information in their office may demonstrate that they work in an environment where they feel secure in voicing their thoughts and opinions. They did not show a concern for others overhearing their responses through the office walls.

Empathy, another important quality of strong relationships, is not only fostered between coworkers, but also between supervisor and employee. In Kimberly's case, her supervisor makes a point to follow up with Kimberly after her doctor appointments. Their individual check-ins allow them to discuss private matters that are unrelated to work but may impact the well-being and performance of the employee. As a result of her supervisor's empathic understanding, Kimberly feels valued both as an employee and also as a person overall (being treated as a "human"). Kimberly also likely experienced empathy, this time from her peers, when her coworkers served as an audience for her to deliver "practice" presentations.

Jacqueline also brings up individual meetings between managers and their advisors. For Jacqueline, these meetings are learning opportunities that help her become a more effective employee. She specifically refers to benefitting from these meetings in the form of mentorship. She can address problems she is having at work, such as conflicts with coworkers, in a safe and private space. Supervisors (in this study, all-female supervisors) who take the time to provide this kind of care and mentorship are 
demonstrating a form of sisterhood, by helping other women overcome challenges and become better versions of their work selves.

In regard to her relationship with her peers, Jacqueline insists on the importance of a shared working space to generate a sense of community and cooperation. Although the women expressed different opinions on whether the advisor role is more independent or collaborative, Jacqueline thinks it is valuable to have a designated area for advisors to get together. Even if the work is independent in nature (answering student inquiries via email, for example), a shared space fosters an environment for advisors to seek each other's company and relate to one another. Performing a simple task such as answering emails together may reaffirm that they are indeed a team and working toward the same goal.

Sharing a common goal may help build bonds between advisors. However, it is necessary to acknowledge that all members are making valuable contributions. Both supervisors and coworkers alike are able to recognize the team members' individual strengths. In Gia's case, she believes all her coworkers bring value to the department because they all have degrees in different fields. This helps the department serve students who may be seeking information about various majors. Gia feels there is no competition between colleagues because they likely would not seek out the same jobs in the future. Managers can assist here by diversifying and seeking candidates with various educational backgrounds when hiring new employees.

Some of the women spoke about moments where advisors were recognized either for their talents or for going above and beyond with students. This was the case for Kimberly, who was nominated by her peers for an advisor award. Melanie expressed a 
similar sentiment, explaining how one's hobby (such as photography) may become a useful skill for a specific project or task. She believes that people are likely to work together when individual talents are acknowledged. For this to happen in work settings, coworkers must be willing to share this information (and be receptive to other people's strengths).

Open communication and interaction are inextricably tied to creating and maintaining strong relationships. Based on Chloe's interview responses, it appears she does not sense an ethic of care in her office. Out of the eight interviews, she is the only one who expressed a lack of connection to her colleagues. She clearly expresses her wish for more face-to-face opportunities with coworkers but admits that advisors are too busy seeing students; therefore, coworker interactions in her office are rare. The physical set up of her department also poses a problem, as the advisor offices are spread out, keeping coworkers far apart from each other in the building. For Chloe, having coworkers nearby is important. In a previous role, her supervisor was in close proximity and she felt this strengthened their relationship. Chloe is the only one of the eight advisors who described her role as independent (as opposed to collaborative) and isolated.

Giselle's office set up is a sharp contrast to Chloe's; Giselle feels there's almost too much closeness between advisors, as they sit in cubicles (referring to some of her coworkers as "cubicle neighbors") and all conversations are easily heard. However, because of the proximity, Giselle is able to engage with her coworkers frequently. Giselle talks about how important it is for her to share moments with her coworkers (moments that may involve tough situations such as disrespectful students), whether it is to vent, discuss weekend plans, or make small talk toward the end of the day. In addition, Giselle 
feels appreciated by her peers when her coworkers compliment her advising style. Since the cubicles are close together, advisors are able to hear each other. For Giselle, this small gesture is meaningful as she used this as an example to describe the friendships she has made with coworkers in her office.

If an ethic of care involves open communication between individuals, then Gia may agree that the intervention staff retreat helped to repair the "disconnect" that existed in her department. In Gia's words, the emotions and vulnerability expressed at the staff retreat led the team to come together and feel more like a "family." This could have a lasting impact on employee satisfaction and morale. Gia expressed that prior to this retreat, she was considering leaving her position. For Gia, the staff retreat was essential because all parties were able to talk about their frustrations and finally be honest with each other. Vaccaro (2011) firmly asserts that women in higher education can assemble together in an effort to overcome potential issues in academia (such as sexism). However, before they can fight these issues head on, existing tensions and conflicts between the women need to be eliminated or reduced. Vaccaro suggests an open discussion to air out problems. In Gia's case, the staff retreat (including both male and female employees, as well as administrators) served as an outlet for this to occur, and the result was a better working environment.

Ultimately, many of the advisors expressed an appreciation for the downtime that allowed them to vent or seek advice from one another, the opportunities for face-to-face meetings that gave them a chance to discuss work-related issues, and the text messages that allow them to take their connections outside of the office. Employees like Ginger, who work remotely, can still maintain a connection to their colleagues using various 
means such as video conferencing or other messaging platforms. The advisors have hundreds of students on their caseload, so they are constantly answering inquiries via email or addressing problems that arise in student appointments. Simply put, advising is largely service-oriented and individuals in helping professions may find the nature of the job can be taxing at times. In essence, many of the women communicated that sometimes they want to be heard, as well. Thus, there is an underlying need for connection between these individuals who primarily serve a large student population. With the instances detailed above, I believe the theory of an ethic of care (a strong yearning for connection despite the busy lives they lead) holds true for the eight female academic advisors working for the same institution in the present study.

\section{Limitations}

Prior to beginning the data collection process, it was known that snowball sampling would be used to recruit participants for the interviews. Initially, I wanted to interview women from 2 or 3 different departments within the university. By focusing on a few departments, I believed I would be able to get an in depth look at intra-office dynamics between the female academic advisors. However, because I relied on snowball sampling, I ended up speaking to eight women working in seven different departments (two of my participants worked in the same department). As a result, the women are providing their single perspective based on first-hand experiences, and their perspectives may not give us the full picture of their environment. I was unable to corroborate the experiences of multiple women working in the same department. However, speaking to women in seven different departments allowed me to explore the inner workings of more office climates than I originally expected to. Consequently, it is possible that I gleaned 
more information and themes that would not have emerged if I had contact with only a few departments.

Due to the snowball sampling technique, I did not have full control of selecting which departments I would be targeting. There were several factors I could not be accountable for; for example, I was unable to control the size of the department (the issue of small teams versus big teams and department climate came up in some of the interviews). Although I would have liked to compare and contrast specific departments, this was largely out of my control. Therefore, inferences regarding departmental differences (such as the climate in a STEM department versus the climate in a non-STEM department) cannot be generated by the results of this study. Furthermore, because I relied on referrals, it is possible that some of the women were previously informed about the nature of my interview questions from the advisor who referred them. This may have led to preconceived notions about the study prior to the actual face-to-face interview. Some of the women may have been able to prepare answers because they were already anticipating my questions.

Though I approached the study motivated and inspired by my own negative experiences, the advisors' responses leaned more toward descriptions of positive relationships marked by support and less on stories of conflict in the office. It is possible that these women chose to omit or downplay reports of tension or hostility in the office due to privacy reasons. Although they were all informed that interviews would be confidential and identifying information would not be released, it could be the case that they were hesitant to share certain experiences. For some of the women, the interview was the first time we were meeting face-to-face. It may be the case that it would take a 
few more encounters to build rapport and ensure more trust between us. A second interview with each of the advisors could have helped build the relationship and gleaned additional information.

The majority of the interviews took place in the summer semester when advisors were experiencing a busy period as they prepared for Fall orientations for the incoming freshmen students. As a result, some advisors were not able to commit to an interview that would take longer than an hour. In addition, some of the women had other duties outside of their advising role. Some of the women work as adjuncts for the institution, and some of them had children and other familial responsibilities that significantly limited their availability. Because of these challenges, I decided to eliminate a second interview, but I acknowledge that it could have been beneficial. A second interview could have built more trust and the advisors could have potentially shared more anecdotes, further highlighting their climate (whether it be that the climate is supportive, competitive, or anything and everything in between).

Additionally, six of the eight women were employed as Academic Advisors in a Level 1 position. This was largely due to the sampling method, as many referrals were made from one friend to another. Some advisors had existing relationships because they graduated from the same Master's program and began their advising career around the same time. The data may differ slightly if more Level 2 or Level 3 advisors were included in the research, as five of the eight women in this study had less than 2 years of advising experience. Those holding the title of Level 2 or Level 3 Academic Advisor presumably have more experience in this field. However, it may be the case that finding an Advisor Level 1 with several years of advising work experience would be challenging 
because it is possible that they have already advanced forward into administrative positions.

\section{Recommendations for Future Research}

Some of the advisors see themselves changing jobs in the future, and some are in the process of pursuing a terminal degree to help them grow toward supervisory roles. Future research can explore job satisfaction for women (and men) working as academic advisors, as job satisfaction is linked to "performance, productivity, absenteeism, and turnover" (Toker, 2011, p. 166).

Gia, an advisor who once described her department as "disconnected" and later referred to it as "family," described how a staff retreat event became a turning point in building a strong work team. Future research can explore the efficacy of a staff retreat used as an intervention in departments that may be showing signs of tension, conflict, or an overall negative work environment. Likewise, even departments with positive climates may benefit from periodic, team-building retreats that emphasize cohesiveness between staff members. A staff retreat may even be used as an opportunity to provide staff recognition in a public way.

It is possible that some of the women did not want to discuss instances that can be interpreted as conflict in their workplace due to the sensitive nature of the topic. Although I had existing connections with a few of the advisors, others were meeting me for the first time when we held our interview. It may be the case that some of them needed more time to share additional personal stories. To address potential confidentiality concerns, this study may be replicated by changing the research design and using a 
survey. This would add another layer of anonymity that could sway participants to disclose more information.

Inspired by the presence of lead advisors, specifically in Chloe's department, it may be worthwhile to look closely at the relationships between lead advisors and the team they oversee. Although the lead advisors are not supervisors on paper, they may be forging a pathway that can open doors to leadership positions. More institutions may want to adopt this model, which could create more incentive for people to remain in the advising field.

It may be relevant to focus on evidence of a sisterhood between female advisors in departments that are made up of mostly male advisors. Additionally, it may be worthwhile to explore the climates of departments that are led by a male supervisor. All eight of the advisors in this study indicated that their immediate supervisor was a woman. Some women may view their boss as a mentor figure in the workplace. Would women view and describe their male supervisor the same way? To reiterate, this study involved a small sample of people, and therefore, it is not representative of the larger population at this institution.

There may be several reasons explaining why the majority of these women share the same ethnic background and other commonalities. For one, I conducted my research in an institution where Hispanic students are the majority (HSI). It is possible that the university has a large Hispanic representation of employees, as well. This may be due to the geographical location of this institution. Second, because I used the snowball sampling method to gather my participants, access to a diverse population was limited. 
My initial interviewees referred me to other potential women who fit my criteria, and seven out of the eight women self-identified as Hispanic.

For future research on staff members in higher education (including academic advisors), their interactions with each other and their perceptions of their departmental climate, it may be beneficial to target institutions with more diverse racial/ethnic backgrounds. Women from other groups may face different challenges such as discrimination or microaggressions. Their descriptions of their department climate (or institutional climate) may vary from those women who are part of a group with a large representation on campus. They may have different relationships with their supervisors and their coworkers. This study can be replicated in other institutions such as those mentioned by Hurtado et al. (1998) (HBCUs, AICs, for example) and still meet the criteria that targets women working in departments with more female advisors than male advisors.

Finally, future research can look at institutions where all of the advisors are at the same hierarchy level, without the possibility of advancement within the advisor role (for example, institutions where there is only one level for academic advisors). This institution is unique in that individuals who genuinely enjoy working as advisors can build an entire career, growing from one level to the next and increasing their salary as they progress. Extra focus can be placed on colleges that are small, and consequently, have little room for promotions. Is there more competition when the availability of jobs is low, and the demand for promotions is high? 


\section{Final Thoughts}

This study contributes to the abundance of research on women in higher education and puts a focus on a group that appears to be hidden and misunderstood by others. Despite the existing research on gender equity in the higher education realm, there are still several challenges women face every day. Allan contends that this area of research is "relatively nascent and ripe for further exploration to help tease out, with more precision, the factors and complex dynamics that shape and enhance gender equity in the context of higher education" (2011, p. 11). Furthermore, Allan specifies that although much literature is devoted to climate studies, very little is dedicated specifically to professional, nonadministrative staff (2011, p. 76). My research attempted to carve out a space exclusively for female academic advisors. Exploring the inner workings of departments comprised of mostly women revealed insight into their perceptions of climate and the relationships they build with each other.

Sometimes the smallest gestures make the biggest impact. There is evidence of work engagement (a connection to the organization) and job embeddedness (for example, the strong connections that are built between colleagues) in the women's anecdotes. Gia appreciates that her office celebrates all birthdays, which reaffirms that the staff is seen and treated as humans, not just workers. Jacqueline likes to sit with her coworkers in a common area as she responds to her student emails, as she enjoys the company of her team. Giselle looks forward to the end of the day when she has finished seeing all of her student appointments and she can sit down with her colleagues to catch up. In these moments, relationships grow and boost employee morale, which can make a difference in the retention of these talented women. 
For some of the women I spoke to, this is an entry-level position as a few of them would like to step into a leadership role eventually. Although they may consider this job as a way to begin their career in higher education, their role requires a Master's degree to even be considered. This implies a certain level of expertise is necessary to carry out the duties of the role. Many of them are actively pursuing a doctoral degree which will make them more marketable in the future. None of the women appear to report the existence of a "sticky floor" preventing them from upward mobility. It is reasonable to assume that many will attempt to find a job that requires the doctorate degree.

A few advisors admitted that they do not see themselves staying in this role longterm, citing reasons such as the workload, low pay, and limited opportunities for advancement. This position is intentionally designed to help build strong connections between academic advisors and students, as they guide and answer any questions they may have. Is the role effective if the advisors are constantly leaving and being replaced with new employees?

It would benefit institutions to consider advisors when making decisions that will affect their work, which consequently affects the student experience. In addition to helping meet student needs and inquiries, advisors are crucial in assisting the institution meet metrics through enrollment and graduation rates. The advisor is largely hidden from view and receives little recognition when compared to faculty and supervisors who may be compensated for their work through promotions, tenure, recognition for research, flexible work hours, and more. The institution, as a whole, is rewarded for each graduating student through performance-based funding, but the advisor who helped the student get there is rarely acknowledged. 
Although not always fully apparent, academic advisors wear many hats; they are messengers, cheerleaders, problem-solvers, and listeners. They have the unique role of being present on the student's first day at orientation, and at the very end as they approve the student's graduation requirements. Although they are not faculty members, they are educators who are connecting with students on a constant basis, continuing the relationship long after each semester ends. Even if their work is considered invisible by some, advisors deserve to be seen and acknowledged as an important piece in the academic world. Just as we focus our efforts on the retention of students, perhaps we can also invest in the retention of our hard-working staff. 


\section{REFERENCES}

Adekola, B. (2010). Gender differences in the experience of work burnout among university staff. African Journal of business management, 4(6), 886-889.

Allan, E. J. (2011). Women's status in higher education: Equity matters: AEHE, Volume 37, Number 1. John Wiley \& Sons.

Allen, T. G., \& Flood, C. T. (2018). The experiences of women in higher education: Who knew there wasn't a sisterhood?. Leadership and Research in Education, 4, 10-27.

Archer, J., \& Coyne, S. M. (2005). An integrated review of indirect, relational, and social aggression. Personality and Social Psychology Review, 9(3), 212-230.

Aultman, B. (2014). Cisgender. TSQ: Transgender Studies Quarterly, 1(1-2), 61-62.

Ballenger, J. (2010). Women's access to higher education leadership: Cultural and structural barriers. In Forum on Public Policy Online (Vol. 2010, No. 5). Oxford Round Table. 406 West Florida Avenue, Urbana, IL 61801.

Carr, J. Z., Schmidt, A. M., Ford, J. K., \& DeShon, R. P. (2003). Climate perceptions matter: A meta-analytic path analysis relating molar climate, cognitive and affective states, and individual level work outcomes. Journal of Applied Psychology, 88(4), 605.

Castleman, T., \& Allen, M. (1995). The forgotten workforce: Female general staff in higher education. Australian Universities' Review, 38(2), 65-69.

Cava, P. (2016). Cisgender and cissexual. The Wiley Blackwell encyclopedia of gender and sexuality studies, 1-4.

Cohen, J., McCabe, L., Michelli, N. M., \& Pickeral, T. (2009). School climate: Research, policy, practice, and teacher education. Teachers college record, 111(1), 180-213.

Costello, C. (2012). Women in the academy: The impact of culture, climate and policies on female classified staff. NASPA Journal about Women in Higher Education, 5(2), 99-114.

Creswell, J. W. (2013). Qualitative inquiry and research design: Choosing among five approaches (3rd ed.). Thousand Oaks, CA: SAGE.

Crick, N. R., \& Grotpeter, J. K. (1995). Relational aggression, gender, and socialpsychological adjustment. Child development, 66(3), 710-722. 
Crothers, L. M., Lipinski, J., \& Minutolo, M. C. (2009). Cliques, rumors, and gossip by the water cooler: Female bullying in the workplace. The Psychologist-Manager Journal, 12(2), 97.

Cullivan, K. (1990). Women in higher education administration: Part of the power or part of a problem?. CUPA Journal, 41(4), 9-15.

Currarini, S., Jackson, M. O., \& Pin, P. (2009). An economic model of friendship: Homophily, minorities, and segregation. Econometrica, 77(4), 1003-1045.

Davis, K. A. (1995). Qualitative theory and methods in applied linguistics research. Tesol Quarterly, 29(3), 427-453.

Deaux, K. (1985). Sex and gender. Annual review of psychology, 36(1), 49-81.

Donnelly, N. (2004). The effect of standards use on academic advisor job satisfaction. NACADA Journal, 24(1-2), 34-47.

Elliott, R., Fischer, C. T., \& Rennie, D. L. (1999). Evolving guidelines for publication of qualitative research studies in psychology and related fields. British journal of clinical psychology, 38(3), 215-229.

Elliott, R., \& Timulak, L. (2005). Descriptive and interpretive approaches to qualitative research. A handbook of research methods for clinical and health psychology, 1(7), 147-159.

Endeley, J. B. M., \& Ngaling, M. N. (2007). Challenging gender inequality in higher education: Attitudes and perceptions of teaching staff and administrators at the University of Buea, Cameroon. Feminist Africa, 9, 63-84.

Forret, M. L., \& Dougherty, T. W. (2004). Networking behaviors and career outcomes: differences for men and women?. Journal of Organizational Behavior: The International Journal of Industrial, Occupational and Organizational Psychology and Behavior, 25(3), 419-437.

Gilligan, C. (1995). Hearing the difference: Theorizing connection. Hypatia, 10(2), 120127.

Gilligan, C. (1993). In a different voice: Psychological theory and women's development. Cambridge, MA: Harvard University Press,. (Original work published 1982).

Greguletz, E., Diehl, M. R., \& Kreutzer, K. (2019). Why women build less effective networks than men: The role of structural exclusion and personal hesitation. human relations, 72(7), 1234-1261. 
Guba, E. G., \& Lincoln, Y. S. (1994). Competing paradigms in qualitative research. Handbook of qualitative research, 2(163-194), 105.

Hafen, C. A., Laursen, B., Burk, W. J., Kerr, M., \& Stattin, H. (2011). Homophily in stable and unstable adolescent friendships: Similarity breeds constancy. Personality and Individual Differences, 51(5), 607-612.

Hakanen, J. (1999). Gender-related differences in burnout. Finnish Institute of Occupational Health. Journal, 2, 1999-02.

Hoepfl, M. C. (1997). Choosing qualitative research: A primer for technology education researchers. Journal of Technology Education, 9(1), 47-63.

Hurtado, S., Milem, J., Clayton-Pedersen, A., \& Allen, W. (1999). Enacting diverse learning environments: Improving the climate for racial/ethnic diversity in higher education. ASHE-ERIC Higher Education Report, Vol. 26, No. 8. ERIC Clearinghouse on Higher Education, One Dupont Circle, NW, Suite 630, Washington, DC 20036-1181.

Hurtado, S., Clayton-Pedersen, A. R., Allen, W. R., \& Milem, J. F. (1998). Enhancing campus climates for racial/ethnic diversity: Educational policy and practice. The Review of Higher Education, 21(3), 279-302.

Jacobs, J. A. (2003). Detours on the road to equality: Women, work and higher education. Contexts, 2(1), 32-41.

Jo, V. H. (2008). Voluntary turnover and women administrators in higher education. Higher Education, 56(5), 565-582.

Kanter, R. M. (2008). Men and women of the corporation: New edition. Basic books.

Kanter, R. M. (1987). Men and women of the corporation revisited. Management Review, 76(3), 14.

Kanter, R. M. (1979). Power failure in management circuits. Classics of organization theory, 342-351.

Keashly, L., \& Neuman, J. H. (2010). Faculty experiences with bullying in higher education: Causes, consequences, and management. Administrative Theory \& Praxis, 32(1), 48-70.

Küskü, F. (2003). Employee satisfaction in higher education: the case of academic and administrative staff in Turkey. Career Development International, 8(7), 347-356. 
Lee, Y. I., \& Metcalfe, A. S. (2017). Academic advisors and their diverse advisees: Towards more ethical global universities. Journal of International Students, 7(4), 944-962.

Lovell, A. (1995). Moral reasoning and moral atmosphere in the domain of accounting. Accounting, Auditing \& Accountability Journal, 8(3), 60-80.

Lugones, M. (1995). Sisterhood and friendship as feminist models. In P.A. Weiss \& M. Freidman (Eds.) Feminism and community (pp. 135-146). Philadelphia, PA; Temple University Press.

Maranto, C. L., \& Griffin, A. E. (2011). The antecedents of a 'chilly climate' for women faculty in higher education. Human relations, 64(2), 139-159.

Martin, A. (2008). Service climate and employee well being in higher education. Journal of Management \& Organization, 14(2), 155-167.

Mayhew, M. J., Grunwald, H. E., \& Dey, E. L. (2006). Breaking the silence: Achieving a positive campus climate for diversity from the staff perspective. Research in Higher Education, 47(1), 63-88.

McPherson, M., Smith-Lovin, L., \& Cook, J. M. (2001). Birds of a feather: Homophily in social networks. Annual review of sociology, 27(1), 415-444.

Merriam, S. B. (2002). Basic interpretive qualitative research. Qualitative research in practice: Examples for discussion and analysis, 37-39.

Merriam, S. B. (2002). Introduction to qualitative research. Qualitative research in practice: Examples for discussion and analysis, 1(1), 1-17.

Merriam, S.B. (1998). Qualitative Research and Case Study Applications in Education. San Francisco, CA: Jossey-Bass.

Miao, K. (2012). Performance-based funding of higher education: A detailed look at Best practices in 6 states. Center for American Progress.

Migden, J. (1989). The professional advisor. NACADA Journal, 9(1), 63-68.

Murray, G. (1987). The advisor under stress: Fired up or burned out? NACADA Journal, $7(2), 47-53$.

Namie, G., \& Namie, R. (2009). Bully at work: What you can do to stop the hurt and reclaim your dignity on the job. Naperville, IL: Sourcebooks. 
National Academic Advising Association (2000). NACADA 2000 member survey preliminary results. (Available from the NACADA Executive Office, 2323 Anderson Avenue, Ste. 225, Manhattan, KS 66502; nacada@,ksu.edu).

National Center for Education Statistics. Retrieved August 17, 2019, from the National Center for Education Statistics Web site: https://nces.ed.gov/ipeds/datacenter/InstitutionProfile.aspx.

O'Banion, T. (1994). An academic advising model. NACADA Journal, 14(2), 10-16.

Opdenakker, R. (2006). Advantages and disadvantages of four interview techniques in qualitative research. Forum Qualitative Sozialforschung/Forum: Qualitative Social Research, 7(4), Retrieved January 26, 2019.

Osman, A. R., \& Alam, M. D. (2017). The impact of service climate and job satisfaction on service quality in a higher education platform. International Journal of Learning and Development, 7(3), 48-72.

Ostroff, C. (1993). The effects of climate and personal influences on individual behavior and attitudes in organizations. Organizational Behavior and Human Decision Processes, 56(1), 56-90.

Ostroff, C., Kinicki, A. J., \& Muhammad, R. S. (2012). Organizational culture and climate. Handbook of Psychology, Second Edition, 12.

Pai, K. \& Vaidya, S. (2009). Glass ceiling: Role of women in the corporate world. Competitiveness Review: An International Business Journal, 19(2), 106-113.

Pellegrino, J. L., Snyder, C., Crutchfield, N., Curtis, C. M., \& Pringle, E. (2015). Leveraging institutional knowledge for student success: Promoting academic advisors. Perspectives: Policy and Practice in Higher Education, 19(4), 135-141.

Rania, N., Siri, A., Bagnasco, A., Aleo, G., \& Sasso, L. (2014). Academic climate, well being and academic performance in a university degree course. Journal of Nursing Management, 22(6), 751-760.

Reyna, R., Reindl, T., Witham, K., \& Stanley, J. (2010). Complete to Compete: Common College Completion Metrics. Technical Guide. NGA Center for Best Practices.

Robertson, D., \& Pelaez, M. (2016). Behavior analytic concepts and change in a large metropolitan research university: The graduation success initiative. Journal of Organizational Behavior Management, 36(2-3), 123-153. 
Robertson, D., \& Pelaez, M. (2018). Rules, rule-governed behavior, and organizational change in a large metropolitan research university. Behavioral Development, 23(1), 1-13.

Rothmann, S., \& Barkhuizen, N. (2008). Burnout of academic staff in South African higher education institutions. South African Journal of Higher Education, 22(2), $439-456$.

Rubin, H. J., \& Rubin, I. S. (2011). Qualitative interviewing: The art of hearing data. Sage.

Sadler, G. R., Lee, H. C., Lim, R. S. H., \& Fullerton, J. (2010). Recruitment of hard-toreach population subgroups via adaptations of the snowball sampling strategy. Nursing \& Health Sciences, 12(3), 369-374.

Saldana, J. (2009). The coding manual for qualitative researchers. Thousand Oaks, CA: Sage.

Sandler, B. R., \& Hall, R. M. (1986). The campus climate revisited: Chilly for women faculty, administrators, and graduate students. Washington, DC: Project on the Status and Education of Women, Association of American Colleges.

Schneider, B., \& Barbera, K. M. (2011). Driving customer satisfaction through hr: Creating and maintaining a service climate. Society for Human Resource Management (SHRM) and the Society for Industrial and Organizational Psychology (SIOP).

Schneider, B., González-Romá, V., Ostroff, C., \& West, M. A. (2017). Organizational climate and culture: Reflections on the history of the constructs in the Journal of Applied Psychology. Journal of Applied Psychology, 102(3), 468.

Schneider, B., White, S. S., \& Paul, M. C. (1998). Linking service climate and customer perceptions of service quality: Tests of a causal model. Journal of applied Psychology, 83(2), 150.

Stuart Hunter, M., \& White, E. R. (2004). Could fixing: Academic advising: Fix higher education. About Campus, 9(1), 20-25.

Sue, D. W., Bucceri, J., Lin, A. I., Nadal, K. L., \& Torino, G. C. (2007). Racial microaggressions and the Asian American experience. Cultural Diversity and Ethnic Minority Psychology, 13, 72-81

Tack, M. W., \& Patitu, C. L. (1992). Faculty job satisfaction: Women and minorities in peril. ASHE-ERIC Higher Education Report No. 4. 
Takawira, N., Coetzee, M., \& Schreuder, D. (2014). Job embeddedness, work engagement and turnover intention of staff in a higher education institution: An exploratory study. SA Journal of Human Resource Management, 12(1), 1-10.

Tang, T. L. P., \& Talpade, M. (1999). Sex differences in satisfaction with pay and coworkers: Faculty and staff at a public institution of higher education. Public Personnel Management, 28(3), 345-349.

Thomas, K. (1990). Gender and subject in higher education. Taylor and Francis Publishers, 1900 Frost Road, Suite 101, Bristol, PA 19007-1598.

Toker, B. (2011). Job satisfaction of academic staff: An empirical study on Turkey. Quality Assurance in Education, 19(2), 156-169.

Tracy, S. J. (2010). Qualitative quality: Eight "big-tent" criteria for excellent qualitative research. Qualitative inquiry, 16(10), 837-851.

Vaccaro, A. (2011). Divisions among us: Women administrators, faculty, and staff on the complicated realities of support and sisterhood. NASPA Journal about Women in Higher Education, 4(1), 26-49.

Walsh, V., \& Morley, L. (2005). Breaking boundaries: Women in higher education. Bristol, PA: Taylor \& Francis.

Wasburn, M. H. (2007). Mentoring women faculty: An instrumental case study of strategic collaboration. Mentoring \& Tutoring, 15(1), 57-72.

Yazan, B. (2015). Three approaches to case study methods in education: Yin, Merriam, and Stake. The qualitative report, 20(2), 134-152. 


\section{APPENDIX A}

\section{Interview Questions}

\section{Demographic questions}

- Could you please tell me your name?

- What is the highest education degree you have earned?

- What is your job title?

- What is your marital status?

- How would you describe your ethnicity?

- What is your age?

- Breakdown of male/female advisors in department:

\section{Interview questions}

1. Tell me about yourself and your history in this institution.

- How long have you been working for this institution?*

2. Tell me about your role in your current department. Describe a typical day.

3. How long have you been in your current position? What do you see yourself doing in 5 years?

- How long do you intend to stay in this position, and why?*

- How does this job contribute to your future professional plans?*

- What are your thoughts about growing into a leadership position?*

- How is your current role helping you grow in that direction?

- What do you know about the promotion process within the advising role?

- How would you describe your relationship with your supervisor?*

- Is your supervisor male or female?*

- Does your supervisor have advising experience?

- Describe any obstacles you have experienced in your career.*

4. How would you describe the overall environment of your department?

- Why would you describe it this way?*

- Would you say your role is more independent in nature or does it require more collaboration? Give me an example.

- How would you describe an ideal work environment or ideal team?

- What would you say is missing from your current environment or team?

- What do you like most about your team?

- Describe a time when you expressed a different opinion or a new idea. How was that received by your department?

- When a new employee comes in, how are they received? 
- Who trains the new person? Is this person always the same or does it change?

5. How would you describe your interactions with your female coworkers?

- Why would you describe it this way?*

6. Do you feel you can turn to your female coworkers for emotional support?

- Describe a situation where a fellow female coworker helped or encouraged you (professionally, personally, etc.)? What did they do? Why do you think they did that?*

7. Describe a time when you had conflict with a female coworker in your department? How would you describe that experience and how did it make you feel?

- Why do you think they behaved this way toward you?*

- Have you ever felt excluded by a coworker?*

- Have you ever felt sabotaged in some way?*

- Have you ever been the subject of rumors at work?*

- If so, could you please describe this situation?*

8. Have you ever applied for the same position as a coworker?

- If yes, tell me about this experience.*

- Was this coworker male or female?*

- Were they offered the job?*

- If so, why do you think they were chosen?*

- If not, why do you think they didn't get it?*

9. Describe a time when you received public recognition at work?

- Did you feel supported by your colleagues?*

* Possible probing questions 


\section{APPENDIX B}

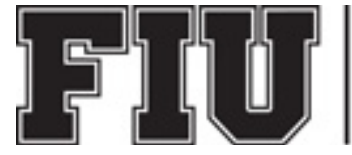

FLORIDA

INTERNATIONAL

UNIVERSITY

\section{ADULT CONSENT TO PARTICIPATE IN A RESEARCH STUDY \\ A Qualitative Study Examining Camaraderie and Conflict Between Female Academic Advisors in One Higher Education Institution}

\section{SUMMARY INFORMATION}

This study will explore the interactions between female advisors in departments that are majority female. Questions will touch on topics such as the individual's history at the institution, their career aspirations and departmental climate.

Things you should know about this study:

- Purpose: The purpose of the study is to explore departmental climates as reported by female advisors in higher education.

- Procedures: If you choose to participate, you will be asked to participate in an audio and video recorded interview.

- Duration: This will take about and hour to an hour and a half. If a second interview is needed, it would be no more than one hour more.

- $\quad$ Risks: If loss of confidentiality occurs, there is a risk of damage to your reputation of future employability. You may also be at risk of becoming upset due to the subject of the interviews.

- Benefits: There is no benefit to you from this research.

- Alternatives: There are no known alternatives available to you other than not taking part in this study.

- Participation: Taking part in this research project is voluntary.

Please carefully read the entire document before agreeing to participate.

\section{PURPOSE OF THE STUDY}

The purpose of this study is to explore departmental climates as reported by female advisors in higher education.

\section{NUMBER OF STUDY PARTICIPANTS}

If you decide to be in this study, you will be one of 15 people in this research study.

\section{DURATION OF THE STUDY}


Your participation will involve one and a half hours in an initial interview, with the possibility of a second one at a later date. The second one will be no longer than an hour and may not even be needed.

\section{PROCEDURES}

If you agree to be in the study, we will ask you to do the following things:

1. The interviews will be recorded (audio and video) and they will be one-on-one.

2. You will be asked a series of questions, of which you do not have to answer any which may make you uncomfortable.

3. The questions will be about the departmental climate in your current job, specifically about your interactions with your peers. The questions will also ask about your career plans within the institution and about instances where you have received recognition, support, conflict, and exclusion within your department.

\section{RISKS AND/OR DISCOMFORTS}

The study has the following possible risks to you: If loss of confidentiality occurs, there is a risk of damage to your reputation of future employability. You may also be at risk of becoming upset due to the subject of the interviews. These risks will be minimized by using pseudonyms during the transcription of the interviews and each recording will be encrypted and kept in a password-protected folder, within a password-protected computer, inside a locked office within FIU. Once the analysis of the video recordings is finished, the digital recordings will be deleted.

\section{BENEFITS}

The study has the following possible benefits to you: There are no benefits you, beyond helping with the research at hand. Organizations will benefit by gaining a better understanding of the relationships present between female academic advisors and their peers.

\section{ALTERNATIVES}

There are no known alternatives available to you other than not taking part in this study. Any significant new findings developed during the course of the research which may relate to your willingness to continue participation will be provided to you.

\section{CONFIDENTIALITY}

The records of this study will be kept private and will be protected to the fullest extent provided by law. In any sort of report we might publish, we will not include any information that will make it possible to identify you. Research records will be stored securely, and only the researcher team will have access to the records. However, your records may be inspected by authorized University or other agents who will also keep the information confidential.

The records will be encrypted and/or password protected to maintain the highest confidentiality measures. 


\section{USE OF YOUR INFORMATION}

- Identifiers about you might be removed from the identifiable private information and that, after such removal, the information could be used for future research studies or distributed to another investigator for future research studies without additional informed consent from you or your legally authorized representative.

\section{COMPENSATION \& COSTS}

You will not receive compensation by participating in the interview. There are no costs to you for participating in this study.

\section{RIGHT TO DECLINE OR WITHDRAW}

Your participation in this study is voluntary. You are free to participate in the study or withdraw your consent at any time during the study. You will not lose any benefits if you decide not to participate or if you quit the study early. The investigator reserves the right to remove you without your consent at such time that he/she feels it is in the best interest.

\section{RESEARCHER CONTACT INFORMATION}

If you have any questions about the purpose, procedures, or any other issues relating to this research study you may contact Alexandra Lejarza at Florida International University, aleja001@fiu.edu.

\section{IRB CONTACT INFORMATION}

If you would like to talk with someone about your rights of being a subject in this research study or about ethical issues with this research study, you may contact the FIU Office of Research Integrity by phone at 305-348-2494 or by email at ori@fiu.edu.

\section{PARTICIPANT AGREEMENT}

I have read the information in this consent form and agree to participate in this study. I have had a chance to ask any questions I have about this study, and they have been answered for me. I understand that I will be given a copy of this form for my records.

Signature of Participant

Printed Name of Participant

Signature of Person Obtaining Consent
Date

Date 
VITA

ALEXANDRA C. LEJARZA

Born, Miami, Florida

2007 B.A., Psychology

University of Miami

Miami, Florida

2007

Tutor/Notetaker, ACCESS Disability Services

Miami Dade College

Miami, Florida

2010

M.S., Counselor Education

Florida International University

Miami, Florida

2010 Lab Instructor, College Prep

Miami Dade College

Miami, Florida

2010

Adjunct Professor of Psychology and Student Life Skills, Social Sciences Miami Dade College

Miami, Florida

2012 Academic Advisor, Advisement and Career Services

Miami Dade College

Miami, Florida

2014 Career Readiness Advisor, Adult Education

Miami Dade College

Miami, Florida

2015 Senior Academic Advisor, Advisement and Career Services

Miami Dade College

Miami, Florida

2018 Learning Disability Specialist, ACCESS Disability Services

Miami Dade College

Miami, Florida 